\title{
An Examination of the Characteristic, Resilience, and Leadership Practices in Public School Elementary Principals
}

\author{
M. Suzanne Offutt \\ West Virginia University
}

Follow this and additional works at: https://researchrepository.wvu.edu/etd

\section{Recommended Citation}

Offutt, M. Suzanne, "An Examination of the Characteristic, Resilience, and Leadership Practices in Public School Elementary Principals" (2011). Graduate Theses, Dissertations, and Problem Reports. 3039.

https://researchrepository.wvu.edu/etd/3039

This Dissertation is protected by copyright and/or related rights. It has been brought to you by the The Research Repository @ WVU with permission from the rights-holder(s). You are free to use this Dissertation in any way that is permitted by the copyright and related rights legislation that applies to your use. For other uses you must obtain permission from the rights-holder(s) directly, unless additional rights are indicated by a Creative Commons license in the record and/ or on the work itself. This Dissertation has been accepted for inclusion in WVU Graduate Theses, Dissertations, and Problem Reports collection by an authorized administrator of The Research Repository @ WVU.

For more information, please contact researchrepository@mail.wvu.edu. 
An Examination of the Characteristic, Resilience, and Leadership Practices in Public School Elementary Principals

M. Suzanne Offutt

Dissertation submitted to the College of Human Resources and Education at West Virginia University

In partial fulfillment of the requirements for the degree of

Doctor of Education in

Educational Leadership Studies

Committee Members:

Paul E. Chapman, PhD, Committee Chair

Reagan P. Curtis, $\mathrm{PhD}$

Ernest R Goeres, PhD

R. Steven Nichols, EdD

Ted S. Price, PhD

Department of Education Leadership

Morgantown, WV

2011

Keywords: Elementary Principals; K-12 Education; Principal Leadership; Resilience 


\section{Abstract \\ An Examination of the Characteristic, Resilience, and leadership Practices in Public School Elementary Principals}

\section{Suzanne Offutt}

The purpose of this study was to identify relationships among the dimensions of resilience, leadership practices, and individual demographics of elementary school principals in West Virginia. The author was looking for skills that could be identified and enhanced to improve the recruitment and retention of public school leaders. Many school systems report problems recruiting effective school leaders, and many school leaders report feeling discouraged and overwhelmed by the increasing demands to implement changes and improvements in schools. This study examined the characteristic resilience, the capacity to change and return to a state of equilibrium comparing those characteristics with various leadership practices. This quantitative study surveyed 88 elementary school principals to collect data on the dimensions of resilience, leadership practices, and demographic information. The author administered two online questionnaires, the Personal Resilience Questionnaire (PRQ) (1993) developed by Organizational Development Resources (ODR, Inc.); the Leadership Profile Inventory developed by Kouzes and Posner (Kouzes \& Posner, 2002); and the demographic variables. The study yielded a number of positive correlations among the individual items on the PRQ and the LPI. A small number of demographic characteristics were correlated with the resilience dimensions and the leadership practices. The researcher recommended a number of areas for further study in the area of resilience in school leaders including using the information in evaluations and staff development. The study of resilience and leaders' responses to change could enhance teaching and learning in public schools. 


\section{Dedication}

This effort is dedicated to my husband, Michael; daughter, Jade; and son, Logan. Only through your loving support could I have ever accomplished such a demanding undertaking. Thanks so much for all of the meals you cooked, housecleaning you did, chores you tended to and fun things you did without me while I studied. You inspired me and taught me much of what I came to understand about resilience. I cannot forget my sister, Jan, who served as a model for resilience and my parents, Vere and Martha Offutt where it all began. 


\section{Acknowledgments}

I would like to acknowledge the generosity of Dr. Linda Hoopes of Resilience Alliance for her assistance in the scoring of the Personal Resilience Questionnaire and Dr. Barry Z. Posner of Kouzes Posner International for permission to use the Leadership Practices Inventory. I'm especially appreciative of the support of my committee members, especially Dr. Paul Chapman, my committee chair; Dr. Larry Dailey for technical support, and Dr. Nancy Williams for moral support.

\section{Contact Information.}

Correspondence concerning this paper can be sent to Suzanne Offutt, 155 Glen Road, Shepherdstown, WV 25443. Address email to: msoffutt@access.k12.wv.us. 


\section{Table of Contents}

Abstract

Page ii

Dedication

Page iii

Acknowledgments

Page iv

Table of Contents.....

Page v

List of Tables and Figures

Page viii

\section{CHAPTERS}

I. An Examination of the Characteristic, Resilience, and Leadership ...... Page 1

Practices in Public School Elementary Principals

Statement of the Problem.

Page 2

Background of the Problem

Page 3

Purpose of the Study. ....

Page 4

Research Questions

Page 5

Significance of the Study

Page 6

Delimitations

Page 7

Definition of Terms

Page 8

Summary

Page 9

II. Review of the Literature.

Page 10

A Shortage of School Principals

Page 10

Demands of the Principalship

Page 14

Theoretical Frameworks

Page 15

Leadership Framework

Page 18 
Leadership, Its Definitions and Purposes...................... Page 19

Principals and Leadership................................. Page 20

Models of Leadership...................................... Page 24

Resilience Framework.................................... Page 33

Definitions............................................. Page 33

A Metatheory of Resilience................................. Page 34

Theoretical Framework for Resilience.......................... Page 40

Models of Resilience....................................... Page 45

Measurement of Resiliencce.................................. Page 49

The Integration of the Concepts of Resilience and Leadership....... Page 53

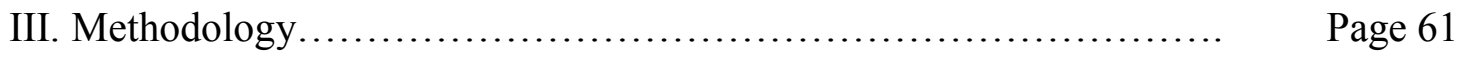

Survey Design............................................... Page 63

Data Collection Process.................................... Page 64

Population................................................ Page 64

Instrumentation............................................ Page 66

Data Analysis.............................................. Page 71

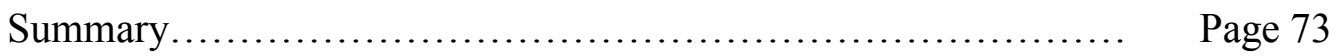

IV. Results..................................................... Page 74

Demographics............................................. Page 74

Findings of the Research Questions............................. Page 79

Results of the Study ......................................... Page 89

V. Discussion....................................................... Page 92 
REFERENCES

Page 103

APPENDICES

Page 110

Appendix A, Letter to Dr. Paine...

Page 110

Appendix B, Cover Letter.

Page 111

Appendix C, Follow-up Letter

Page 112

Appendix D, IRB Proposal.

Page 113

Appendix E, Personal Resilience Questionnaire

Page 120

Appendix F, Leadership Practices Inventory

Page 123

Appendix G, Demographic Information

Page 125

Appendix H, Email to Conner Partners.

Page 128

Appendix I, LPI agreement letter.

Page 129

\section{LIST OF TABLES AND FIGURES}

Table 1: Three Waves of Resilience Inquiry

Page 39

Table 2: The Resilience Dimension of the Leadership Performance Matrix

Page 58

Table 3: Coefficient of the Seven Dimensions of the Personal Resilience

Page 69 Questionnaire

Table 4: Reliability (Cronbach Alpha) Coefficients for the LPI's Leader Report

Table 5: Age of Respondents

Page 71

Page 75

Table 6: Gender of Respondents.

Page 75

Table 7: Level of Education

Page 76

Table 8: Number of Years Taught.

Page 76

Table 9: Number of Years Worked as a Principal.

Page 77 
Table 10: Number of Students in Current School ...

Page 77

Table 11: Number of Superintendents Worked For

Page 78

Table 12: Number of Professionals Supervised.

Page 78

Table 13: Percentage of Students on Free and Reduced Lunch.

Page 79

Table 14: Correlations Between Dimensions of Resilience and Leadership

Page 81 Practices

Table 15: Correlations Between Demographic Characteristics and

Page 83

Dimensions of Resilience.

Table 16: Independent Samples t Test of Gender and Dimensions of

Resilience

Table 17: Means and Standard Deviations of Level of Education and

Dimensions of Resilience.

Table 18: Correlations Between Demographic Characteristics and

Leadership Practices.

Table 19: Independent Samples t Test of Gender and Leadership Practices.

Table 20: Mean and Standard Deviation of Level of Education and Leadership Practices.

Table 21: Significant Relationship Matrix of RQ1

Page 86

Page 87

Page 88

Page 89

Page 92

Figure 1: The Resilience Model 


\section{Chapter One \\ An Examination of the Characteristic, Resilience, and Leadership Practices in Public School Elementary Principals}

The American public school system faces an impending crisis in the shortage of individuals to fill the leadership roles of principals and superintendents. Many factors influence this shortage including the high demands of the job coupled with diminishing financial and emotional rewards (Henderson, 2003). Many currently practicing principals cite a high burn-out rate and decreasing capacity to successfully address the problems that public schools face (Gates, 1998). In addition to greater stresses, the nature of school leadership has undergone radical change in the last quarter century. School leaders must take on the roles of instructional leadership, visionary leadership, financial planner, public relations specialist, and mediator among teachers, students, parents, and the general public. Federal legislation places increasingly greater demands for accountability on school leaders (Winter, 2004). All of these demands occur in the context of an accelerated pace of change in contemporary society. A number of researchers have examined the role of school leaders in this changing context (Berry, 1996; Hoffman, 2004; Kelehear, 2003; Pulley, 2001). They have looked at the changing demographics of an increasingly older school leader population in the face of the job demands, the increased stress, and the need for flexibility and adaptation to evolving societal demands. This research examined a group of school administrators comparing their leadership styles with their capacity to be resilient. The adult resilience model theorizes that adults who have a greater capacity to recover from adversity are more successful as leaders (Conner, 1992). They are able to maintain an optimistic outlook, inspire their followers, and communicate a shared vision with their school 
community (Tugade, 2004). This study explored the relationship between leadership practices and adult resilience in elementary principals working in West Virginia.

\section{Statement of the Problem}

The American public school system increasingly finds itself at risk of taxing its leadership to the point that few individuals will want to step into the leadership role of principal or superintendent. Many current principals who began their jobs in the early 1980s talk about long hours, too many job requirements, excessive governmental mandates and accountability, societal problems reflected in student populations, Special Education requirements, inadequate school funding, little financial incentive for the job, inability to fire poor teachers, and being stymied by the central office as reasons for getting out of the profession (Lovely, 2003). In the face of these towering demands, principals and superintendents receive fewer resources and less pay than that offered in a corporate world while being compared as the CEOs of public education. With less job mobility, longer contract periods, and fewer wage increases as administrators, principals may find that they actually earn less hourly wages than classroom teachers with a similar number of years of experience (Lovely, 2003).

But as an administrator, principals and superintendents are often treated not to rewards but to daily challenges to their authority, to intimidation from board members, and harassment from parents, teachers, and students (Berry, 1996). As an added weight, principals and superintendents have little job security since they don't acquire tenure as administrators. Faced with these problems and decreased benefits, more principals are leaving the profession and fewer young teachers are willing to enter the principalship. Principals have a higher median age than leaders in other industries. Many of these aging school administrators will retire in the near 
future (Malone, 2002). The public school system must develop strategies to help sustain principals in dealing with the complex problems facing school administrators while providing a high quality education for all students.

\section{Background of the Problem}

With all of the challenges in public education, one might ask why anyone is entering or remaining in the principal profession. Yet many people are. Some school districts in less urbanized areas have many applicants for these leadership jobs. Some researchers find that the principal shortage is a crisis in challenging areas like inner city and low income areas with high minority populations but are not so significant in suburban, affluent, middle class, or rural school districts. But the problems in the crisis areas are so great that they exaggerate the problem across the country. In spite of extreme problems in high risk areas, new principals do come into the profession (Roza, 2003a). They share unique characteristics of leadership and self-awareness that help them survive in the job. Many researchers have begun to explore the areas of how school leaders perform their jobs, what leadership skills are most effective in bringing about student learning, how schools sustain professionals, and what psychological and social skills contribute to high quality job performance. Many leadership studies have sought the ideal principal model. Few are successful because it is difficult and inappropriate to narrowly define the job in ideals without considering other factors. The role is defined by the context of the job, the personality of the principal, and the age and background of the principal. Some researchers have found that the personality that the principal brings to the job is as important as any of the myriad other skills in achieving success in this demanding profession (Hausman, 2000). 
This research study will examine elementary school administrators in West Virginia. This state's unique geographical and economic challenges provide a wide range of sociological experiences for educators. Some may find themselves working in rural areas characterized by low median incomes while others work in areas considered to be within the major East Coast metropolitan areas. Levels of affluence in the state range from a median income of $\$ 16,931$ in McDowell County to a high of $\$ 44,374$ in Jefferson County while the national median income is $\$ 41,994$. The percentage of the population with college or professional degrees ranges from 5.6 in McDowell County to 21 in Jefferson County (WV County Profiles, 2004). The state ranks $47^{\text {th }}$ in teacher salaries among the 50 states (WVDE, 2005). The state faces a crisis in its underfunded public employees' retirement system. Many counties are having difficulty attracting young teachers as populations decline and fewer teachers are needed. Many counties on the borders of the state lose teachers to adjoining states where teacher salaries are significantly higher. In this challenging environment poised for population declines in the western part of the state and dramatic population increases in areas now within the Washington, D.C. and Baltimore metropolitan areas, school administrators must cope with challenges to educating children (Łegislative Updates,” 2005). Declining financial resources for education will make for even greater challenges for school administrators. In this climate of disequilibrium, WV school administrators may provide valuable insights for investigating the need for resilience in school leaders.

\section{Purpose of the Study}

The purpose of this study was to identify relationships among the characteristics of resilience, leadership practices, and individual demographics in elementary school principals in 
West Virginia. Leadership studies, including those of Reeves (2004) showed that the leadership characteristics of resilience were important ones for sustaining leaders who can work effectively in their schools. He included the dimension of resilience in his model for assessing school leaders. Conner (1992) has spent his professional life working with the concept of change in individuals and organization. In his research he has identified seven dimensions of resilience including: Positive (Yourself), Positive (The World), Focused, Flexible (Thoughts), Flexible (Social), Organized, and Proactive. Conner found that across the globe leaders who successfully handled change demonstrated similar characteristics. He developed the Personal Resilience Questionnaire (PRQ) to assess the seven dimensions of resilience. This instrument was applied to elementary public school principals in West Virginia in 2009.

In order to compare resilience to leadership practice, Kouzes and Posner's Leadership Practices Inventory was administered to these same principals. This questionnaire measures leadership actions and behaviors based on the five leadership practices including: Modeling the Way, Inspiring a Shared Vision, Challenging the Process, Enabling Others to Act, and Encouraging the Heart.

In addition to the two questionnaires, respondents completed nine demographic questions. These questions helped delineate some variations in personal experiences based on the type and amount of experience that principals had.

\section{Research Questions}

In order to explore the interaction of resilience and its impact on leadership, the researcher examined the following research questions: 
1. Are there significant relationships among the dimensions of resilience and leadership practices of elementary school principals? The hypothesis was that principals who demonstrate higher levels of resilience had correspondingly higher values on leadership practices.

2. Are there significant relationships among the dimensions of resilience and demographic characteristics: age, gender, level of education, years of teaching experience, years of administrative experience, number of students in current school, number of superintendents worked for, number of professionals supervised, and percentage of students on Free and Reduced Lunch?

3. Are there significant relationships among leadership practices and demographic characteristics: age, gender, level of education, years of teaching experience, years of administrative experience, number of students in current school, number of superintendents worked for, number of professionals supervised, and percentage of students on Free and Reduced Lunch?

\section{Significance of the Study}

This study is significant to the investigation of public school principals and the challenges that they face in the workplace. Research from the field of psychology focusing on survivors of trauma, positive psychology, and change leadership has identified the importance of resilience as a characteristic that helps individuals sustain themselves as productive, effective professionals. Effective school leadership is essential to the development of effective schools (Senge, 1990). School systems are challenged to find and sustain leaders who have the knowledge base and skills and can garner the resources and energy to overcome systemic barriers to student achievement while promoting success for all students (U.S. Dept. of 
Education, 2005). With the increased stresses found in public school settings, school systems regard hiring and retaining effective leaders as critical in assuring that all students receive a high quality education. This study contributes to an examination of elementary principals development of resilience, a characteristic of their personality and work habits which will sustain them as productive leaders. Leaders who are more emotionally competent are better able to withstand the pressures of their vocations and continue to perform in an outstanding manner (Williams, 2004). Resilient school leaders, those who are self-confident, conscientious and focused on student achievement, are able to manage conflict and serve as catalysts for change in their schools, and succeed as school leaders in a challenging society (Williams, 2004).

Other researchers including Goldstein (2003), Isaacs (2003), Payne (1994), and Scott (2001) have studied the effects of stress and leadership characteristics and the relationship of resilience among principals in public and private elementary and secondary schools. Isaacs (2003) studied the relationships between leadership and resilience on secondary principals in five counties in Florida. He described his study as the first to address the issue of resilience in principals and recommended that further studies be conducted among more principals. The results of these studies may lead to staff development initiatives that help principals develop resilience in their leadership practices. This study concentrated on resilience and leadership in public elementary school principals in West Virginia.

\section{Delimitations}

This study had the following delimitations:

1. Only elementary principals working in WV were included in the investigation.

2. The study was conducted during the spring and summer 2009. 
3. The study was conducted via Survey Monkey surveys completed by principals who responded to an emailed request. The researcher also sent two follow-up requests to potential respondents.

\section{Definition of Terms}

Elementary school principals. educators who have an administrative license or certificate serving public schools that include Pre-Kindergarten or Kindergarten through Grade Five or Grade Six.

Free and reduced lunch. an income guideline established by the Federal government for determining students whose family incomes qualify them to receive school meals for free or at a reduced cost. This guideline is often used to determine schools that might be at higher risk for student failure including schools that are designated as Title I schools.

Leadership. a reciprocal relationship between those who choose to lead and those who decide to follow (Kouzes and Posner, 2002)

Leadership. -ability to empower others" (Burns, 1978); intending to — bing about a major change in form, nature, and function of some phenomenon" (Leithwood, Begley, \& Cousins, 1994).

Resilience. ability to bounce back from negative life experiences and become stronger while overcoming them (Henderson, 2003). The motivational force within everyone that drives them to pursue wisdom, self-actualization, and altruism and to be in harmony with a spiritual source of strength.” (Richardson, 2002, p. 309). 
Resilience in School Leadership. the identification, acquisition, allocation, coordination, and use of the social, material and cultural resources necessary to establish the conditions for the possibility of teaching and learning (Spillane, 1999).

\section{Summary}

The American public educational system is facing challenging times in the administration of public schools. Many studies have investigated the possible shortage of principals and superintendents to administer schools and the rates of high stress and burn-out among administrators. This paper investigated the construct of resilience, the ability to bounce back from adversity, and its relationship to leadership characteristics in elementary school principals in WV. The author's findings identified possible staff development topics and strategies for bolstering resilience among principals, contributions to mentoring programs, and personal guidance in developing leadership skills. The remaining four chapters review the literature about the challenges facing public school administrators, resilience in school leaders, and leadership in school settings; the methodology for the research study; the results of the study; and the conclusions and recommendations for application and further research. 


\section{Chapter Two}

\section{Review of the Literature}

Some of the many problems facing American public education include how we train new principals and how we retrain seasoned principals who have lost their enthusiasm for their jobs. This research focused on investigating the personality characteristic, resilience, described as the ability to - boune back"(Hoffman, 2004, p.35), and its contributions to leadership in elementary schools. Some research has shown that principals, who report more positive outlooks on life, are more flexible in their responses to the frequently changing environment of public education (Schmidt, 2004). Principals whose leadership skills include resilience have been shown to withstand negative criticism, setbacks on the job, disgruntled teachers, uncooperative parents, and community environments that are dangerous to children. These principals are able to maintain a focus on learning in the school and their role as an instructional leader. Their enthusiasm for the job is infectious and they contribute to effective schools (Henderson, 2003). Studying resilience and its relationship to the leadership capacity of school leaders could help alleviate a shortage of candidates to fill the principal job and further enhance public education for the nation's children.

\section{A Shortage of School Principals}

A number of challenges confront public school administrators making them vulnerable to those challenges. Many school districts are facing increasing difficulties in recruiting and retaining capable administrators. Hoffman (2004, p. 35) cited a number of probable causes including expectations for greater accountability, fewer resources to support reform initiatives, increased dismissal of principals for school failures, greater demands from the federal 
government and communities, decreased relative compensation for administrators, greater time demands to do the job, increased media focus on school failings over successes, and chronic stress. Portraying this dilemma in a humorous manner, Lovely (2003, p. 9) adapted Copland's depiction of the dilemma of staffing the principalship by creating a mock list of job qualifications that included the wisdom of a sage, the leadership of a point guard, the moral strength of a nun, and the charisma of a stage performer. She concluded the job description with a salary offering that would be fower than you would expect” (p. 9).

Potential leaders need to know whether they can successfully take on these challenges and have or can develop the requisite skills to successfully interact in so many varying roles. Once they hold the position, they have to develop healthy habits that will sustain them personally and professionally. Principals have to recognize that they are the subject of considerable pressure and take steps to build their own resilience and to acquire the competencies that are essential to manage and to cope" (Finlayson, 2003, p. 14). Troubled principals should be able to receive mentoring, staff development or some combination that will help them rediscover the resilience that it takes to carry on in such a difficult job.

Building better principals who will not only survive but will excel in the job is important. But it's even more so, if there are fewer individuals seeking the job. Several organizations have investigated the topic drawing conflicting conclusions. The National Association of Elementary School Principals (NAESP) and the National Association of Secondary School Principals (NASSP) commissioned a study in 1998. They found that approximately half of the school districts surveyed reported a shortage in the labor pool for K-12 principal positions they were trying to fill (that) year, 'regardless of the schools' grade levels and whether they were rural, 
suburban or urban schools" (Is There a Shortage of Qualified Candidates for Openings in the Principalship?, 1998). The Educational Research Service (ERS, 1999) and the Center for Reinventing Public Education found a number of studies that supported this conclusion and others that show that we are facing a shortage of candidates for the principalship (Roza, 2003a).

In looking at the average age of elementary school principals, the NAESP concluded in 1990 that as many as 50 percent could retire by the year 2000. Their study also found that at an average age of 57, over half of principals said that they planned to retire as soon as they were eligible for retirement. In 2002 in the NAESP survey 66 percent of principals responding said they would be retiring in 6-10 years (Roza, 2003a).

Various state reports have found similar trends in their own studies which indicate that public school principals are planning to retire in large numbers in the near future. In the summer of 2002 Maryland reported that it would need about 600 new principals, about 45 percent of those jobs in the state for the 2003-2004 school term. In 1999, 33 percent of Massachusetts ${ }^{6}$ principals said that they expected to retire in less than five years. Forty- eight percent of principals in New York State said that they planned to retire by 2006. Overall, the U.S. Bureau of Labor Statistics (BLS) concludes that there will be a 13 percent increase in the number of jobs for education administrators in the decade between 2000 and 2010 (Roza, 2003a).

When Roza concluded her study for the center on reinventing public education, she found that school principal shortages aren't really the norm. The center examined 83 school districts that had strong likelihood of experiencing principal shortages across ten different regions of the country. They found that on average the districts received 17 applicants for principal openings when they had received an average of 19 in the previous seven years About 
66 percent of the Human Resource directors who responded didn't report a shortage of principals. There are some variations among regional markets with some reporting increases in applicants while other locations report fewer applicants. In rural locations, school systems consistently receive fewer applicants for principal vacancies but don't report a concern for the situation. Overall, the Center found that there are more individuals who hold principal certification than there are jobs for them. Therefore, they concluded that there wasn't a shortage of principals. However, these prospective principals aren't necessarily in the locations where they are needed. In both urban and rural settings which may have high poverty and great challenge or low paying status, there are principal shortages for these undesirable locations (Roza, 2003b).

A more relevant point about prospective principals may not be whether they are available in numbers but rather whether they bring the amount and kind of preparation and leadership skills needed for the job. Human Resource directors tended to report that they found adequate numbers of applicants for principal openings. But superintendents often reported that they weren't satisfied with the skills and leadership qualities that these applicants had. The superintendents looked for leadership experience in principal applicants while Human Resource departments sought principal candidates with teaching experience. Superintendents reported that teaching experience didn't provide the leadership capabilities needed for the highly challenging and multi-faceted principal's job (Roza, 2003b). In addition to the superintendents ' perception that teaching experience didn't develop leadership skills, many principals reported that the coursework that they' $d$ taken in law, finance, and school facilities hadn't prepared them for the managerial and leadership demands of a modern public school (Berry, 1996). 


\section{Demands of the Principalship}

The principalship is a multi-layered complex profession requiring a diverse number of roles and skills that many principals must continue to develop throughout their careers. This diversity places a high demand on the emotional health of those who hold the position. Successful principals forge working relationships with many people. The job requires that they flexibly respond as -mediators, mentors, negotiators and networkers" within their school, community, and profession (Cherniss, 1998, p.26). Effective principals are self-confident, a confidence that emerges from realistic assessments of strengths and weaknesses (Cherniss). Other characteristics of resilient principals include a tolerance for ambiguity, ability to delay gratification, and a propensity to tap internal and external sources of support and resistance (Scott, 2001). Other research supports that individuals who demonstrate high resilience characteristics report a greater job satisfaction and greater success in carrying out a demanding role (Montano, 1998).

Resilience theory in healthy adults has been applied to individuals who work in high stress environments including the financial industry, high level management, nursing, and educational administration (ODR, 1996). Reeves found the characteristic of resilience to be important in the assessment of educational leaders. In his leadership studies, he found that principals who were more resilient were more effective in their job performance (2004). He listed the development of resilience as an important skill to train and develop in both new and seasoned principals. Some investigators have begun to explore the development of professional training that would enhance personal resilience (Henderson et al., 2000; Wolin, 1994; and WestEd, 2000). Resilience viewed as a set of skills rather than as a personality trait, could be 
taught and nurtured in new or experienced principals. Some educational institutions are including resiliency as one of the course requirements in leadership training. In Gonzaga University's leadership program, instructors offer coursework that explores the development of leadership qualities that enable leaders to persist in spite of adversity. As a Jesuit institution, they foster the development of the qualities of hopefulness and possibility in future leaders (Shepard, 2004). This research could have implications leading to improvements in training future school administrators, mentoring new principals, and sustaining experienced principals as change agents in their schools.

\section{Theoretical Frameworks}

This writing explored the constructs of leadership and resilience across a number of disciplines. The researcher examined frameworks for resilience from its origin as responses to adverse conditions and debilitating life experiences to a more contemporary examination of resilience as a response to disequilibrium and a return to a homeostatic condition. Leadership was examined through the lens of more contemporary models which are multi-dimensional. Within this theoretical framework section, both leadership and resilience are explored through an examination of definitions, the application to the school setting, and models for resilience and leadership found in current literature.

In the first area, that of leadership, there are numerous definitions in the literature. Bennis and Nanus reported in 1985 that they could find over 350 definitions for leadership in the literature they reviewed. Moving beyond definitions, many theories of leadership developed throughout the twentieth century. In an article by Bensimon, Neumann, and Birnbaum, (1989) the authors outlined a summary of the major theories of leadership as applied to educational 
settings . The descriptive movement begins with trait theory in which desirable leadership qualities in successful leaders are identified then used to identify and select potential new leaders. Trait theories regard leadership characteristics as fixed and discrete within individuals. To apply trait theory to the identification of potential leaders, search committees identified characteristics in previously successful leaders. These successful academic leaders have been described as having personal attributes like: —humorcourage, judgment, integrity, intelligence, persistence, hard work, vision, and being opportunity conscious" (p. 214). Power and influence theories postulated that either power emanates from the leader's position and the ability to transform followers or that power is mutually exchanged between leaders and followers in reciprocal, transactional relationships (p. 217). Behavioral theories emerged in the 1960s with greater emphasis on the behavior of the leader rather than on fixed attributes. Blake, Mouton, and Williams in 1981 proposed the five styles of academic administration including -earetaker, authority-obedience, comfortable-pleasant, constituency-centered, and team" (p. 217). They determined that the ideal style was team since those leaders whose behavioral style was identified as strong in teamwork scored the highest on institutional performance and concern for people (p. 218) . Dill in 1984 applied management behavioral theory to education administrators and found that these administrators do a lot of work rather than directing the work of others; functioned in fragmented, widely varying interactions; preferred current and specific issues; preferred verbal communication; and developed informal informational systems (p. 219).

In the 1980s contingency theories emerged with contributions to leadership theories. In these models leaders adapted their style to situational factors. Leaders may have appeared to be egalitarian one day and authoritarian the next as they strove to motivate followers to meet goals. 
Burton Clark in the 1970s authored a classic study of three unique American colleges and contributed to theories of academic leaders as cultural and symbolic agents. Their actions help institutions develop sagas about their identity enabling constituents to clarify the identity. These leaders guide the institution to define itself as a unique college that has developed idiosyncratic customs and traditions that set it aside from other similar institutions. The last domain of cognitive theories posits that leaders through their wise practices have caused events in their institutions whether for good or for bad (p. 221). Kouzes and Posner's work (2002) supported the cognitive theory of leadership, that it is an observable set of skills and abilities that can be developed in any motivated individual. Most of the contemporary leadership frameworks fit within these broad concepts.

Resilience and resiliency are terms that have been applied in a wide variety of disciplines (Benard, 1991; Conner, 1992; Demos, 1989; Eisenberg et al., 1997; Flach, 1988; Garmezy, 1993; Werner \& Smith, 2001). From physiology in medicine through the development of the personality in developmental psychology, researchers have adapted this term to describe the ability of an individual to experience a negative incident or disruption and react to the event. These reactions fall into three response modes including adaptation and return to the earlier state, failure to adapt with deterioration to a dysfunctional state, or absorption of the disruption leading to improvement from the experience. These expanded models have led to more complex definitions of the concept of resilience.

A variety of definitions have been identified to demonstrate the widely varying applications of the concept while preserving the universality of the term. The definitions and applications share a commonality of adaptation and restoration of homeostasis. Richardson's work in 1990 
examined the role of resilience in the psychology of personality from the development of the theory to successive waves of application. In the first wave, he found that through phenomenological studies researchers defined the term and described the resilient qualities of individuals and support systems that they observed. During the second wave of research about resilience, researchers addressed the process of resilience breaking it down into discrete experiences from singular moments to a succession of events that leads to a breakdown followed by reintegration to a comfort zone, resilient reintegration, or reintegration with loss. The model was applied to psychopathological conditions in which individuals who experienced remarkable trauma like drug and alcohol addiction and child abuse, or who grew up in toxic environments were studied to determine the processes by which individuals adapted following traumatic experiences. In the third wave, Richardson described a paradigm shift in the application of the concept of resilience from a negative, deficit model to a proactive, wellness based model (Richardson, 1990). This paper used the third wave model of resilience in applying the model to elementary school principals. In the third phase researchers examined how individuals experience setbacks, learn from those negative experiences and improve their leadership from them. This model may generate the identification of characteristics of resilience that can help principals work more effectively with students, teachers, parents, and their communities to improve education.

Leadership framework. This literature review of leadership did not provide an exhaustive review of that vast literature trove but described leadership from several approaches. The first approach defined leadership and established its purposes, then secondly, applied the principles of leadership to the school setting. In the third area, the reviewer examined a set of contemporary 
leadership models. In the last area, the researcher reviewed Kouzes and Posner's model of leadership as a challenge and their assessment tool, the Leadership Practices Inventory.

Leadership, its definitions and purposes. There are numerous authors who have written vast quantities about leadership. They've written about what it is, what leaders do, and how to develop leadership in oneself and in others. In the Kellogg Leadership Project in 1997 cited in Cunningham (2000), the authors suggested that the two main purposes of leadership are: to create an accommodating environment where people can prosper, develop, and live in harmony with each other and to encourage people to live in harmony with each other. Paul Hersey defines leadership as -any attempt to influence the behavior of another individual or group" (Hackman \& Johnson, 2000, p. 11). Bernard Bass differentiated between attempted leadership when leaders try to influence others and successful leadership when others actually change (Hackman \& Johnson). The essence of most definitions of leadership centered around the concept of the individual who has influence.

Pfeffer (2000) attempted to summarize research into leadership and concluded that it remained an ambiguous role. He wrote that despite numerous years of study and a primary focus of social and organizational psychology, the dimensions and definition of the concept of leadership remain unclear. In examining the dichotomy of leadership and power, he found that leadership studies showed that influence rights are voluntarily conferred" (p. 205) implying some congruence between the objectives of the leader and the led. Conversely, power doesn't require any goal compatibility between leader and led but rather the existence of a dependence relationship between them. Since he found few meaningful distinctions between leadership definitions and those of social influence, he concluded that a general consensus may be drawn 
that leadership is about social influence. The dimensions of leadership behavior are more difficult to define but he found general agreement that organizational groups have two tasks: one is to maintain the group and the second is to perform some task or activity. He, therefore, synthesized modern research into leadership as a definition of social influence over groups when the group's task is to maintain its identity and engage in some meaningful task. When this definition of leadership of groups, that of establishing a group identity and carrying out a specific task, is applied to school leadership, it lacks an essential element. Educators measure effectiveness. Education is continually assessed and measured with comparisons made among students, teachers, schools, states, and other nations. These efforts institutionalize the accountability of school leaders.

Principals and leadership. Educational leadership and its contribution to school effectiveness has been widely studied and is extant in the literature about school reform, effective leadership, improving student achievement, and educating for the next century (Cunningham, 2000). Many researchers have found that effective leadership is critical to the success of an organization and can exert tremendous influence over the organization's capacity for change (Patterson, 1993). Most reports on effective schools reflect that improving principals capacity to lead can facilitate change and lead to high achievement in students (Kelehear, 2003). Good principals function as good leaders and understand three important things: they understand the context of their job, they understand themselves, and they focus on what is best for students (Hausman, 2000). Bennis (Smith \& Andrews, 1989) stated that there are four competencies of leaders ---the management of meaning, of attention, of trust, and self-management. School leaders must therefore manage the meaning of schooling demonstrating a clear understanding of 
the purposes of schools and managing the symbols of the schools toward accomplishing those purposes. School leaders must manage attention by getting teachers to use their energies for teaching children. They manage trust by behaving in such a way that others believe in them; and they manage themselves by knowing who they are by playing to their strengths and shoring up their weaknesses. In order to prioritize among the varied demands of the job, school principals must choose how to spend their time dividing it among the demands as a school leader, a school administrator, and a school manager. Greenfield (1995) suggested that if leadership is to be successful, it must focus on five demands: moral, social, instructional, managerial, and political. The National Association of Secondary School Principals (NASSP) (Cunningham, 2000) began to study necessary proficiencies in principals that would help them address the rapidly changing educational environment. Both federal and state governments have increased accountability in teaching while parents and community members have asked for more proficient, prepared public school graduates. In order to address the challenges, the NASSP developed a set of proficiencies that covered a range of social and academic competencies for school leaders. These proficiencies for school leaders include:

Develop teams, delegate responsibilities and include team members from the community. Initiate and manage change and deal with ambiguities resulting from a dynamic system. Design effective learning environments for a wide range of students Comment orally and in writing with acute sensitivity to a diversity of public. Motivate students and staff to reach high expectations. Use technology to assist in instructing students and to manage the school. Evaluate programs and be accountable for student learning. Value and integrate culturally diverse students and staff into the life of the school, creating a positive school culture.

Work within the political forces which shape schooling. (Cunningham, 2000 p. 35)

In January, 1998, the U.S. Department of Education held a forum on educational leadership in Washington, D.C. They defined an effective school leader for today's schools as 
one who is skilled in instructional leadership, management, communication, collaboration, and community building. They added that the effective leader also possesses vision, can facilitate changes for improvement, and takes risks. The purpose of the conference was to address the question of what to do to improve the quality of leadership in the education system in the next century. Their recommendations are summarized in the following recommendations from the National Policy Forum on Educational Leadership:

- Redesign the principalship from middle management (responsible for basic building operations) to instructional leadership, community leadership, and visionary leader with priority on leadership for student learning;

- Provide powerful, on-going professional development, focusing on strategies for improving student learning;

- Provide sufficient job compensation;

- Enhance principal autonomy and authority in building-level decision making;

- Make frequent, meaningful principal assessments designed to generate information for professional growth and school improvement; and

- Collect better data and information on the supply, effectiveness, and changing roles of principals. ( U.S. Department of Education, 1999, p. 6)

In the recent past, a number of studies have been devoted to determining how principals spend their time. Though vision and leadership are often the first responsibilities ascribed to principals, much of their time may be consumed by managerial tasks. The principal holds key responsibilities for helping the school develop its vision by exploring the community's beliefs about education, children, and the community`s responsibilities for educating its children (Cunningham, 2000). The amount of time and effort that the principal spends on these tasks will indicate the priorities that the principal has for the myriad of roles within the profession. Without good leadership, schools will not engage in systemic improvement that will lead to improved student achievement. Without a commitment to effective leadership principals will 
fail to adapt to the changing circumstances that this challenging profession presents (Tirozzi, 2001).

The Institute for Educational Leadership assembled a task force to study issues surrounding school leadership in 2000. They were funded by the Department of Education, the Ford Foundation, UPS Foundation, Carnegie Corporation, and Metropolitan Life Foundation. Bringing together national educational and government leaders and including leaders from business and civic organizations, the task force recommended models for improving school leadership. They received input from principals by surveying individuals from both public and private school asking them what their major challenges were and what they found discouraging. They found that those surveyed said that the major challenges that they faced included the changing job demands, inadequate compensation, time constraints, lack of parent and community support, negativity of the media and the public toward schools, and a lack of respect for educators. In the face of these increasing challenges, many in the educational leadership community see an even more important emphasis on recruiting and retaining effective school leaders.

Many authors have written about effective leadership spanning the education, business, government, and nonprofit domains including Tichy (1997), Bolman and Deal (2003), and Goleman et al. (2002). John Goodlad (1984) was an early proponent of applying the results of studying leadership in other environments to the arena of education. Much of these findings can be synthesized to three main points. First, leadership matters. Even when other variables such as resources and personnel are set aside, a single individual who exercises leadership over an organization has a great impact on that organization. Secondly, leadership effectiveness is a 
complex interplay of personal characteristics and acquired knowledge and skills. Third, all leaders benefit from a process of introspection and evaluation that helps them improve their performance as well as the function of their institution (Reeves, 2004). Many of the most recent models for leadership can be applied to educational settings.

Models of leadership. The researcher selected three contemporary models of leadership to illustrate leadership studies and their application to school leadership. They included: Kouzes and Posner's (2002) model of leadership practices, Peter Senge's (2000) work on Schools that Learn, and Bolman and Deal's (2003) application of their work with leadership frames to educational settings.

This study used Kouzes and Posner's model for leadership as a challenge, to study leadership in educational settings. They studied leadership for over 20 years postulating that leadership is a reciprocal relationship between those who choose to lead and those who decide to follow. Credible leaders are able to motivate their followers who have faith and confidence in those leaders. These leaders' utterances are regarded as truthful based on that trust. These leaders must have the knowledge and skill to lead these enthusiastic followers. Part of this knowledge base is the ability to articulate a shared vision of the future and to share it with a variety of constituencies. These leaders don't work as commanders but as supporters of their people. They create an atmosphere that is familial and caring. Followers of these caring leaders had four basic expectations of their leaders, that of honesty, vision, inspiration, and competence. They regard leadership as a collection of practices and behaviors that enable leaders to get extraordinary things done" (p.13). For these followers, leadership is more than just a position of authority. 
Kouzes and Posner first published their work on leadership in the late 1980s. They had studied leaders through surveys, focus groups, interviews, and observations. In revising their work first in the mid 1990s and again in 2002, they found that the content of leadership had not changed significantly though the context of leadership had. They have maintained the essence of their five essential practices of good leadership while acknowledging that our contemporary world is characterized by heightened uncertainty. In the face of world tragedies, we've watched as business and government addressed the needs of people first. We have become a more connected global society with internet connection and a diversity of communication tools. We've returned to an appreciation of social capital as an economic resource; that is, the human heart is as important in how we do business as the human head (2002). With these changes in the culture of leadership, they maintained the enduring value of their five practices of effective leaders: they are Model the Way, Inspire a Shared Vision, Challenge the Process, Enable Others to Act, and Encourage the Heart.

a. Model the Way. Exemplary leaders must model the behavior that they expect of others. They know that they can't ask someone to do something that they are unwilling to do. Leaders must have a clear understanding of their own life's guiding principles, share those values openly with others, and stand up for their values (Kouzes and Posner, 2002).

b. Inspire a Shared Vision. Exemplary leaders need to have dreams for what their organization could be. They need to want to change things and create something that hasn't been created before. And even more importantly, they must enlist the engagement of their followers in a shared vision. Leaders generate enthusiasm for hopes and dreams of others showing that these dreams can be a part of the common good (Kouzes and Posner, 2002). 
c. Challenge the Process. Leaders challenge the status quo and are willing to adopt innovations and take risks. They face potential failure but are willing to accept responsibility for the outcomes, especially if they are failures. They regard disappointments as learning opportunities (Kouzes and Posner, 2002).

d. Enabling Others to Act. Leaders require partners in order to accomplish extraordinary things in organizations. They recruit other people to participate in the planning and decisionmaking. They empower other people to encourage a feeling of shared ownership and personal responsibility for the outcomes. When groups in organizations have common goals, they have a higher level of trust which leads to a more cooperative environment to work in and produce extraordinary outcomes (Kouzes and Posner, 2002).

e. Encouraging the Heart. Leaders recognize the successes of the organization and regularly acknowledge the accomplishments of the team. They look for opportunities to celebrate. They articulate clear expectations for employees and give tangible rewards to recognize them. Kouzes and Posner developed guidelines for effective rewards including: developing tough, measurable achievement standards; having a formal systematic process ; being creative about rewards; letting others help design the non-monetary compensation system, making recognition a public affair; going out and searching for people who are doing the right thing, and coaching people (Kouzes and Posner, 2002).

Following a decade of research into leadership practices of many leaders in a wide variety of settings, Kouzes and Posner developed their model assessing leadership. They developed the Leadership Practices Inventory (LPI), a 30 question survey which synthesized the actions and performances of leaders. Their surveys involved over 3,000 people working in 
management positions and their subordinates. They found that across a wide variety of work settings and disciplines, the five essential leadership principles outlined in their model were consistent in these various contexts. They concluded that managers who engaged in the five leadership practices were involved in extraordinary accomplishments (Kouzes and Posner, 2002).

In the second model of educational leadership, Toward a New Model of Educational Leadership, Peter Senge in his book, Schools that Learn (2000) applied his theory of organizations that function as learning environments to the world of schools themselves. The fundamental principle that guided these schools is that principals strove for an environment that allows people, both teachers and students, to lead without having to control them. Some of Senge"s work was based on Wheatly's (1992) exploration of organizational theory. Wheatly postulated a shift in thinking in organizational theory from one where leaders look for order rather than control in organizations. Living systems seek order by seeking coherence in their environments. Coherence doesn't come from avoiding turbulence or from establishing tightly controlled procedures and orders. When living systems encounter disequilibrium, they will seek coherence. The disequilibrium creates growth, and, under proper conditions, the system will respond and evolve to a new, improved order. When leaders try to manage the disequilibrium by trying to gain control, they inhibit the learning and close off the natural process of the organization to seek equilibrium. Administrators whose response is to stop the organization from learning and regenerating itself inhibit change and force a return to equilibrium or resumption of the status quo. Through the tolerance for chaos and the evolution of the natural process, administrators could facilitate the institution's growth. These growth opportunities 
involved taking more time for thoughtful conversations, greater participation, and more risk taking. This foundation of leadership welcomed diverse viewpoints, the inclusion of many different people in the process of thinking together in self-renewal, and continuous improvement. Applying some of the terminology first introduced by Wheatly, some concepts from that leadership model were related to those emerging in resilience theory including the systemic reactions to disequilibrium and a return to coherence.

Similarly Senge‘s (2000) educational model represented a shift from an authoritarian model of leadership to one in which everyone is engaged in a continual learning process. Senge's model flowed from the belief that schools must prepare students to function in an evermore complex environment by moving from authoritarian practices to one of personal development and shared responsibility for learning. He posed five bodies of study and practice" (p. 7) that educators and faculties might adopt in order to adapt to the rapidity of change and for preparing students. He outlined five key competencies that enabled school leaders to lead their organizations without imposing controls that inhibited learning:

(a) Personal Mastery is the practice of articulating a coherent image of your personal vision - the results you most want to create in your life-alongside a realistic assessment of the current reality of your life today. This produces a kind of innate tension that, when cultivated, can expand your capacity to make better choices and to achieve more of the results that you have chosen.

(b) Shared Vision establishes a focus on mutual purpose. People with a common purpose can learn to nourish a sense of commitment in a group or organization by developing shared images of the future they seek to create and the principles and guiding practices by which they hope to get there. A school or community that hopes to live by learning needs a common shared vision process.

(c) Mental Models: This discipline of reflection and inquiry skills is focused around developing awareness of attitudes and perceptions - your own and those of others around you. Working with mental models can also help you more clearly and honestly define current reality. Since most mental models in education are often difficult to discuss and hidden from view, one of the critical acts for a learning school is to develop the capability to talk safely and productively about dangerous and discomfiting subjects. 
(d) Team Learning is a discipline of group interaction. Through such techniques as dialogue and skillful discussion, small groups of people transform their collective thinking, learning to mobilize their energies and actions to achieve common goals and drawing forth an intelligence and ability greater than the sum of individual members" talents. Team learning can be fostered inside classrooms, between parents and teachers, among members of the community, and in the pilot groups' that pursue successful school change.

(e) Systems Thinking: In this discipline, people learn to better understand interdependency and change and thereby are able to deal more effectively with the forces that shape the consequences of their actions. Systems thinking is based on a growing body of theory about the behavior of feedback and complexity - the innate tendencies of a system that lead to growth or stability over time. (Senge, 2000, pl. 7-8)

In the third model Bolman and Deal developed the Four Frame Model of Leadership. In their model, they consolidated major patterns of leadership practices into four perspectives. Through these perspectives, they hoped that managers could develop - metal models, maps, mind-sets, schema, and cognitive lenses" (2003, p. 12) to facilitate understanding the situations encountered and to develop possible courses of action. They called their frames - windows on the world of leadership and management" (p. 13). Each of the four frames defines reality from a different approach, some more appealing than others to many leaders. Their research into leaders' understanding and affinity for four-framed leadership found that leaders who used multiframed approaches were more effective in their personal lives and in the workplace. Using multi-frames requires greater flexibility in thinking about approaches to leadership tasks. Bolman and Deal's four frames include: the structural frame which focuses on hierarchy of organizations with rules, roles, policies, and flowcharts for guiding decisions; the human resource frame relies on a people-centered approach to understanding organizations focusing on human strengths and weaknesses, emotions, and internal drives and fears; the political frame views organizations as competitive environments with scarce resources and struggles for power and advantage; and the 
symbolic frame focuses on issues of meaning and faith. It puts ritual, ceremony, story, play, and culture at the heart of organizational life" (2003, p. 19).

a. The Structural Frame. There are six assumptions that form the foundations for the structural approach to organizations.

(1) Organizations exist to achieve established goals and objectives.

(2) Organizations increase efficiency and enhance performance through specialization and a clear division of labor.

(3) Appropriate forms of coordination and control ensure that diverse efforts of individuals and units mesh.

(4) Organizations work best when rationality prevails over personal preferences and extraneous pressures.

(5) Structures must be designed to fit an organization's circumstances (including its goals, technology, workforce, and environment).

(6) Problems and performance gaps arise from structural deficiencies and can be remedied through analysis and restructuring. (Bolman and Deal, 2003, p. 45)

The structural frame uses a blueprint for outlining how players will interact internally.

Structures show who will do the work, how the roles will be differentiated, and how the diverse groups will communicate. Usually, a boss" is designated and policies and procedures are established, thereby reducing the latitude that the boss might have. Organizations are structured so that they describe both horizontal and vertical communication and chain of command patterns. Structures become increasingly more complex as organizations face the greater multidimensional quality of contemporary culture (2003).

b. The Human Resource Frame. This frame is often applied in school settings finding appeal among both principals and teachers. Its salient features include meeting individual needs and examining motives. The most successful environment is one that is trusting and caring where shared decision making is a hallmark. Teachers and principals enlist the assistance of others in 
decision making in order to foster a sense of shared ownership in what happens in the classroom (Bolman \& Deal, 2002).

There are six assumptions that underlie the human resource approach to management:

(1) Build and implement a Human Resources Management strategy based on a shared philosophy for managing people with systems and practices to implement the philosophy.

(2) Hire the right people by knowing what you want and being selective.

(3) Keep these people by rewarding them well, protecting their jobs, promoting from within, sharing the wealth.

(4) Invest in them by investing in learning and creating development opportunities.

(5) Empower these people by providing information and support, encouraging autonomy and participation, redesigning work, fostering self-management teams, and promoting egalitarianism.

(6) Promote diversity by being explicit and consistent about the organization's diversity philosophy and hold managers accountable. (Bolman \& Deal, 2003, p. 136)

c. The Political Frame. This frame focuses on the limits of authority and the scarcity of resources. In both schools and classrooms principals and teachers vie for power. Goals and targets are met through bargaining and compromise rather than through rational decisionmaking. Within this frame, conflict is inevitable but it may benefit through constant supply of energy and renewal (Bolman \& Deal, 2003).

The political frame operates under five basic propositions:

(1) Organizations are coalitions of diverse individuals and interest groups.

(2) There are enduring differences among coalition members in values, beliefs, information, interests, and perceptions of reality.

(3) Most important decisions involve allocating scarce resources - who gets what.

(4) Scarce resources and enduring differences make conflict central to organizational dynamics and underline power as the most important asset. (5) Goals and decisions emerge from bargaining, negotiation, and jockeying for position among competing stakeholders. (Bolman \& Deal, 2003, p. 186) 
d. The Symbolic Frame centers the focus on culture, meaning, belief, and faith. These symbols are useful for both principals and teachers to foster the development of commitment, hope, and loyalty among all of the constituents including parents and the school community. The use of symbols helps to manage behavior through shared values, informal agreements, and implicit understandings. Schools employ the symbolic frame through the stories, metaphors, heroes and heroines, rituals, ceremonies, and play that they engage in. Using these tools, schools can be joyful places for students and teachers (Bolman \& Deal, 2002).

The symbolic frame is based on five assumptions:

(1) What is most important is not what happens but what it means.

(2) Activity and meaning are loosely coupled; events have multiple meanings because people interpret experience differently.

(3) In the face of widespread uncertainty and ambiguity, people create symbols to resolve confusion, increase predictability, find direction, and anchor hope and faith.

(4) Many events and processes are more important for what is expressed than what is produced. They form a cultural tapestry of secular myths, heroes and heroines, rituals, ceremonies, and stories that help people find purpose and passion in their personal and work lives.

(5) Culture is the glue that holds an organization together and unites people around shared values and beliefs. (Bolman \& Deal, 2003, p. 242-243)

School leaders find the use of the four-framed leadership model developed by Bolman and Deal useful in the school setting. Accustomed to limiting their perspective on leadership to the human resources frame and the structural frame, school leaders benefit from expanding their reflection on changes in school to guiding assumptions found in the political and symbolic frames as well. These guiding principles are easily memorized for ready access as reframing guidelines. By reframing problems, challenges, and events, principals and teachers can be more creative in imagining more versatile and effective responses in leading schools (Bolman \& Deal, 2002). 
The resilience framework. This section on resilience is divided into five subsections. The first describes a variety of definitions for the term. The second subsection reviews the metatheory of resilience with three major paradigmatic waves. This metatheory of resilience cites some longitudinal studies that describe the evolution of the theoretical framework from the initial identification of developmental assets and protective factors. The second wave of resilience research applied the model to individuals at risk for developing psychopathologies, while the third wave shifted from a negative model to a health and well-being model. The third subsection describes theoretical framework for the concept of resilience. The fourth and fifth subsections describe models for resilience and a variety of measurement tools for resilience.

Definitions. The term resilience comes from the Latin root for bouncing back (Conner, 1992). Within psychiatry, psychology, and social sciences, the term refers to resilience as strength (Fuller, Bellhouse, \& Johnston, 2003). In some of the psychiatric literature authors have described resilience as a trait inherent in individuals (Garmezy, 1993; Flach, 1988; Fonagy, 1993). Wagnild and Young (1993) described resilience as a trait, _. . . a personality characteristic that moderates the negative effects of stress and promotes adaptation. . ' (p. 165). Garmezy offered one of the most articulate definitions of resilience:

The central element in the study of resilience lies in the power of recovery and in the ability to return once again to those patterns of adaptation and competence that characterized the individual prior to the pre-stress period... to spring back' does not suggest that one is incapable of being wounded or injured. Metaphorically, it is descriptively appropriate to consider that under adversity; a (resilient) individual can bend... yet subsequently recover... (Garmezy, 1992, p. 129)

The concept of resilience as a trait or skill that enables people to withstand adversity is widespread across a number of disciplines. From the human development field, Werner and Smith (2001) defined resilience as the ability to withstand or successfully cope with adversity" 
(p. 15). In nursing literature Jacelon (1997) described resilient people as those who -spring back in the face of adversity" (p. 123). Henderson and Milstein (2003) addressed the topic in educational psychology describing resilience as the ability to bounce back from negative life experiences" and sometimes grow stronger (p. 2). In the field of clinical psychology, Richardson (2002) called resilience the process of coping with adversity, change, or opportunity in a manner that results in the identification, fortification, and enrichment of resilient qualities or protective factors (p. 308). The concept and definition of resilience also occurs in the field of change management with Conner's (1995) definition as the -ability to demonstrate both strength and flexibility during the change process, while displaying minimal dysfunctional behavior" (p. 219). These definitions of resilience apply to human behavior. While the term resilience occurs in reference to materials like steel indicating its ability to hold a shape or yield to strong forces, this discussion will only address resilience and its relation to human psychological development. Resilience, as it applies to human development, is an integral part of the biological imperative to grow and change. Thus, resilience is an innate drive to develop - soil competence, problemsolving skills, a critical consciousness, autonomy, and a sense of purpose" (Bernard,1991, p. 1).

A metatheory of resilience. Richardson (1990) summarized the evolution of resilience and resiliency theory in his metatheory of resilience, one that encompasses many other theories. He described the development of his theoretical framework for resilience theory posing a metatheory with three major waves of development. His theory encompasses perspectives on the role of resilience as a personality trait or a set of skills. He moved the resiliency model from one that describes resilience as a set of skills to one that embraces resilience as a process that individuals may experience as a result of a series of stressful events or a singular stressful event. This 
singular point or disruption may be followed by a brief or prolonged recovery. In Richardson's model, adversity which produces a negative experience can provide opportunities for individuals to experience personal growth and reintegration. An individual can learn to become more resilient by experiencing adversity. - -. an individual must pass through challenges, stressors, and risks, become disorganized, reorganize his or her life, learn from the experiences, and surface stronger with more coping skills and protective factors" (1990, p. 35). In the first wave, researchers identified a paradigm shift from one where researchers concentrated on identifying risk factors that result in psychosocial problems to viewing benefits derived from surviving adversity. Later studies concentrated on the identification of strengths that helped individuals overcome the adversity. They pursued the identification of qualities that characterized a central concept they called resilience. In a variety of longitudinal studies, researchers looked for factors in a child's life which would predict the development of resilience and the ability to overcome adversity.

The first wave. In 1955 Werner and her colleagues began the Kauai Longitudinal Study, a prospective longitudinal study to observe and document children from birth to adulthood noting outcomes for children who had birth complications, childhood traumas, and experienced adverse child-rearing practices. (Werner \& Smith, 1992). For nearly forty years they monitored all 505 births in one community. The researchers were interested in measuring the impact of a spectrum of biological and psychosocial risk factors, stressful life events, and protective factors on the individuals` development. By assigning potential risk for maladaptation based on the number of risk factors the members had, the researchers attempted to isolate factors that caused some members of the study group to develop resilience in spite of their potential for maladaptation. 
Their numerous studies surrounding this data yielded many insights into the protective factors found in resilient children, adolescents, young adults, and adults (Werner \& Smith, 1992).

Werner (1992) identified a collection of protective factors including: high self-esteem, an internal locus of control, a sense of meaning from one's religious faith, a sense of control, and a variety of sources of social support. Werner found that self-esteem and self-efficacy were aided by: 1) supportive relationships, 2) effective reading skills by the fourth grade, 3) interests and hobbies, and 4) additional responsibilities, such as taking care of a sibling or household chores. These individuals described as resilient demonstrated a sense of hopefulness or the confidence that the odds could be surmounted. The risk factors that jeopardized the development of resilience included parental psychopathology, stressful life events, economic hardship, divorce, and breakdown of parenting (Werner \& Smith, 1992).

In another longitudinal study Demos (1989) and colleagues developed psychological profiles of infants based on factors in their first two years of life. Later, they attempted to match these profiles to data collected from the subjects when they had reached adulthood. They surmised that resilience couldn't be described as a simple, unidimensional capacity but rather was a pattern of resiliency.” They found that resiliency, like other complex, psychic organizations, does not function uniformly and automatically, but waxes and wanes in response to contextual variables" (p. 4). Demos also determined that temperament and behavioral actions interacted to develop resilience including behaviors like taking an active stance toward obstacles, being persistent, developing a range of skills and strategies for coping, and knowing when to use such skills and/or strategies. This researcher identified protective factors like parental understanding and support, the degree of resilience in the family system, and positive support 
after a negative experience (Demos, 1989). Demos ‘ work added to the growing body of longitudinal studies that identified a constellation of consistent positive attributes that were described as resilience.

The second wave. In Richardson's metatheory of resilience, he described a second wave of theoretical development in which much of the work with resilience was applied to the psychopathology of human development. In his second wave resilience was described as a -disruptive and reintegrative process for accessing resilient qualities" (p. 307). Researchers were searching for the means by which individuals developed resiliency. Flach suggested that individuals acquired resilience through a faw of disruption and reintegration" (1988, p. 15). During this phase, individuals who had endured abusive family situations, drug and alcohol addiction, life threatening illnesses, grief or loss of loved ones, internment in concentration camps, and other severely disruptive psychological events were the subjects of study. In spite of their high risk status, many research studies showed that most subjects successfully overcame their adverse situations to emerge as adjusted, productive adults. Researchers wanted to identify personality traits, characteristics, or attributes that had helped some individuals overcome these adverse events while others succumbed to their debilitating effects. Whether these characteristics or skills could be identified and subsequently taught to other high risk individuals would have significant ramifications for mental health practitioners and others working with both children and adults.

Werner and Smith's (2001) longitudinal study conducted on children born in Kauai has been the most often cited study of resilience. Beginning in 1955, the researchers conducted longitudinal studies for over 40 years on 698 children identified as at risk. The studies that they 
generated as these children matured provided rich data about the power of regeneration in spite of loss and deprivation. These children's lives were threatened with poverty, prenatal stress, family discord, divorce, parental alcoholism, or parental mental illness. Most of their parents had limited public school education (eighth grade). The researchers found that about two-thirds of this at risk group had problems during their childhoods, but most had become responsible adults by the time they reached their mid-thirties. The researchers found particular characteristics associated with these resilient children including: kindly, good-natured, a sense of well-being, above average self-control, a high tolerance for others, above average verbal ability, high achievement motivation, a sense of coherence, and an internal locus of control. In adolescence the resilient subjects exhibited characteristics such as: being adaptable, efficient, organized, sincere, unassuming, enterprising, idealistic, intelligent, resourceful, confident, energetic, humorous, rational, realistic, strong, emotionally responsive, gentle, nurturing, and sensitive. Werner and Smith mined longitudinal data about the emergence and evolution of resilience characteristics in their writings about the Kauai subjects describing them as *ulnerable but invincible" and children who had overcome the odds (p. ii, 2001).

The third wave. Richardson considers that resilience research is now in a third wave characterized as part of the postmodern scientific movement. Research has evolved from a problem- based model to a process- based model. Rather than regard resilience as a set of characteristics that is present in some individuals and not in others, researchers have shifted to a theoretical approach that considers that resilience characteristics can be nurtured within individuals. In the postmodern era researchers have explored resilience and its applications to individuals who are psychologically healthy and use inherent strengths to tap inner resilience 
when faced with adversity. These applications have broadened the understanding of resilience from individuals who have survived adversities such as war, abusive parents, poverty, and neglect to examining healthy individuals who function in stressful environments. Richardson (2002) further expands our understanding of resilience to a human energy model. He has connected resiliency to spiritual initiatives which may help promote healing at a -deeper, softer, more efficacious level.” (2002, p. 320). Much of the more recent research has looked at educators, education administrators, and CEOs in volatile industries to identify patterns of behavior that enable these individuals to adapt to adversity and demands for change. Table 1

Three Waves of Resilience Inquiry

\section{Description}

First Wave: Resilient Qualities

Second Wave: The Resiliency Process

Third Wave: Innate Resiliency
Phenomenological descriptions of resilient qualities of individuals and support systems that predict social and personal success.

Resiliency is the process of coping with stressors, adversity, change, or opportunity in a manner that results in the identification, fortification, and enrichment of protective factors.

Postmodern multidisciplinary identification of motivational forces within individuals and groups and the creation of experiences that foster the activation and utilization of the forces.

\section{Outcome}

List of qualities, assets, or protective factors that help people grow through adversity (i.e., selfesteem, self-efficacy, support systems, etc.)

Describes the disruptive and reintegrative process of acquiring the desired resilient qualities described in the first wave; a model that helps clients and students to choose between resilient reintegration, reintegration back to the comfort zone, or reintegration with loss. Helps clients and students to discover and apply the force that drives a person toward selfactualization and to resiliently reintegrate from disruptions.

(Richardson, 2002, p. 308) 
Theoretical Framework for Resilience. The development of the theory of resilience had its origins in initial attempts to describe the phenomenon of survival or recovery found in individuals who suffered in adverse situations. Researchers like Block and Block (1980), Flach (1988), Henderson \& Milstein (2003), Richardson (2002), Rutter (1989), Shepard (2004), and Werner and Smith (2001) made significant contributions to the definitions of the term and the subsequent identification of characteristics that elucidated the concept of resilience. Block's early work linked the concept of resilience within developmental psychology and the characteristics of personality. Richardson's summary of the evolution of a metatheory of resilience has helped to frame resilience as a paradigmatic shift from a negative identification to having a role in the emerging positive psychology.

In 1980 Block and Block released the results of their longitudinal study on children from ages 2-11. They were trying to expand on theories of developmental psychology regarding social psychology positing the dual development of ego control and ego resiliency. Commenting that much of the earlier work in developmental psychology had focused on cognitive development, they turned their attention to the development of the interpersonal realm and personality in children. They noted that the child's ability to test the nature of interpersonal reality was more complex and ambiguous in the feedback derived from attempts to determine social principles than when a child attempts to derive cognitive principles from testing their environment. The Blocks built their work on ego control and ego resiliency on Lewin's work on the psychological system of the individual. Lewin theorized that human psychology had two dimensions: 
First a system of needs that becomes both more differentiated and more hierarchically integrated in the course of development, and second, a sensori-motor system mediating between the internal need system and the external environment that also becomes both more differentiated and more integrated during development. (p. 42)

Between this need system and the sensori-motor reception that guided behavioral responses, Lewin inserted a boundary system that related to the personality concept of the ego. This boundary system had both permeability and elasticity.

The Blocks' work expanded on this concept of the development of boundaries and elasticity as it relates to ego formalizing the theory of ego control and ego resilience. Ego control has two dimensions, overcontrol and undercontrol, which describe an individual's ability to express or contain impulses, feelings, and desires. Ego resilience, the property of elasticity, is — the æpacity of a boundary to change its characteristic level of permeability-impermeability depending upon impinging psychological forces and to return to its original modal level of permeability after the temporary, accommodation-requiring influence is no longer pressing” (Block \& Block, pp 4748). In the Blocks theoretical framework for ego resilience they felt that it had implications for the individual's adaptive or equilibrative capabilities under conditions of environmental stress, uncertainty, conflict, or disequilibrium" (p. 48). In their longitudinal study, the Blocks found that ego-resiliency development could be identified early in life through observations of the way in which infants responded to environmental changes, could be comforted, and modified their sleep-wake states implying a genetic predisposition to ego resiliency. They also observed that individuals described as ego-resilient tended to have mothers described as loving, patient, and competent; a sexual compatibility of parents; and an agreement on values and a concern for moral issues between the parents. Children that they described as ego-brittle tended to come from families in which mothers could be described as neurotic and anxious in which families 
placed little emphasis on intellectual or philosophical development. Through the development of assessment tools and observations, the Blocks operationalized their theory of ego resilience. They generalized these results to adults who on standardized assessments could be described as functioning on a continuum ranging from responsible, bright, productive, compassionate, likeable, and adept at coping with stress to self-defeating, anxious, vulnerable, and distrustful. Applying their work on children as predictive tools for adolescents and adults, they posited the framework for ego resilient and ego brittle.

Richardson (2002) built on the work of Flach (1988) and designed his model for resilience. He described an initial point of balance which he called Biopsychospiritual Homeostasis, a point in time when one has adapted physically, mentally, and spiritually to a set of circumstances whether good or bad" (p. 311). This homeostatic position is challenged by internal and external prompts, stressors, adversity, opportunities and other forms of change. For most of these needs, human beings learn strategies for overcoming or accommodating the challenges. They learn to drive, earn a living, learn to cook, and take care of their personal needs without significant disruption. The up arrows in the model show resilient responses to these disruptions in an individual. When one doesn't adapt to changes well, the stressors become chronic and may lead to debilitating low function. Disruptions may be brief or prolonged but result in primary emotions like hurt, loss, guilt, fear, confusion or perplexity and may lead to introspection. When one's response is to reintegrate with resilience, some learning with new perspectives has occurred. When one clings to the homeostatic condition, the individual absorbs the disruption but returns to their former state of equilibrium. Some adversities are so life altering, like a permanent physical injury or loss of a loved one that the resilience process is to 
recover with loss. Some individuals don't respond resiliently and reintegrate dysfunctionally, often needing therapeutic intervention in order to recover. Figure 1 shows an adaptation of Richardson‘s Resilience Model.

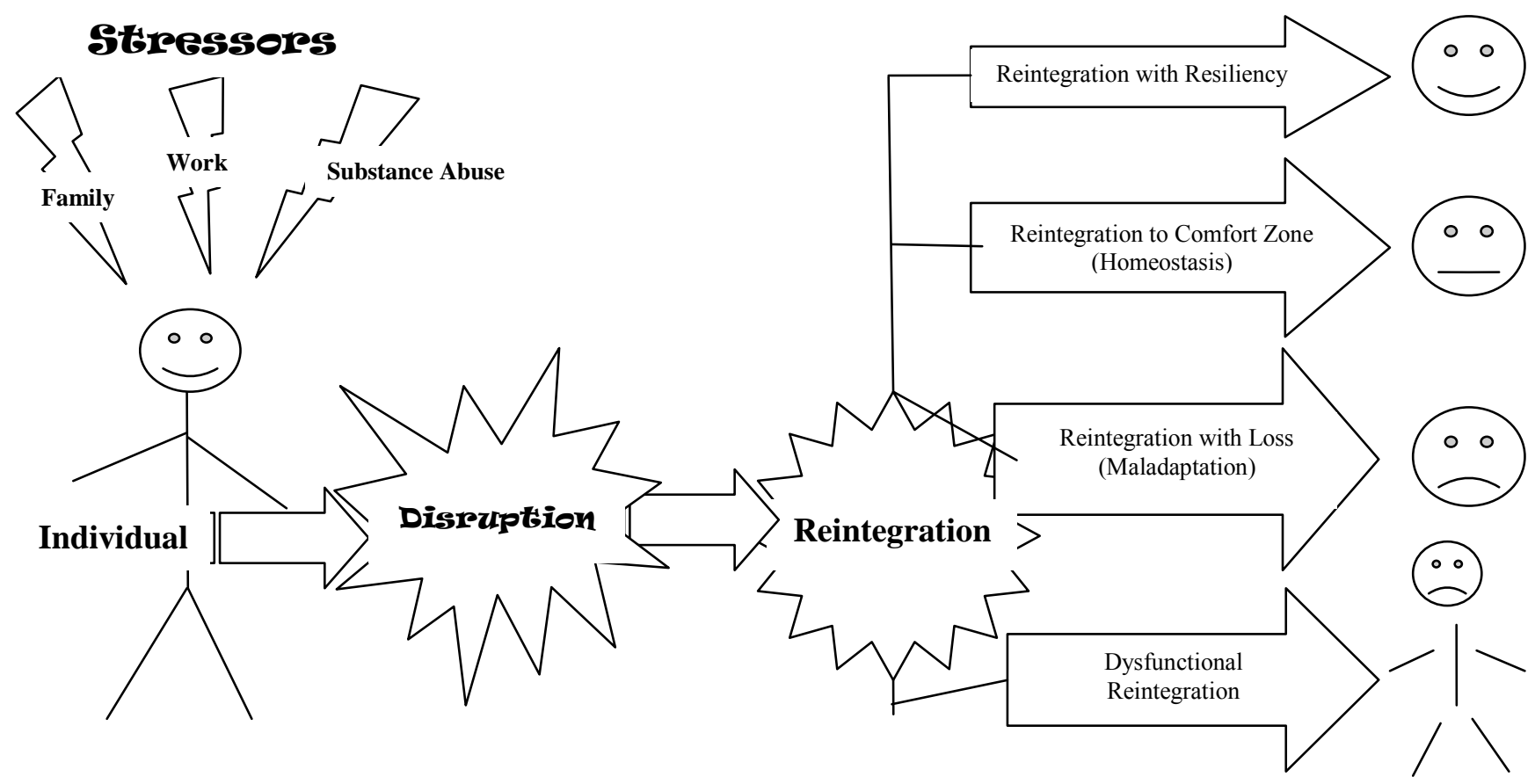

Figure 1: The Resilience Model (Adapted from Richardson, 1990)

Daryl Conner authored the book, Managing at the Speed of Change, How Resilient

Managers Succeed and Prosper Where Others Fail. He and his organization, Organizational Development Resources, Inc., have investigated resilience as the key component needed for management to succeed in a volatile, ever-changing corporate environment. He views leadership as the behavior of individuals who guide organizations to thrive in a culture with a constant demand for change. Most people have an orientation to change that is either danger-oriented or opportunity-oriented. Danger-oriented people tend to react with insecurity and fear when faced with uncertainty and ambiguity, while opportunity-oriented people view instability as a chance to gain an advantage. The key to Conner's work is that both extremes, however, have an 
expectation of change though one is pessimistic and the other is optimistic. In reality, most people's responses are on a continuum between the polarities. This anticipated change becomes a crisis when one's expectations are significantly disrupted, when one doesn't anticipate the changes that do occur. The non-resilient response or the response that leads to disruption is that the individual is surprised that he or she is surprised. In other words, when an individual's threshold for assimilating change is exceeded, the individual may become disengaged and dysfunctional. To avert catastrophes in individuals, organizations, and society, Conner described the need for leaders and managers to expand their range of responses to crises. Leaders can learn a repertoire of responses that lead to greater resilience in individuals and the organizations and culture in which they work and live.

Conner introduced the five essential characteristics of resilience that he later refined and expanded in his measurement tool, the Personal Resilience Questionnaire (1996). These include, Positive, which is demonstrated when an individual is self-assured and views the world as full of opportunity. Individuals who are Focused have a clear vision of what they want to achieve. Individuals who are Flexible are pliable in the face of uncertainty. Resilient individuals develop their organization skills so that they can implement structured responses to ambiguous situations. In the development of resilience, individuals become more proactive in their engagement in change rather than remaining defensive and resistant to change. The questionnaire about resilience was developed to provide tools for leaders to identify and strengthen their resilience characteristics so that individuals, institutions, and society can better accommodate the extraordinary pace of change in contemporary society.

Most of the earlier research about resilience examined the trait or process in children and 
teenagers. More recent research has begun to focus on adults and how they respond to adversity. Richardson's model for resilience as cited in Henderson and Milstein“s (2003) work on resiliency in schools appears to be relevant to adults also. Adults faced with adversity appear to adapt and change when they are bolstered with adequate protections or competencies for adaptation. They return to a level of homeostasis." If adults haven 't developed these protection skills, they may go through a period of psychological disruption that is permanent or temporary; some adults will be able to reintegrate after the period of disruption (p. 5-6).

Models of resilience. A number of researchers have developed models for resilience emerging from phenomenological studies and the application of standardized assessment instruments. The Blocks adapted the first factor of the Minnesota Multiphasic Personality Inventory (MMPI) and suggested that individuals who scored at the extreme end should be labeled resilient. These adults were characterized as — sigificantly more responsible, bright, productive, compassionate, likeable, verbally fluent, adept in coping with stress, self-accepting, and as less self-defeating" (1980, p. 77). Out of this earlier work, later models have included similar concepts including these five models for resilience.

In the first model for resilience, Flach (1988) commented that he first used the term, resilience, in 1966 when he wrote an article about the nature of psychiatric illness and the role of psychotherapy in treatment. Later, when he wrote his work on depression, he noted that emotional breakdowns that may occur with depression may not necessarily be unfortunate. In his professional practice, he had begun to observe that the breakdown episodes were often the prelude to a personal renewal. Flach's early observations and descriptions of characteristics that he felt exemplified a resilient personality formed the foundation for much of the later work in 
this field. He included ideas like a supple self-esteem and independence in thoughts and actions. His resilient individuals had a strong network of personal friends including a few close confidants; they had good insights into themselves and others. Describing them as dreamers, he noted that they were open-minded and had a keen sense of humor and a high tolerance for distress. He observed that they had the capacity to frame their personal experiences with meaning and hope even in the face of great adversity. Other researchers began to include investigations around these attributes as they stabilized the concept of resilience in individuals.

In the second resilience model, Henderson and Milstein (2003) wrote in Resiliency in Schools about the need to promote resiliency among students and educators and outlined a curriculum for it. They cited environmental and internal factors which threaten resiliency in educational settings. Externally, the role and expectations for schools is changing with demands coming from businesses and the society at large. The student body is changing with mandates to educate all children rather than only those who are interested and able. Many educators face communities and legislators that are hostile toward public schools and refuse to increase funding for them. Internal challenges include the fact that the teaching workforce is aging. Many educators have remained in the same positions seldom seeking opportunities for growth and change. The school institution itself poses many structural challenges from making phone calls to ordering materials. And finally, schools are a primary focus for reform efforts often implemented haphazardly and inconsistently. Henderson and Milstein (2003) outlined a resilience model for educators to follow:

a. Increase bonding by developing caring relationships among students, staff and faculty. b. Set clear and consistent boundaries. Assure that rules and policies are communicated in writing to everyone. 
c. Teach life skills. Provide meaningful staff development opportunities and build educator self-worth.

d. Provide care and support. Use evaluation tools to provide regular feedback to enable administrators to maintain a satisfactory progrss level. Provide rewards for excellent, dedicated professionals.

e. Set and communicate high expectations. Help the staff develop vision, mission, and goals and post them prominently.

f. Provide opportunities for meaningful participation: Provide opportunities for members of the staff to contribute their skills and abilities to their work. (pp 53-56)

The third model comes from the work of Conner and colleagues at Organizational

Development Resources (ODR). Conner has spent his career studying change in institutions and how individuals react to change both in domestic and international settings. Through this work, ODR developed an assessment tool for resilience including five major characteristics and two sub characteristics. Results of this assessment tool help managers learn to manage and respond to change in the workplace. These seven characteristics include:

a. Positive, The World: Characteristics of people who view the world with a positive perspective include a view of their environment as complex and challenging. They see opportunities and possibilities rather than problems. People who have a positive attitude toward their life are better able to overcome negative situations and create positive situations.

b. Positive, Yourself: People who hold a positive view about themselves see themselves as valuable and capable. They are able to take action confidently and endure failure without jeopardizing their own sense of self-worth. They utilize an internal locus of control regarding themselves as capable of making decisions that affect their future.

c. Focused: Individuals who have a strong sense of direction and goals are more likely to be able to manage difficult situations. They are able to right themselves and use their energy efficiently in challenging situations. 
d. Flexible, Thoughts: Individuals with flexible thinking patterns are able to see multiple points of view and tolerate ambiguity. They are able to reframe events from different perspectives leading to more creative actions and effective solutions.

e. Flexible, Social: Individuals who are able to turn to others for support have stronger social bonds. They recognize the interdependence with others that they can rely on in difficult times.

f. Organized: Organized individuals are able to tame chaos and create structure in ambiguous situations. They are able to assess situations, choose a direction and plan the steps needed to move forward.

g. Proactive: The final characteristic in Conner's model of resilience is the proactive stance in which individuals are willing to act decisively. They are willing to take some risks and endure discomfort believing that they will have positive outcomes. They seek challenges rather than avoid them.

In the fourth model, Richardson (2002) described a model of resilience that included a state of homeostasis, disruption, and a possibility of four response modes. These were reintegration with resilience, reintegration to the comfort zone, reintegration with loss, and dysfunctional reintegration. He provided seven key facets to summarize his resiliency model:

a. The simplistic linear model only reflects one event as it pertains to a particular role, relationship, or experience. There are multiple disruptive and reintegrative ongoing growth opportunities that may be happening simultaneously.

b. The resiliency process may take place in a matter of seconds, for minor new pieces of information, to years to adapt to traumatic events.

c. Without resilient reintegration in the wake of disruptions, life prompts will continue to disrupt because people have not acquired resilient qualities.

d. The resiliency process applies to individuals, couple, families, schools, communities, and other groups.

e. Disruption is required to access the components of innate resilience because 
biopsychospiritual homeostasis makes no demands for improvement and growth. f. The value in therapy and education is that clients can visually recognize that have choices to grow, recover, or lose in the face of disruptions. (p. 309-310)

These overviews of models of resilience show a number of common features. In summary resilience appears to be a set of characteristics that are present in many individuals. Resilience comes from skills and attitudes with the individual and may be supported by environmental influences. Richardson's (2002) model succinctly describes the process of resilience. Much of his work with the concept was linked to the application of tools for facilitating the enhancement of resilience in healthy individuals. His work is a part of the expansion in psychology to -posite psychology" (p. 310). In these areas, psychologists have described optimal characteristics that Richardson terms resilient qualities. Much of the work of positive psychology has concentrated on the application in the therapeutic setting to teach people healthier ways to recover from depression and other forms of poor mental health. Conner's model appears to be the most comprehensively developed and grounded in his measurement tool, the Personal Resilience Questionnaire. In Conner's comments on leadership (1993), he notes that the leadership dimensions of administrators includes the areas of perception, thinking, and behavior and appear to be related to resilience and how people deal with changing circumstances amidst an ever changing world. Measurement of resilience as determined by the Personal Resilience Questionnaire should prove valuable to school administrators as they support changes in the educational setting.

Measurement of Resilience. Since the 1950s when researchers began studying the characteristic, later named resilience, four types of measurements have been applied. They`ve included observation (Werner \& Smith, 2001); structured interview (Block, 1980); parent and 
teacher rating of children's resilience (Eisenberg et al., 1997); and self-report paper and pencil responses (Bennett et al., 1998; and ODR, Inc., 1996). The latter area has proved the most promising for generating a large amount of data across many different settings and groups of individuals. The Resilience Scale, a 65 item scale developed in 1991 applied the tool to adolescents first then generated a questionnaire that could be administered to adults. Conner's work with the Personal Resilience Questionnaire has been used most extensively across multiple individuals in widely varying settings in many different countries.

Despite nearly 50 years of interest in the concept of resilience in people and its noted value for helping people overcome adversity, recover from major setbacks, or sustain a healthy personal outlook on life, few measurement tools are available to succinctly identify the presence and degree of resilience in individuals. The Blocks (1980) developed a sub-scale for EgoResiliency but didn't measure it as a singular characteristic or asset. Within the realm of psychopathology, a number of tools have been used to measure stress, coping, or vulnerability (Folkman \& Lazarus, 1988; Moos \& Billings, 1982). Murphy and Moriarity (1976) measured vulnerability, considered one of the risk factors for psychopathology, but didn't measure the positive concept of resilience. Investigating the stability of resilience, Jew in 1991 (Bennett et al. 1998) developed a scale to measure three facets of resilience including optimism, skill acquisition, and risk-taking and applied it to early and late adolescents and adults. Later researchers used this tool to measure resilience over time to determine whether early resiliency was predictive of later resiliency. Other resilience scales have been developed but have not been widely applied to healthy individuals without psychopathology. 
As his doctoral dissertation, Ahn developed the Washington Resilience Scale; a 22-item self-report questionnaire developed using exploratory factor analyses and internal reliability checks (Shields, 1998). Using a seven-point Likert scale respondents could choose between strongly disagree to strongly agree. The scale tapped six independent areas including: problem solving ability, familial support, sociability, emotional coping ability, endurance, and goal persistence. Generally used with college age students, some of the statements included: Iget along with people in authority. I like to do enough work to just get by. My parent(s) gave me the attention that I needed when I was growing up" (Shields, p. 39). The WRS was reasonably reliable in measuring resilience over a two week period with test-retest reliability coefficients of individual items ranging from .30 to .75 . Shields (1998) used Ahn's resilience scale applying it to the relationship between creativity and resiliency. He found that there is a relationship between the two with the creativity subscales of Self-Confidence and Self-Strength having the strongest relationship with resilience.

Connor and Davidson (2003) developed the Connor-Davidson Resilience Scale (CDRISC) as a measure of stress coping ability. This measurement tool consists of 25 items rated on a 5-point scale (0-4) with higher scores reflecting greater resilience. Their subjects included five groups: community sample, primary care outpatients, general psychiatric outpatients, clinical trial of generalized anxiety disorder, and two clinical trials of PTSD (Post Traumatic Stress Disorder). They found that the scale had sound psychometric properties and could distinguish between those with greater and lesser resilience. Through multiple assessments they found that subjects could modify their resilience and improve following treatment. The Connor-Davidson Resilience Scale (CD-RISC) is valuable for quantifying resilience and in assessing treatment 
response. Its application has been to disorder populations needing therapeutic interventions. The authors commented that there is a great need to develop a resiliency scale with wide application to both quantify resilience and monitor treatment. They noted that the 2000 edition of the American Psychiatric Association's textbook of psychiatric measures, there were no measures for resilience offered.

In 2003, a Norwegian group of psychologists led by Friborg offered the Resilience Scale for Adults (RSA). They wanted to identify the resources that healthy people have to protect against the development of psychiatric disturbances. The initial scale had 45 items including statements: - My future feels promising. There are strong bonds in my family. I keep up my daily routines even at difficult times" (p. 70), covering the five dimensions of: personal competence, social competence, family coherence, social support, and personal structure. They concluded that the RSA-scale was a valid and reliable measurement of both healthy and unhealthy adults identifying the presence of protective factors that could help maintain and regain mental health. In 2005, the Norwegian group of psychologists released a further study of the Resilience Scale for Adults (RSA) comparing subjects' performance on measures of personality, cognitive abilities, and social intelligence. They concluded that individuals scoring high on this scale are psychologically healthier, better adjusted, and thus more resilient” (p. 29). The RSA when available as a standardized instrument may be a useful tool for future measurements of the construct of resiliency.

Conner's Personal Resilience Questionnaire is the most frequently applied measurement for resiliency having been used with over 12,000 individuals in a wide variety of work settings 
(ODR, Inc., 1996). Since it has been applied in the work setting on subjects who are not reporting psychopathology, it was found to be the most useful tool for this study.

\section{The Integration of the Concepts of Resilience and Leadership}

The characteristic, resilience, may play a key role in sustaining principals over time in their jobs. The importance of sustainable school leaders can't be overstated in their importance to effective teaching and learning. The school leader's role has become more complex and demanding with a myriad of roles to fill. Principals must act as principal change agents responsible for facilitating adaptation in themselves and their school communities. Their effectiveness as school leaders will rest on their ability to both foresee and respond to the opportunities possible in this dynamic environment.

Resilience, the ability to overcome obstacles and face adversity, may best describe the most important prerequisite skill in the profession of principalship. In this challenging profession principals need strong resilience, the motivational force within everyone that drives them to pursue wisdom, self-actualization, and altruism and to be in harmony with a spiritual source of strength" (Richardson, 2002). It would appear that the nonresilient administrator would have a difficult time surviving in this demanding profession. One of the fundamental characteristics of any successful candidate for the principalship would be a resilient one. Heart, knowledge and courage are about being well — about well-being. They relate directly to what is known about the elements that together make a person resilient—-the experiences of caring relationships, opportunities to participate and contribute, and high but achievable expectations" (Leonard, 2002). In this paper I investigated the personality characteristic, resilience, and its relationship to leadership skills in elementary school principals. 
In the great scheme of things, schools may be relatively small organizations, but their leadership challenges are far from small, or simple" (Spoehr, 2004). School leadership is one of the most crucial elements of successful schools and is at the heart of effective schools. Kouzes and Posner (2002) studied leadership behavior defining it as the art of mobilizing others to want to struggle for shared aspirations" (p.21). Much research has been devoted to exploring the significance of school administrators in bringing about needed school reform and raising student achievement in schools. Most of the reports confirm that improved leadership of school administrators could lead to improved student achievement and could facilitate change (Henderson \& Milstein, 2003).

A 1999 report from the National Association of State Boards of Education stated that a principal's job that has become more complex and demanding (Tirozzi, 2001). According to Smith and Andrews (Smith, 1992) the central role of the principal has been viewed variously, as building manager, politician, administrator, change agent, boundary spanner, and instructional leader" (p. 1). Marks et al. (1992) described four stages in the development of the principal's duties. The first developmental stage is clerical; the second, disciplinary; the third, administrative; and the fourth, is the supervisory stage. More contemporary research has supported an even more complex evolution of the principal's role in the development of a leadership stage. As leader, the principal's contribution to the school organization is to develop a vision and motivate the faculty and staff toward student achievement. At the beginning of the twenty first century, a principal must possess the requisite skills, capabilities, and commitment to deal with increased responsibilities and to be held even more accountable for the expenditure of 
limited resources on one of the most complex of society's needs, that of educating children (Cunningham, 2000).

Leadership in public schools is critical to change, reform, and renewal. Making changes will come most expeditiously through the relationships established in an organization which is where real power and energy are generated. In an organization the capacity to form relationships is more important than tasks, functions, roles, and positions within the organization (Wheatley, 2001). Leadership comes from with and is about influencing others. Effective leadership helps develop a rich learning environment. Leadership builds both professional and management capability as well as inspiring leadership actions and aspirations in others (Hurley, 2004).

Hurley (2004) postulates that there are five categories in learning about leadership. The first is the intra-personal learning that occurs in the individual. The second is the interpersonal learning that occurs between and among individuals. The third is the curriculum, teaching, and learning environment that the growth occurs in. The fourth is the professional and management thrusts of the job, and the last category of growth in the individual is the fostering of leadership in others. Effective educational leaders know themselves, they act on a well formed set of values, have a high degree of self efficacy and a deep sense of commitment and responsibility. They have a clear personal vision for optimizing student learning and well being and have the courage and determination to achieve it (Hurley, 2004). This paper pursued the particular area of intra-personal learning and development. This area included the growth of the personal identity; the vision, values and beliefs that the individual brings to the job; courage; resilience, confidence and commitment; and self efficacy. In particular, this paper addressed the growth of leadership skills through an examination of the intra-personal skill of resiliency. 
A wide variety of authors have supported the importance of school settings in the nurturing of resilience in students (Bearman et al., 1997; Bush \& Wilson, 1997; and Rutter, 1989). Henderson and Milstein (2003) after summarizing hundreds of studies on resiliency developed a model that included three steps for reducing risk factors in the environment then building resiliency in the educational environment. They advocated teacher practices that increased the prosocial bonding among students and teachers, the identification of clear, consistent boundaries and a curriculum that taught life skills. To build the resilient environment, they trained teachers in the necessity of providing caring and support, communicating high expectations to students and providing all students with opportunities for meaningful participation. Other authors advocated including the development of the resilient learner in teacher and principal evaluations.

Reeves (2004) in his seminal work on the assessment of educational leaders developed a matrix for leadership performance domains that would more effectively assess leaders ${ }^{6}$ performance and provide more effective feedback that principals could use to improve their skills. Reeves placed the leadership dimension of resilience as his primary characteristic on which to evaluate leaders. He described resiliency as how one reacts to disappointment and failure, a willingness to admit error and learn from it, handling disagreements with leadership and policy decisions constructively, handling dissent from subordinates constructively, and making explicit efforts to improve performance areas based on the previous evaluation. Within his suggested framework of leadership dimensions, he suggested that leaders be evaluated as exemplary, proficient, progressing, or not meeting standards. He further explicitly described these dimensions in behavioral, observable performance standards that clearly describe the 
possible range of performance. Few job applications, screening processes, or evaluative tools, however, include resilience, a high performance indicator. Few administrators recognize its value to the inexperienced principal. Only as one develops a depth of experience with enough mistakes accumulated or challenges faced, can any principal recognize that the sheer demands of the job will never allow perfection or complete satisfaction. As the concept of resilience and its emergence as a construct for framing personal skills evaluation has emerged, the need for tools for evaluating principals, teachers, and students in their resilience skills has become more urgent. Just as Reeves (2004) work on a principal evaluation tool that looks at resilience characteristics has shown the merits of these investigations, this will be an area of further research on training new school leaders. 
Table 2

The Resilience Dimension of the Leadership Performance Matrix

Leadership
Dimension
1.0 Resilience
1.1 Constructive
reaction to
disappointment and
failure

1.2 Willingness to admit error and learn from it.

1.3 Constructively handles disagreement with leadership and policy decisions.

1.4 Constructively handles dissent from subordinates

\section{Exemplary (Systemwide \\ Proficient (Local Impact)} Impact)

Public reports include frank acknowledgment of prior personal and organizational failures, and clear suggestions for systemwide learning resulting from those lessons.

Shares case studies of personal and organizational errors in a way that is used to guide, inspire, and teach colleagues throughout the organization.

In disagreements with policy and leadership decisions, is able to articulate the disagreement and advocate for a point of view based on the best interests of the organization and is willing to challenge executive authority appropriately, but once the decision is made, fully supports and enthusiastically implements policy. Creates constructive contention, assigning roles if necessary to deliberately generate multiple perspectives and consider different sides of important issues. Recognizes and rewards thoughtful dissent.

Previous evaluations are combined with personal reflection and 360-degree feedback to formulate an action plan that is reflected in the leader's daily choices.
Readily acknowledges personal and organizational failures.

Admits failures openly with direct supervisor and immediate colleagues. Evidence of learning from past errors. Nondefensive attitude in accepting feedback. Accepts and implements leadership and policy decisions.

Leader uses dissent to inform final decisions, improve the quality of decision making, and broaden support for final decisions.

Previous evaluations are explicitly reflected into projects, tasks, and priorities. quickly, honestly, and

\section{Progressing (Leadership Potential)}

Acknowledges personal and organizational failure when confronted with evidence.

Able to accept evidence of mistakes when offered by others. Some evidence of learning from mistakes.

Sometimes challenges executive and policy leadership without bringing those concerns to appropriate executive and policy authorities. Sometimes implements unpopular policies unenthusiastically or because $+\mathrm{m}$ just following orders, but I don't like it."

Leader tolerates dissent, but there is very little of it in public because subordinates do not understand the leader's philosophy about the usefulness of dissent.

Leader is aware of previous evaluations, but has not translated them into an action plan.
Unwilling to acknowledge errors. When confronted with evidence of mistakes, is defensive and resistant to learning from mistakes.

Ignores or subverts executive and policy decisions that are unpopular or distasteful.
Dissent is absent due to a climate of fear and intimidation.
No evidence of reference to previous leadership evaluations in the leader's choices of tasks and priorities. 
Conner (1993), suggested training leaders to manage change is a critical step in helping organizations implement their visions. - Our lives are the most effective and efficient when we are moving at a speed that allows us to appropriately assimilate the changes we face (p.12)." He uses the term future shock, first coined by Alvin Toffler in 1965, to describe the potential that the changes that individuals encounter will be greater than they anticipated. We face disequilibrium when we are surprised that we are surprised" (p. 28). Conner offered a concept of resiliency as the most significant resource for change agents to have in order to implement and respond to changes within organizations. He developed a model that included five basic characteristics of resilience. They include: Positive, displaying a sense of security and self assurance; Focused, having a clear vision of what they want to achieve; Flexible, demonstrating a special pliability; Organized, developing structured approaches to managing ambiguity; and Proactive, engaging change rather than defending against it (p. 238).

Isaacs, (2003) completed a similar dissertation comparing the resilience dimensions on the Personal Resilience Questionnaire (PRQ) and the Leadership Practices Inventory (LPI) of secondary principals in five counties in Florida. He extended his evaluation of leadership practices by having teachers and assistant principals complete surveys of the principals that they worked for. He found significant relationships among the resilience dimensions of Positive: The World, Focused, Flexible: Thoughts, Organized, and Proactive and the leadership practices of challenging the process, inspiring a shared vision, enabling others to act, modeling the way, and encouraging the heart of high school principals. Isaacs concluded that - mre research is needed on resiliency in education because it is a critical component to successfully managing change ( $\mathrm{p}$. 108). He noted that resilient principals — boune back" more readily leading to greater strength 
and capabilities. Resilient people tend to accomplish their goals without sacrificing the quality of their work, while maintaining physical and emotional health. He recommended that a similar study could be done -determining the relationships among the dimensions of resilience, leadership practices, and individual demographics of elementary school principals" (p. 108). 


\section{Chapter Three}

\section{Methodology}

Chapters one and two provided background information about the concepts of leadership and resilience and their relationship to public school principals. Principals play key roles in the educational process and are faced with increasingly complex demands from federal and state government forces, local Boards of Education, and the parent and student constituencies that they serve. Principals need support and sustenance to survive in their roles as critical instructional leaders. As the concept of resilience has evolved, this set of characteristics has been significant in developing and sustaining individuals who become and remain productive in challenging situations. Chapter three described the two survey instruments and the demographics that seek to identify correlations among leadership practices and characteristics of resilience. These relationships may be beneficial in the recruitment, retention, and sustenance of elementary school principals and their integral role in student learning. Chapter three also described the survey design, the data collection method from the census of the population, the instrumentation, and the statistical analyses of the data. Here, the author provided an examination of the measurement instruments, the Personal Resilience Questionnaire (PRQ) (1993) (see Appendix E) and The Leadership Practice Inventory (Self) (1987) (see Appendix F).

The purpose of this research was to identify relationships among resilience, leadership, and demographic characteristics of elementary school principals in West Virginia. The research questions included: 
1. Are there significant relationships among the dimensions of resilience and leadership practices of elementary school principals? The hypothesis is that principals who demonstrate strong levels of resilience will have corresponding strengths on leadership practice.

2. Are there significant relationships among the dimensions of resilience and demographic characteristics: age, gender, level of education, years of teaching experience, years of administrative experience, number of students in current school, number of superintendents have worked for, number of professionals supervised, and percentage of students on Free and Reduced Lunch? The hypothesis was that factors in the work environment would positively or negatively influence principals` sense of resilience.

3. Are there significant relationships among leadership practices and demographic characteristics: age, gender, level of education, years of teaching experience, years of administrative experience, number of students in current school, number of superintendents they have worked for, number of professionals supervised, and percentage of students on Free and Reduced Lunch? The hypothesis was that factors in the work environment would positively or negatively influence principals‘ leadership practices.

Greater resilience characteristics may help principals facilitate the change process in their institutions sustaining school leaders through difficult challenges. From this research school administrators may develop more relevant staff development programs and provide more formative evaluation tools for school principals. Further understanding of the relationship between resilience, the process of recovering homeostasis following disruptions, and effective leadership practices will help principals improve their effectiveness as school leaders. 


\section{Survey Design}

This quantitative study employed a survey method of investigating responses from the individuals who chose to complete the survey. As Creswell (2003) pointed out, a survey provides a fumeric description of trends, attitudes, or opinions of a population" (p. 153). Babbie (1990) described the purpose of a survey as one that generalizes from a sample to a population so that the research can infer some characteristic, attitude or behavior about the target population. Babbie stated that three purposes for survey research include description, explanation, and exploration. Surveys are frequently conducted for the purpose of making descriptive assertions about some population, that is, discovering the distribution of certain traits or attributes" (p. 52). Through the use of two standardized instruments, the Personal Resilience Questionnaire (ODR, 1993) and the Leadership Practices Inventory (Self) (Kouzes \& Posner, 2002), the researcher expected to see a pattern of relationships among the resilience dimensions and the leadership practices within each instrument respectively. The study examined the effects of two independent (predictor) variables, resilience and leadership, on the reported behaviors of the elementary school principals. The survey method of gathering data provided an efficient, economical means of collecting information about a specific group of principals and generalizing to the population of elementary principals.

Surveys may be administered through five methods: mail, telephone, personal administration, interview and the internet based method (Gay, 2000). Three methods: telephone, personal administration, and interview are not practical for the size and geographically dispersed area covered by this survey. Therefore, the researcher elected to use an internet based method for collecting survey responses. 


\section{Data Collection Process}

The researcher obtained Institutional Review Board (Appendix D) approval from West Virginia University before beginning the research process. Initially, the researcher developed a database of principal emails through the WV Department of Education's website Our Schools (2007) information after securing permission from the WV Superintendent of School's office (Appendix A). The introductory email (Appendix B) with one or two follow-up emails (Appendix C) asked each potential member of the population to participate indicating a link to the Survey Monkey survey site to complete the surveys and the demographic information. The respondents were advised that participation was voluntary with no negative consequences attached to failure to participate. The respondents' returned surveys were coded with their preassigned number attached to their two surveys and the demographic questions. The email addresses and the assigned numbers were maintained by an independent webmaster thereby assuring anonymous responses made to the researcher. The ODR (now Resilience Alliance) staff scored the responses to the Personal Resilience Questionnaire and returned those to the researcher (Appendix H). Kouzes \& Posner International gave permission to reproduce and use the LPI for research purposes (Appendix I). The examiner used the software that accompanied the LPI, $3^{\text {rd }}$ edition to score the responses and collect the data. The demographic responses (Appendix G) were also returned with emailed responses coded with the respondents` assigned numbers.

\section{Population}

The population for this survey included all elementary school principals working in rural and lightly urbanized areas of the U.S. The author chose to survey 400 elementary principals 
working in WV (WV Department of Education, 2007). These respondents were selected for convenience and availability through the WV Department of Education, thus limiting the ability to generalize results of this survey to the general population of elementary principals in the United States. The researcher employed a single stage census procedure in which the researcher had access to all of the names in the population and could request direct responses from everyone in the population. The population was not stratified to reflect the general population of all elementary school principals in the nation. Suskie (1996, p.14) recommends that for a population size of 500, researchers should sample 217 individuals. The researcher addressed concerns with sampling error, the possible difference between your findings and the true results if you were able to obtain valid responses from everyone" (p. 13). With a rate of return of approximately $20 \%$, this number didn't meet the tolerable $5 \%$ sampling error for generating predictive information about the total population of WV principals (p. 13). The $20 \%$ return rate meets the minimum number to generate data to describe the population of respondents. In summary, the researcher contacted all 400 elementary principals in the largely rural and lightly urbanized state of West Virginia in a single stage census procedure with no stratification of the subjects to match the general population. Two waves of follow-up were conducted to increase the participation rate.

A pilot study was conducted with three individuals in education-related occupations to insure that they could adequately complete the instruments and identify potential problems. The researcher interviewed each of those individuals to identify any difficulties they had and to identify the length of time it took them to complete the instruments. 


\section{Instrumentation}

Two important characteristics of instruments are their reliability and validity. The reliability of a standardized instrument is the consistency with which the instrument produces the same results under the same conditions at different times (Gliner \& Morgan, 2000). Kouzes and Posner defined reliability as the extent to which an instrument contains _measurement errors“ that cause scores to differ for reasons unrelated to the individual respondent" $(2002, \mathrm{p} .5)$. When an instrument has fewer errors, it is considered a more reliable instrument. Reliabilities above .60 are considered good (Kouzes \& Posner, 2002). The more important quality of any standardized instruments is its validity, whether the scores on the instrument have meaning and usefulness. Validity has three forms: content validity, whether the items measure what they were intended to measure; predictive or concurrent validity, whether scores correlate with other similar test measures; and construct validity, whether items measure hypothetical constructs or concepts (Creswell, 2003). The authors of both the PRQ and the LPI have conducted extensive research on the reliability and validity of the instruments.

The researcher used two online surveys to gather data for this study including The Personal Resilience Questionnaire (PRQ) (ODR, 1993) and the Leadership Practices Inventory (Self) (LPI-S) (Kouzes \& Posner, 2003). Demographic information was appended to the surveys and included a single response to the following:

1) Age: $20-30,31-40,41-50,51-60,61+)$

2) Gender: (Male or Female)

3) Level of education (Bachelor, Masters, Specialist, Doctorate)

4) How many years have you taught? (0-5, 6-10, 11-15, 16-20, 21+) 
5) How many years have you worked as a principal? (0-5, 6-10, 11-15, 16-20, 21+)

6) Number of students in current school $(<100,101-200,201-300,301-400,400+)$

7) As a principal how many superintendents have you worked for? (1-2, 3-5, 6-8, >8)

8) How many professionals do you supervise? (1-15, 16-30, 31-45, 45+)

9) Approximate percentage of students on Free and Reduced Lunch? $(0-25 \%, 26-50 \%$, $51-75 \%$, and $>76 \%)$

\section{The Personal Resilience Questionnaire}

The Personal Resilience Questionnaire (PRQ) (1993) (see Appendix E) was developed by Daryl Conner and his associates at ODR, Inc. in Atlanta, Georgia. The $P R Q$ is intended to identify a combination of traits that enable people to assimilate change in a continuum of responses labeled opportunity-oriented through danger-oriented (see Literature Review in Chapter 2). The instrument assesses the seven dimensions of resilience: POSITIVE (The World), POSITIVE (Yourself), FOCUSED, FLEXIBLE (Thoughts), FLEXIBLE (Social), ORGANIZED, and PROACTIVE. Respondents completed 70 questions choosing responses from a Likert scale ranging from: strongly disagree, disagree, slightly disagree, slightly agree, agree, and strongly agree. The response range didn't permit a neutral response (ODR, 1993).

Conner and his associates spent two decades studying the construct of resilience in organizations before developing a tool to measure resilience in 1993 . They identified seven discrete dimensions that encompassed the concept of resilience while minimizing overlap between them. Wording the questions at an approximate seventh grade level, the authors reduced semantic challenges and potential sources of partiality. They reverse scored some of the 
items to reduce response bias. They established the test validity and reliability of the instrument through a variety of studies.

A study completed with 226 undergraduate students at the Georgia Institute of Technology in 1993 examined the construct validity of the instrument. Students were given extra credit to participate in the study which compared responses on the $P R Q$ with 26 other instruments including the Personal Resilience Profile sub-scales, all measuring the construct of resilience. The authors concluded that their instrument measured seven discrete dimensions including: POSITIVE (The World), POSITIVE (Yourself), FOCUSED, FLEXIBLE (Thoughts), FLEXIBLE (Social), ORGANIZED, and PROACTIVE (ODR, 1996).

Conner and his associates established the predictive validity of the $P R Q$ by conducting studies that compared subjects' scores on the instrument with subjects rated as high or low performing managers. In a study of 86 managers in a leading financial institution undergoing significant change, they found that subjects identified as high performing had higher scores than the low performers on the seven dimensions of the $P R Q$. Therefore, they concluded that the instrument could be used to predict job performance in organizations that are undergoing rapid change. The relationship may not be as significant in more static organizations (Conner, 1993).

ODR, Inc. examined the discriminate validity of the $P R Q$ in differentiating between high and low performing managers. Applying the 26 scales to the Personal Resilience Profile subscales, they tested whether each scale correlated highly with one of the seven dimensions on the $P R Q$ and had a low correlation with the other six dimensions. Their results showed that the instrument had low discriminate validity, with some variation among the subscales. The researchers concluded that some of the sub-scales were interrelated (ODR, 1994). 
ODR, Inc. applied Cronbach's alpha coefficients to determine internal consistency reliability of the $P R Q$. Using this formula the researchers determined whether the instrument consistently predicted when measures of one variable produce numbers that are larger or smaller, the numbers for some other measured variable will be similarly larger or smaller" (Locke, et al., 1998, p. 128). Cronbach's alpha yields a value between 0 and 1, ranging from low reliability near 0 to high reliability near 1 . The following coefficients resulted for the $P R Q$ : Table 3

Coefficients of the seven dimensions of personal resilience questionnaire

Seven Dimensions of Personal Resilience Questionnaire

POSITIVE (The World)

POSITIVE (Yourself)

FOCUSED

FLEXIBLE (Thoughts)

FLEXIBLE (Social)

ORGANIZED

\section{Coefficients}

.83

.81

.82

.71

.74

.68

These results showed that the resilience scale has a high level of correlation. Respondents tended to answer similar questions in a similar manner across different measurement tools. Results of all of these studies show that the $P R Q$ had acceptable validity and reliability. As a copyrighted questionnaire, ODR, Inc., doesn't permit the scoring methodology for the $P R Q$ to be published This investigator worked with ODR and signed non-disclosure agreements with the company (see Appendix G). 


\section{The Leadership Practices Inventory}

The Leadership Practices Inventory ( $3^{r d}$ ed.)-Self, (LPI), (see Appendix F), the second questionnaire, was administered to the subjects to measure their leadership actions and behaviors. Kouzes and Posner provide a 30 item questionnaire with six statements per each leadership practice to examine the areas they call: modeling the way, inspiring a shared vision, challenging the process, enabling others to act, and encouraging the heart (see Literature Review). The LPI offers 10 statements on a Likert scale ranging from: (1) almost never; (2) rarely; (3) seldom; (4) once in a while; (5) occasionally; (6) sometimes; (7) fairly often; (8) usually; (9) very frequently; and (10) almost always for respondents to choose for an explicit description of their leadership behaviors. The LPI is intended as a tool for leaders to use to evaluate their own leadership practices and yields guidelines on personal leadership behaviors.

Internal Reliability and Validity of the LPI. Reliability refers to a test instrument's amount of errors in measurement that would cause scores to differ among individuals based on factors unrelated to the individual respondents. Internal reliability for the LPI is consistently above .60 , considered a good score. In a number of studies cited by the researchers internal reliability ranged from .71 to .97 . These studies have been conducted with diverse groups including engineering managers, women in executive positions, college presidents, correctional institution leaders, frontline supervisors in a large telecommunications firm, female college student affairs officers, nursing managers, and healthcare managers. The authors reported similar reliability ratings when the instrument was used with non-U.S. populations . Test-retest reliability for the five leadership practices is generally at the .90 level and above (Kouzes \& Posner, 2002). 
Table 4

Reliability (Cronbach Alpha) Coefficients for the LPI's Leader Report

\begin{tabular}{cc} 
Leadership Practice & Reliability Coefficient \\
\hline Modeling the Way & .77 \\
Inspiring a Shared Vision & .87 \\
Challenging the Process & .80 \\
Enable Others to Act & .75 \\
Encouraging the Heart & .87
\end{tabular}

The authors of the LPI determined that the instrument has excellent content or face validity, whether the instrument measures what it intends to measure, since the 30 statements used reflect statements that participants often use to describe leadership practices. By subjecting the instrument to a number of factor analyses, the authors determined that the LPI has strong construct validity. They determined that the LPI has excellent concurrent validity indicating that the scores achieved by respondents are consistently associated with important aspects of their professional effectiveness including work-group performance, team cohesiveness, commitment, satisfaction, and credibility (Kouzes \& Posner, 2002). Scores on the LPI have been found to be unrelated to various demographic characteristics (e.g. age, marital status, years of experience, educational level) (Kouzes \& Posner, 2002).

\section{Data Analysis}

The researcher analyzed the required data for each research question in this study searching for interactions of the two independent variables, dimensions of resilience and leadership practices. The author examined the data generated from the surveys using the Pearson Product Moment (PPM) correlation, Spearman rho correlation, and independent samples t test. 
The Pearson Product Moment was used to determine correlations among leadership practices and resilience characteristics of elementary school principals to address the first research question. The resulting responses to the seven dimensions of the Personal Resilience Questionnaire were examined to determine if there were significant correlations with the five dimensions of the LPI. For example, are the responses for the positive dimension of the Personal Resilience Questionnaire correlated with each of the major categories (model, inspire, challenge, enable, encourage) within the LPI?

Research question two asked if there were significant relationships among the dimensions of resilience and the demographic characteristics, while research question three examined leadership practices and relationships among the demographic characteristics. The demographic characteristics include: age, gender, level of education, years of teaching experience, years of principal experience, number of students in current school, number of superintendents worked for, number of professionals supervised, and percentage of students on Free and Reduced Lunch (Appendix G). Since the responses from the $P R Q$ and the LPI generated responses on ordinal scales, the researcher used the Spearman rho to calculate the correlation. In two of the demographic questions, gender and level of educaton, responses generated only one of two responses. In the gender demographic question, the researcher used the Independent Samples T Test since these are dichotomous variables. In the demographic question about level of education three respondents indicated that they held Specialist's degrees and five held Doctorate degrees. Because this group size was not comparable to the number of respondents (72) who indicated that they held Master's degrees, no statistical analysis was reported other than mean and standard 
deviation. The author used the Statistical Package for the Social Sciences (SPSS) software program to facilitate the data analysis.

\section{Summary}

The author studied the relationship between personal resilience and leadership qualities of elementary school principals in WV characterized by nine different demographics. The researcher surveyed the subjects using emails to each potential participant requesting their participation in the online surveys. These surveys included two commercial instruments, the Personal Resilience Questionnaire and the Leadership Practices Inventory. Responses to these two surveys were analyzed through a variety of correlational studies. 


\section{Chapter Four}

\section{Results}

This study explored the dimensions of resilience and leadership practices in elementary school principals and collected demographic information on the respondents. The researcher used Pearson Product Moment (PPM) and Spearman correlations to determine relationships among the responses. Two of the demographic questions were treated differently since they generated dichotomous independent variables (only one of two choices).

\section{Demographics}

The participants in this study were all elementary school principals working in West Virginia public schools in May of the school term for 2008-2009. Of the total population of 400 elementary principals, eighty-eight individuals responded to the survey though ten individuals“ returns were rejected due to incompletion of at least one complete survey among the three total surveys. The number of responses $(\mathrm{N})$ to each resilience dimension, leadership practice, or demographic question varied due to respondents' omissions of some questions in the surveys. Therefore, $20 \%$ of the total number of principals returned usable surveys meeting the minimally acceptable level for studying the population. The respondents completed nine demographic questions and two online surveys.

Of the respondents the majority were aged 51-60 $(n=45)$ and female $(n=55)$. Their highest level of education was, for the majority, a master's degree $(n=80)$ and most had taught for over 21 years $(n=44)$. The majority had worked as a principal for $6-10$ years $(n=32)$ followed closely by those working as a principal for $0-5$ years $(n=28)$. The larger majority of respondents served larger elementary schools of over 400 students $(n=31)$ while only three 
respondents served schools with student populations of less than 100. Most principals had worked for only one superintendent $(n=49)$. The number of professionals employed had closely balanced ranges of 16-30 $(n=29)$ and 31-45 $(n=26)$. Most principals $(n=44)$ worked in schools where over $50 \%$ of the students were on Free and Reduced Lunch status, a poverty line determined by the Federal government.

Table 5

Age of Respondents

\begin{tabular}{lrc}
\hline & $\mathrm{N}$ & $\%$ \\
a. $20-30$ & 0 & 0 \\
b. $31-40$ & 8 & 9.2 \\
c. $41-50$ & 29 & 33.3 \\
d. $51-60$ & 45 & 51.7 \\
e. $61+$ & 5 & 5.7 \\
\hline
\end{tabular}

As shown in Table 5 the majority of the respondents were 51-60 years of age. When combining the two age ranges of 41-50 and 51-60, the great majority (85\%) of the respondents are in the middle-aged range of 41-60.

Table 6

Gender

\begin{tabular}{lll}
\hline & $\mathrm{N}$ & $\%$ \\
a. Female & 55 & 63.2 \\
b. Male & 32 & 36.8 \\
\hline
\end{tabular}

The majority of the 88 respondents were female $(n=55)$. 
Table 7

Level of Education

\begin{tabular}{lrr}
\hline & N & $\%$ \\
a. Bachelor's degree & 0 & \multicolumn{1}{c}{0} \\
b. Master's degree & 80 & 90.9 \\
c. Specialist's degree & 3 & 3.4 \\
d. Doctoral degree & 5 & 5.7 \\
\hline
\end{tabular}

The majority of respondents (91\%) have a Master's degree with no one working as a principal with only a Bachelor's degree.

Table 8

Number of Years Taught

\begin{tabular}{lrr}
\hline & $\mathrm{N}$ & $\%$ \\
a. $0-5$ years & 6 & 7.0 \\
b. $6-10$ years & 12 & 14.0 \\
c. $11-15$ years & 13 & 15.1 \\
d. $16-20$ years & 11 & 12.8 \\
e. $21+$ & 44 & 51.2 \\
\hline
\end{tabular}

The simple majority of respondents (51.2\%) had taught in the classroom over 21 years before becoming principals. 
Table 9

Number of Years Worked as a Principal

\begin{tabular}{lrr}
\hline & $\mathrm{N}$ & $\%$ \\
a. $0-5$ years & 28 & 32.2 \\
b. $6-10$ years & 32 & 36.8 \\
c. $11-15$ years & 8 & 9.2 \\
d. $16-20$ years & 8 & 9.2 \\
e. $21+$ & 11 & 12.6 \\
\hline
\end{tabular}

Most of the respondents (36.8\%) had worked as a principal for 6-10 years with $69 \%$ of principals working 0-10 years when combining results from the first two groups.

Table 10

Number of Students in Current School

\begin{tabular}{lcc}
\hline & $\mathrm{N}$ & $\%$ \\
a. $<100$ & 3 & 3.5 \\
b. $101-200$ & 21 & 24.4 \\
c. $201-300$ & 16 & 8.6 \\
d. $301-400$ & 15 & 17.4 \\
e. $401+$ & 31 & 36.0 \\
\hline
\end{tabular}

As an indication of school size, the greatest percentage of principals (36\%) served in schools with over 400 students. The next largest group at $24.4 \%$ served in schools at less than half that size (101-200 students). 
Table 11

Number of Superintendents Worked For

\begin{tabular}{lrl}
\hline & $\mathrm{N}$ & $\%$ \\
a. $1-2$ & 49 & 55.7 \\
b. $3-5$ & 28 & 31.8 \\
c. $6-8$ & 5 & 5.7 \\
d. $>8$ & 6 & 6.8 \\
\hline
\end{tabular}

Over half the respondents $(55.7 \%)$ had worked for the least number of superintendents (1-2). Combining the latter two categories $12.5 \%$ of the respondents had worked for six or greater number of superintendents.

Table 12

Number of professionals supervised

\begin{tabular}{lll}
\hline & $\mathrm{N}$ & $\%$ \\
a. $1-15$ & 13 & 14.9 \\
b. $16-30$ & 29 & 33.3 \\
c. $31-45$ & 26 & 29.9 \\
d. $45+$ & 19 & 21.8 \\
\hline
\end{tabular}

One third of the respondents (33.3\%) supervise 16-30 professional employees. Slightly less than $15 \%$ of the respondents supervise small staffs of 15 or fewer professionals. 
Table 13

Percentage of students on Free or Reduced Lunch status

\begin{tabular}{lcc}
\hline & $\mathrm{N}$ & $\%$ \\
a. $0-25 \%$ & 5 & 5.7 \\
b. $26-50 \%$ & 29 & 33.0 \\
c. $51-75 \%$ & 44 & 50 \\
d. $>76 \%$ & 10 & 11.4 \\
\hline
\end{tabular}

Half of the respondents (50\%) reported that they served in schools where the number of students receiving Free or Reduced Lunch ranges from 51-75\%. Only 5.7\% of schools had the lowest rate of Free or Reduced Lunch status ranging from $0-25 \%$.

\section{Findings of the Research Questions}

$R Q 1$. Are there significant relationships among the dimensions of resilience and leadership practices of elementary school principals? The results of the Pearson Product-moment (PPM) correlations among the resilience dimensions [Positive (Yourself), Positive (The World), Focused, Flexible (Thoughts), Flexible (Social), Organized and Proactive] and leadership practices [Modeling the way, inspiring a shared vision, Challenging the process, enabling others to act, and encouraging the heart] are shown in Table 16. The statistical significant level was set at $p \leq .05$. The following correlations showed statistically significant positive relationships; there were no negative correlations.

- Positive: The World with modeling the way $(\mathrm{r}=.290, \mathrm{p}=.012)$, inspiring a shared vision $(\mathrm{r}=.248, \mathrm{p}=.030)$, and challenging the process $(\mathrm{r}=.332, \mathrm{p}=.003)$. 
- Positive: Yourself with modeling the way $(\mathrm{r}=.394, \mathrm{p}=.000)$, inspiring a shared vision $(\mathrm{r}=.299, \mathrm{p}=.008)$, challenging the process $(\mathrm{r}=.382, \mathrm{p}=.001)$, and enabling others to act $(\mathrm{r}=.283, \mathrm{p}=.012)$.

- Focused with modeling the way $(\mathrm{r}=.579, \mathrm{p}=.000)$, inspiring a shared vision $(\mathrm{r}=.464$, $\mathrm{p}=.000)$, challenging the process $(\mathrm{r}=.589, \mathrm{p}=.000)$, and enabling others to act $(\mathrm{r}=.348$, $\mathrm{p}=.002)$.

- Flexible (Social) with modeling the way $(\mathrm{r}=.317, \mathrm{p}=.006)$, inspiring a shared vision $(\mathrm{r}=.343, \mathrm{p}=.002)$, challenging the process $(\mathrm{r}=.328, \mathrm{p}=.004)$, and encouraging the heart $(\mathrm{r}=.224, \mathrm{p}=.049)$.

- Organized with modeling the way $(\mathrm{r}=.360, \mathrm{p} \leq .001)$.

- Proactive with modeling the way $(\mathrm{r}=.297, \mathrm{p}=.010)$, inspiring a shared vision $(\mathrm{r}=.351$, $\mathrm{p}=.002)$, and enabling others to act $(\mathrm{r}=.245, \mathrm{p}=.031)$. 
Table 14

Correlations Between Dimensions of Resilience and Leadership Practices

\begin{tabular}{|c|c|c|c|c|c|c|}
\hline \multirow{2}{*}{$\begin{array}{l}\text { Resilience } \\
\text { Dimensions }\end{array}$} & & \multicolumn{5}{|c|}{ Leadership } \\
\hline & & \multicolumn{5}{|c|}{ Practices } \\
\hline & & MTW & ISV & СТP & $\mathrm{EOA}$ & ETH \\
\hline Positive: & Pearson Correlation & $.290 *$ & $.248^{*}$ & $.332 * *$ & .200 & .127 \\
\hline \multirow[t]{2}{*}{ The World } & Sig. (2 tailed) & .012 & .030 & .003 & .078 & .269 \\
\hline & $\mathrm{N}$ & 75 & 77 & 77 & 78 & 78 \\
\hline Positive: & Pearson Correlation & $.394 * *$ & $.299 * *$ & $.382 * *$ & $.283 *$ & .143 \\
\hline \multirow[t]{2}{*}{ Yourself } & Sig. (2 tailed) & .000 & .008 & .001 & .012 & .211 \\
\hline & $\mathrm{N}$ & 75 & 77 & 77 & 78 & 78 \\
\hline \multirow[t]{3}{*}{ Focused } & Pearson Correlation & $.579 * *$ & $.299 * *$ & $.382 * *$ & $.283 *$ & .143 \\
\hline & Sig. (2 tailed) & .000 & .000 & .000 & .002 & .021 \\
\hline & $\mathrm{N}$ & 75 & 77 & 77 & 78 & 78 \\
\hline Flexible: & Pearson Correlation & .023 & .132 & .186 & .148 & -.014 \\
\hline \multirow[t]{2}{*}{ Thoughts } & Sig. (2 tailed) & .846 & .253 & .106 & .197 & .904 \\
\hline & $\mathrm{N}$ & 75 & 77 & 77 & 78 & 78 \\
\hline Flexible: & Pearson Correlation & $.317 * *$ & $.343^{* *}$ & $.328 * *$ & .216 & $.224^{*}$ \\
\hline \multirow[t]{2}{*}{ Social } & Sig. (2 tailed) & .006 & .002 & .004 & .057 & .049 \\
\hline & $\mathrm{N}$ & 75 & 77 & 77 & 78 & 78 \\
\hline \multirow[t]{3}{*}{ Organized } & Pearson Correlation & $.360 * *$ & .132 & .205 & .139 & .174 \\
\hline & Sig. (2 tailed) & .001 & .253 & .074 & .226 & .128 \\
\hline & $\mathrm{N}$ & 75 & 77 & 77 & 78 & 78 \\
\hline \multirow[t]{3}{*}{ Proactive } & Pearson Correlation & $.297 * *$ & $.351 * *$ & .444 & $.245^{*}$ & .198 \\
\hline & Sig. (2 tailed) & .010 & .002 & .000 & .031 & .082 \\
\hline & $\mathrm{N}$ & 75 & 77 & 77 & 78 & 78 \\
\hline \multicolumn{7}{|c|}{ **. Correlation is significant at the .01 level ( 2 tailed). *. Correlation is significant at the .05 level ( 2 tailed) } \\
\hline \multicolumn{7}{|c|}{ MTW - Modeling the Way } \\
\hline \multicolumn{7}{|c|}{ ISV - Inspiring a Shared Vision } \\
\hline \multicolumn{7}{|c|}{ CTP - Challenging the Process } \\
\hline \multicolumn{7}{|c|}{ EOA - Enabling Others to Act } \\
\hline $\mathrm{ETH}-\mathrm{Enc}$ & ging the Heart & & & & & \\
\hline
\end{tabular}


$R Q 2$. Are there significant correlations among demographic characteristics: age, gender, level of education, years of teaching experience, years of administrative experience, number of students in current school, number of superintendents worked for, number of professionals supervised, and percentage of students on Free and Reduced Lunch and dimensions of resilience? Using Spearman's rho statistical analyses, there was a significant negative correlation between age and flexible (thoughts) $(\mathrm{CC}=-.296, \mathrm{p}=.008)$, flexible (social) $(\mathrm{CC}=-.276, \mathrm{p}=.015)$, and proactive $(\mathrm{CC}=-.227, \mathrm{p}=.046)$. There were significant positive correlations between years as a principal and positive (yourself) $(\mathrm{CC}=.258, \mathrm{p}=.022)$ and organized $(\mathrm{CC}=.225, \mathrm{p}=.047)$. There was a significant positive correlation between number of superintendents worked for and positive (yourself) $(\mathrm{CC}=.228, \mathrm{p}=.049)$. There was a significant positive correlation between number of professional staff supervised and positive (the world) $(\mathrm{CC}=.226, \mathrm{p}=.047)$. There was a significant negative correlation between percentage of students who received free and reduced lunch and flexible (social) $(\mathrm{CC}=-.240, \mathrm{p}=.033)$. There were no significant positive correlations found in number of years taught and number of students in school and the resilience dimensions. 
Table 15

Correlations Between Demographic Characteristics and Dimensions of Resilience

\begin{tabular}{|c|c|c|c|c|c|c|c|c|}
\hline \multirow[t]{2}{*}{ Demographics } & \multicolumn{8}{|c|}{ Resilience Dimensions } \\
\hline & & $\begin{array}{l}\text { Positive: } \\
\text { The World }\end{array}$ & $\begin{array}{l}\text { Positive: } \\
\text { Yourself }\end{array}$ & Focused & $\begin{array}{l}\text { Flexible: } \\
\text { Thoughts }\end{array}$ & $\begin{array}{l}\text { Flexible: } \\
\text { Social }\end{array}$ & Organized & Proactive \\
\hline \multirow[t]{3}{*}{ Age } & $\mathrm{CC}$ & -.072 & .097 & -.117 & $-.296 * *$ & $-.276^{* *}$ & .050 & $-.227 *$ \\
\hline & Sig. & .531 & .397 & .309 & .008 & .015 & .666 & .046 \\
\hline & $\mathrm{N}$ & 78 & 78 & 78 & 78 & 78 & 78 & 78 \\
\hline \multirow[t]{3}{*}{ Years Taught } & $\mathrm{CC}$ & .010 & -.008 & -.028 & -.050 & -.276 & -.094 & .055 \\
\hline & Sig. & .932 & .947 & .807 & .667 & .728 & .417 & .633 \\
\hline & $\mathrm{N}$ & 77 & 77 & 77 & 77 & 77 & 77 & 76 \\
\hline \multirow{3}{*}{$\begin{array}{l}\text { Years as a } \\
\text { Principal }\end{array}$} & $\mathrm{CC}$ & .124 & $.258 *$ & .166 & -.129 & -.018 & $.225^{*}$ & .003 \\
\hline & Sig. & .280 & .022 & .146 & .260 & .878 & .047 & .983 \\
\hline & $\mathrm{N}$ & 78 & 78 & 78 & 78 & 78 & 78 & 78 \\
\hline \multirow{3}{*}{$\begin{array}{l}\text { Number of } \\
\text { Students }\end{array}$} & $\mathrm{CC}$ & .162 & .167 & .181 & .069 & .099 & .101 & .110 \\
\hline & Sig. & .156 & .143 & .112 & .547 & .386 & .377 & .337 \\
\hline & $\mathrm{N}$ & 78 & 78 & 78 & 78 & 78 & 78 & 78 \\
\hline \multirow{3}{*}{$\begin{array}{l}\text { Number of } \\
\text { Superintendents }\end{array}$} & $\mathrm{CC}$ & .191 & $.228 *$ & .117 & -.027 & -.050 & .152 & -.140 \\
\hline & Sig. & .101 & .049 & .318 & .815 & .672 & .193 & .230 \\
\hline & $\mathrm{N}$ & 75 & 75 & 75 & 75 & 75 & 75 & 75 \\
\hline Number of & $\mathrm{CC}$ & $.226^{*}$ & .218 & .107 & .173 & .065 & .125 & .105 \\
\hline Professional & Sig. & .047 & .055 & .351 & .129 & .571 & .275 & .361 \\
\hline Staff & $\mathrm{N}$ & 78 & 78 & 78 & 78 & 78 & 78 & 78 \\
\hline Percentage of & $\mathrm{CC}$ & -.074 & -.007 & -.118 & .206 & $-.240 *$ & -.096 & .043 \\
\hline Free \& Reduced & Sig. & .519 & .949 & .302 & .069 & .033 & .399 & .704 \\
\hline Lunch & $\mathrm{N}$ & 79 & 79 & 79 & 79 & 79 & 79 & 79 \\
\hline
\end{tabular}


In the demographic characteristics two questions, that of gender and level of education, generated one of two possible responses. The demographic characteristic of gender showed a significant difference in the responses of males and females in the resilience dimensions of positive (the world) $(\mathrm{p}=.025)$ and flexible (social) $(\mathrm{p}=.002)$. The resilience dimensions of positive (yourself), focused, flexible (thoughts), organized, and proactive maintained a homogeneity of variance, that the variability of the two groups, males and females, is similar. Only three respondents indicated possession of a specialist's degree so that category was combined with the doctoral level for a total of eight. For statistical purposes the researcher combined the low number of responses for specialist's and doctorate for a total of eight respondents. However, since the two groups, that of Master's with $\mathrm{N}$ of 72 and the Specialist's/Doctor's with an N of seven, did not have comparable sizes, the researcher examined the mean, standard deviation, and tests of significance but not the independent samples $t$ test which requires that both groups be of similar size. 
Table 16

Independent Samples T Test of Gender and Dimensions of Resilience

\begin{tabular}{|c|c|c|c|c|c|c|c|c|}
\hline \multirow[b]{2}{*}{ Resilience Dimensions } & \multirow[b]{2}{*}{ Gender } & \multirow[b]{2}{*}{$\mathrm{N}$} & \multirow[b]{2}{*}{ Mean } & \multirow[b]{2}{*}{$\begin{array}{l}\text { Standard Error } \\
\text { Mean }\end{array}$} & \multirow[b]{2}{*}{$\begin{array}{c}\text { Sig. } \\
2 \text { tailed }\end{array}$} & \multirow[b]{2}{*}{$\begin{array}{l}\text { Std Error } \\
\text { Difference }\end{array}$} & \multicolumn{2}{|c|}{$\mathrm{t}$ - test for Equality of Means } \\
\hline & & & & & & & e & $\mathrm{df}$ \\
\hline \multirow[t]{2}{*}{ Positive (World) } & Female & 46 & 80.2826 & 1.47136 & $.025^{*}$ & 2.45072 & 2.283 & 76 \\
\hline & Male & 32 & 74.6875 & 2.04113 & & & & \\
\hline \multirow[t]{2}{*}{ Positive (Yourself) } & Female & 46 & 82.8913 & 1.27792 & .163 & 2.05085 & 1.410 & 76 \\
\hline & Male & 32 & 80.000 & 1.63505 & & & & \\
\hline \multirow[t]{2}{*}{ Focused } & Female & 46 & 81.4783 & 1.19165 & .096 & 2.02878 & 1.684 & 76 \\
\hline & Male & 32 & 78.0625 & 1.72852 & & & & \\
\hline \multirow[t]{2}{*}{ Flexible (Thoughts) } & Female & 46 & 60.7391 & 1.72210 & .332 & 2.51629 & .977 & 76 \\
\hline & Male & 32 & 58.2813 & 1.72227 & & & & \\
\hline \multirow[t]{2}{*}{ Flexible (Social) } & Female & 46 & 74.1739 & 1.38707 & $.002 *$ & 2.26919 & 3.203 & 76 \\
\hline & Male & 32 & 66.9063 & 1.85207 & & & & \\
\hline \multirow[t]{2}{*}{ Organized } & Female & 46 & 65.5652 & 1.51088 & .870 & 2.86492 & .165 & 76 \\
\hline & Male & 32 & 65.0938 & 2.66525 & & & & \\
\hline \multirow[t]{2}{*}{ Proactive } & Female & 46 & 61.1739 & 1.31484 & .084 & 2.34908 & 1.750 & 76 \\
\hline & Male & 32 & 57.0625 & 2.09066 & & & & \\
\hline
\end{tabular}


Table 17

Means and Standard Deviations of Level of Education and Dimensions of Resilience

\begin{tabular}{|c|c|c|c|c|c|}
\hline \multirow{2}{*}{ Resilience Dimensions } & Level of & $\mathrm{N}$ & Mean & Standard Error & Sig. \\
\hline & \multicolumn{3}{|l|}{ Education } & Mean & 2 tailed \\
\hline \multirow[t]{2}{*}{ Positive (World) } & Master's & 72 & 78.1250 & 1.31976 & .925 \\
\hline & $\mathrm{Sp} / \mathrm{Doc}$ & 7 & 77.7143 & 2.94161 & \\
\hline \multirow[t]{2}{*}{ Positive (Yourself) } & Master's & 72 & 81.4444 & 1.08714 & .190 \\
\hline & $\mathrm{Sp} / \mathrm{Doc}$ & 7 & 86.1429 & 1.93254 & \\
\hline \multirow[t]{2}{*}{ Focused } & Master's & 72 & 79.9722 & 1.03196 & .377 \\
\hline & $\mathrm{Sp} / \mathrm{Doc}$ & 7 & 83.1429 & 4.38302 & \\
\hline \multirow[t]{2}{*}{ Flexible (Thoughts) } & Master's & 72 & 59.8472 & 1.30151 & .976 \\
\hline & $\mathrm{Sp} / \mathrm{Doc}$ & 7 & 59.7143 & 3.79043 & \\
\hline \multirow[t]{2}{*}{ Flexible (Social) } & Master's & 72 & 71.9861 & 1.17394 & .052 \\
\hline & $\mathrm{Sp} / \mathrm{Doc}$ & 7 & 64.0000 & 4.82059 & \\
\hline \multirow[t]{2}{*}{ Organized } & Master's & 72 & 65.3472 & 1.44948 & .716 \\
\hline & $\mathrm{Sp} / \mathrm{Doc}$ & 7 & 67.1429 & 5.17976 & \\
\hline \multirow[t]{2}{*}{ Proactive } & Master's & 72 & 59.4722 & 1.23445 & .084 \\
\hline & $\mathrm{Sp} / \mathrm{Doc}$ & 7 & 63.1429 & 4.75809 & \\
\hline
\end{tabular}

$R Q 3$. Are there significant relationships among demographic characteristics: age, gender, level of education, years of teaching experience, years of administrative experience, number of students in current school, number of superintendents worked for, number of professionals supervised, and percentage of students on Free and Reduced Lunch and leadership practices? The researcher found a significant positive relationship between years as a principal and modeling the way 
$(\mathrm{CC}=.229, \mathrm{p}=.049)$; number of students and challenging the process $(\mathrm{CC}=.241, \mathrm{p}=.036)$; and number of professional staff and challenging the process $(\mathrm{CC}=.238, \mathrm{p}=.039)$. There weren't any significant correlations among age, years taught, number of superintendents worked for, or percentage of students on free and reduced lunch and the leadersip practices.

Table 18

Correlations Between Demographic Characteristics and Leadership Practices

\begin{tabular}{|c|c|c|c|c|c|c|}
\hline & & \multicolumn{4}{|c|}{ Leadership Practices } & \multirow[b]{2}{*}{$\begin{array}{l}\text { Encouraging } \\
\text { the Heart }\end{array}$} \\
\hline & & $\begin{array}{l}\text { Modeling the } \\
\text { Way }\end{array}$ & $\begin{array}{l}\text { Inspiring } \\
\text { Shared } \\
\text { Vision }\end{array}$ & $\begin{array}{l}\text { Challenging } \\
\text { the Process }\end{array}$ & $\begin{array}{l}\text { Enabling } \\
\text { Others to Act }\end{array}$ & \\
\hline Age & $\begin{array}{l}\mathrm{CC} \\
\text { Sig. } \\
\mathrm{N}\end{array}$ & $\begin{array}{r}-.060 \\
.609 \\
74\end{array}$ & $\begin{array}{c}-.077 \\
.508 \\
76\end{array}$ & $\begin{array}{c}-.075 \\
.522 \\
76\end{array}$ & $\begin{array}{r}-, 166 \\
.148 \\
77\end{array}$ & $\begin{array}{r}-.034 \\
.769 \\
77\end{array}$ \\
\hline $\begin{array}{l}\text { Years } \\
\text { Taught }\end{array}$ & $\begin{array}{l}\mathrm{CC} \\
\text { Sig. } \\
\text { N }\end{array}$ & $\begin{array}{r}-.023 \\
.848 \\
73\end{array}$ & $\begin{array}{r}.113 \\
.335 \\
75\end{array}$ & $\begin{array}{r}.023 \\
.845 \\
75\end{array}$ & $\begin{array}{c}.122 \\
.295 \\
76\end{array}$ & $\begin{array}{c}.097 \\
.405 \\
76\end{array}$ \\
\hline $\begin{array}{l}\text { Years as a } \\
\text { Principal }\end{array}$ & $\begin{array}{l}\text { CC } \\
\text { Sig. } \\
\text { N }\end{array}$ & $\begin{array}{c}.229 * \\
.049 \\
74\end{array}$ & $\begin{array}{r}.182 \\
.116 \\
76\end{array}$ & $\begin{array}{r}.220 \\
.056 \\
76\end{array}$ & $\begin{array}{r}.078 \\
.502 \\
77\end{array}$ & $\begin{array}{c}-.018 \\
.879 \\
77\end{array}$ \\
\hline \# of Students & $\begin{array}{l}\text { CC } \\
\text { Sig. } \\
\text { N }\end{array}$ & $\begin{array}{r}.169 \\
.151 \\
74\end{array}$ & $\begin{array}{c}.205 \\
.075 \\
76\end{array}$ & $\begin{array}{c}.241 * \\
.036 \\
76\end{array}$ & $\begin{array}{r}.182 \\
.113 \\
77\end{array}$ & $\begin{array}{c}.130 \\
.258 \\
77\end{array}$ \\
\hline $\begin{array}{l}\text { \# of Super- } \\
\text { intendents }\end{array}$ & $\begin{array}{l}\text { CC } \\
\text { Sig. } \\
\text { N }\end{array}$ & $\begin{array}{r}.145 \\
.228 \\
71\end{array}$ & $\begin{array}{r}.071 \\
.551 \\
73\end{array}$ & $\begin{array}{r}.108 \\
.361 \\
73\end{array}$ & $\begin{array}{r}-.005 \\
.968 \\
74\end{array}$ & $\begin{array}{r}.060 \\
.614 \\
74\end{array}$ \\
\hline $\begin{array}{l}\text { \# Professional } \\
\text { Staff }\end{array}$ & $\begin{array}{l}\text { CC } \\
\text { Sig. } \\
\text { N }\end{array}$ & $\begin{array}{r}.111 \\
.346 \\
74\end{array}$ & $\begin{array}{c}.210 \\
.069 \\
76\end{array}$ & $\begin{array}{c}.238 * \\
.039 \\
76\end{array}$ & $\begin{array}{r}.162 \\
.158 \\
77\end{array}$ & $\begin{array}{r}.188 \\
.102 \\
77\end{array}$ \\
\hline $\begin{array}{l}\text { \%age of Free } \\
\& \text { Reduced } \\
\text { Lunch }\end{array}$ & $\begin{array}{l}\text { CC } \\
\text { Sig. } \\
\text { N }\end{array}$ & $\begin{array}{r}-.022 \\
.852 \\
75\end{array}$ & $\begin{array}{c}.012 \\
.920 \\
77\end{array}$ & $\begin{array}{r}-.041 \\
.721 \\
77\end{array}$ & $\begin{array}{r}.075 \\
.514 \\
78\end{array}$ & $\begin{array}{r}-.007 \\
.952 \\
78\end{array}$ \\
\hline $\begin{array}{l}\mathrm{CC}-\text { Correlati } \\
* * \text {. Correlation } \\
* \text { Correlation is }\end{array}$ & $\begin{array}{l}\text { on Coe } \\
\text { is sign } \\
\text { signif }\end{array}$ & $\begin{array}{l}\text { fficient } \\
\text { ificant at the } 0.0 \\
\text { cant at the } 0.05\end{array}$ & $\begin{array}{l}\text { level ( } 2 \text { tail } \\
\text { vel ( } 2 \text { taile }\end{array}$ & & & \\
\hline
\end{tabular}


In the demographic characteristics, two questions, that of gender and level of education, generated either one of two possible responses. (Only three respondents indicated a specialist's degree so that category was combined with the doctoral level.) The result was that respondents had a master's degree or a specialist's/doctoral degree as their level of education. For statistical purposes the researcher combined the low number of responses for specialist's and doctorate for a total of seven respondents. However, since the two groups still did not have comparable sizes, the researcher examined the mean, standard deviation, and tests of significance. There were no significant correlations in scores for gender (Table 19) or for level of education (Table 20) when compared with leadership practices.

Table 19

Independent Samples T test of Gender and Leadership Practices

\begin{tabular}{|c|c|c|c|c|c|c|c|c|}
\hline Leadership & Gender & $\mathrm{N}$ & Mean & Standard Error & Significance & Standard Error & \multicolumn{2}{|c|}{$t$ test for Equality of Means } \\
\hline Practices & & & & Mean & 2 tailed & Difference & $\mathrm{t}$ & df \\
\hline \multirow[t]{2}{*}{ MTW } & Female & 42 & 52.2143 & .69804 & \multirow[t]{2}{*}{.100} & \multirow[t]{2}{*}{1.15998} & \multirow[t]{2}{*}{1.666} & 72 \\
\hline & Male & 32 & 50.2813 & .96327 & & & & \\
\hline \multirow[t]{2}{*}{ ISV } & Female & 44 & 49.3182 & 1.07281 & \multirow[t]{2}{*}{.169} & \multirow[t]{2}{*}{1.62304} & \multirow[t]{2}{*}{1.390} & 74 \\
\hline & Male & 32 & 47.0625 & 1.20226 & & & & \\
\hline \multirow[t]{2}{*}{ СТP } & Female & 44 & 47.7273 & .93520 & \multirow[t]{2}{*}{.118} & \multirow[t]{2}{*}{1,48622} & \multirow[t]{2}{*}{1.583} & 74 \\
\hline & Male & 32 & 45.3750 & 1.17668 & & & & \\
\hline \multirow[t]{2}{*}{ EOA } & Female & 45 & 53.2000 & .51208 & \multirow[t]{2}{*}{.248} & \multirow[t]{2}{*}{.94928} & \multirow[t]{2}{*}{1.165} & 75 \\
\hline & Male & 32 & 52.0938 & .86644 & & & & \\
\hline \multirow[t]{2}{*}{ ETH } & Female & 46 & 52.6522 & .93572 & \multirow[t]{2}{*}{.176} & \multirow[t]{2}{*}{1.53908} & \multirow[t]{2}{*}{1.367} & 75 \\
\hline & Male & 31 & 50.5484 & 1.26052 & & & & \\
\hline
\end{tabular}


Table 20

Mean and Standard Deviations of Level of Education and Leadership Practices

\begin{tabular}{|c|c|c|c|c|c|}
\hline Leadership & Level of & $\mathrm{N}$ & Mean & Standard Error & Significance \\
\hline Practices & Education & & & Mean & 2 tailed \\
\hline \multirow[t]{3}{*}{ MTW } & Masters & 68 & 51.5735 & .54849 & \multirow{3}{*}{.570} \\
\hline & Spec / & 7 & 50.4286 & 3.42162 & \\
\hline & Doctorate & & & & \\
\hline \multirow[t]{3}{*}{ ISV } & Masters & 70 & 48.5000 & .81466 & \multirow[t]{3}{*}{.899} \\
\hline & Spec/ & 7 & 48.1429 & 3.64122 & \\
\hline & Doctorate & & & & \\
\hline \multirow[t]{3}{*}{ CTP } & Masters & 70 & 46.8429 & .74590 & \multirow[t]{3}{*}{.866} \\
\hline & Spec / & 7 & 47.2857 & 3.67562 & \\
\hline & Doctorate & & & & \\
\hline \multirow[t]{3}{*}{ EOA } & Masters & 71 & 52.9437 & .47762 & \multirow[t]{2}{*}{.271} \\
\hline & Spec / & 7 & 51.1429 & 1.84428 & \\
\hline & Doctorate & & & & \multirow{4}{*}{.302} \\
\hline \multirow[t]{3}{*}{ ETH } & Masters & 72 & 52.0972 & .75193 & \\
\hline & Spec / & 6 & 49.1667 & 3.91933 & \\
\hline & Doctorate & & & & \\
\hline
\end{tabular}

\section{Results of the Study}

The study generated the following statistically significant relationships:

Positive Correlations found among Resilience Dimensions and Leadership Practices

Positive: The World with modeling the way $(\mathrm{r}=.290, \mathrm{p}=.012)$, inspiring a shared vision $(\mathrm{r}=.248, \mathrm{p}=.030)$, and challenging the process $(\mathrm{r}=.332, \mathrm{p}=.003)$.

Positive: Yourself with modeling the way $(\mathrm{r}=.394, \mathrm{p}=.000)$, inspiring a shared vision ( $\mathrm{r}=.299, \mathrm{p}=.008)$, challenging the process $(\mathrm{r}=.382, \mathrm{p}=.001)$, and enabling others to $\operatorname{act}(\mathrm{r}=.283, \mathrm{p}=.012)$. 
Focused with modeling the way $(\mathrm{r}=.579, \mathrm{p}=.000)$, inspiring a shared vision $(\mathrm{r}=.464, \mathrm{p}=.000)$, challenging the process $(\mathrm{r}=.589, \mathrm{p}=.000)$, and enabling others to act $(\mathrm{r}=.348, \mathrm{p}=.002)$.

Flexible (Social) with modeling the way $(\mathrm{r}=.317, \mathrm{p}=.006)$, inspiring a shared vision $(\mathrm{r}=.343, \mathrm{p}=.002)$, challenging the process $(\mathrm{r}=.328, \mathrm{p}=.004)$, and encouraging the heart $(\mathrm{r}=.224, \mathrm{p}=.049)$.

Organized with modeling the way $(\mathrm{r}=.360, \mathrm{p} \leq .001)$.

Proactive with modeling the way $(r=.297, \mathrm{p}=.010)$, inspiring a shared vision $(\mathrm{r}=.351, \mathrm{p}=.002)$, and enabling others to act $(\mathrm{r}=.245, \mathrm{p}=.031)$.

Positive Correlations Among Demographic Questions and Resilience Dimensions

Years as a principal and positive (yourself) $(\mathrm{CC}=.258, \mathrm{p}=.022)$

Years as a principal and organized $(\mathrm{CC}=.225, \mathrm{p}=.047)$

Number of superintendents worked for and positive (yourself) $(\mathrm{CC}=.228, \mathrm{p}=.049)$

Number of professional staff supervised and positive (the world) $(\mathrm{CC}=.226$, $\mathrm{p}=.047)$.

Negative Correlations Among Demographic Questions and Resilience Dimensions

Age and flexible (thoughts) $(\mathrm{CC}=-.296, \mathrm{p}=.008)$

Age and flexible (social) $(\mathrm{CC}=-.276, \mathrm{p}=.015)$

Age and proactive $(\mathrm{CC}=-.227, \mathrm{p}=.046)$

Percentage of students who received free and reduced lunch and flexible (social) $(\mathrm{CC}=-.240, \mathrm{p}=.033)$ 
Positive Correlations Among Demographic Questions and Leadership Practices

Years as a principal and modeling the way $(\mathrm{CC}=.229, \mathrm{p}=.049)$

Number of students and challenging the process $(\mathrm{CC}=.241, \mathrm{p}=.036)$

Number of professional staff and challenging the process $(\mathrm{CC}=.238, \mathrm{p}=.039)$

Significant Differences in Dichotomous Variables

Gender and positive (the world) $(\mathrm{p}=.025)$

Gender and flexible (social) $(\mathrm{p}=.002)$ 


\section{Chapter Five}

\section{Discussion}

This chapter reviews the findings of the investigation of resilience and leadership practices in elementary school principals by examining the results of the data and comparing it to the literature and to the three models utilized for this research. The author also provided recommendations for further study and implications for the research.

\section{Comparison of the Models of Resilience and Leadership}

\section{Kouzes and Posner's Leadership Practices compared with Conner's Resilience}

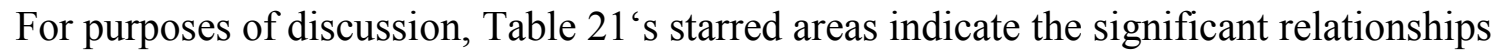
found among resilience dimensions and leadership practices in the first research question.

Table 21

Significant Relationship Matrix of RQ1

\begin{tabular}{|c|c|c|c|c|c|}
\hline & $\begin{array}{l}\text { Modeling } \\
\text { The Way }\end{array}$ & $\begin{array}{l}\text { Inspiring a } \\
\text { Shared Vision }\end{array}$ & $\begin{array}{l}\text { Challenging } \\
\text { The Process }\end{array}$ & $\begin{array}{l}\text { Enabling } \\
\text { Others to Act }\end{array}$ & $\begin{array}{l}\text { Encouraging } \\
\text { The Heart }\end{array}$ \\
\hline Positive:World & $*$ & $*$ & $*$ & & \\
\hline Positive: Yourself & $*$ & $*$ & $*$ & $*$ & \\
\hline Focused & $*$ & $*$ & * & $*$ & \\
\hline \multicolumn{6}{|l|}{ Flexible: Thoughts } \\
\hline Flexible: Social & $*$ & $*$ & $*$ & & $*$ \\
\hline Organized & $*$ & & & & \\
\hline Proactive & $*$ & $*$ & & & $*$ \\
\hline
\end{tabular}


The following comparisons were drawn relating the dimensions of resilience to the model of resilience developed by Conner (1993). The resilience dimension of Positive: The World was correlated with the three leadership practices of modeling the way, inspiring a shared vision, and challenging the process. In Conner's model of resilience he described those leaders as ones who focus on positive view of the environment while viewing it as complex and challenging. They seek opportunities and possibilities with an optimistic attitude.

The resilience dimension of Positive: Yourself was correlated with four of the leadership practices including modeling the way, inspiring a shared vision, challenging the process, and enabling others to act. Conner, in his model of resilience, described these leaders as ones who believe in themselves as valuable, capable and extremely powerful people. They have the ability to assess their capabilities and achieve self-acceptance. They believe that there are important lessons to be learned from challenges and that they can influence the environment and what happens in life. They are able to take action confidently and withstand failure without losing the feeling of self-worth. Though they see major changes as uncomfortable, they believe that hidden opportunity may exist.

The resilience dimension of Focused was correlated with all five of the leadership practices including modeling the way, inspiring a shared vision, challenging the process, enabling others to act, and encouraging the heart. Conner described these individuals as strongly committed to goals and priorities; they are leaders who have a sense of purpose and focus in life with a strong vision. They are masters at using personal energy more effectively and efficiently. 
The resilience dimension of Flexible: Social was correlated with four of the leadership practices including modeling the way, inspiring a shared vision, challenging the process, and encouraging the heart. Conner's model of resilience describes Flexible: Social as having the ability to elicit support of others by establishing strong social bonds of support. They are empowered during the change process and can recover quickly from disappointments or difficult situations. They recognize personal strengths and weaknesses in themselves.

The resilience dimension of Organized was correlated with one leadership practice, modeling the way. Conner described the organized resilient leader as one who finds order in chaos and structure in ambiguity; these leaders can mange several simultaneous tasks and demands successfully but recognize when they need help from others. These leaders choose information that is relevant and helpful, focus on important elements, and logically structure them into workable detailed plans.

The resilience dimension of Proactive was correlated with the leadership practices of modeling the way, inspiring a shared vision, challenging the process, and enabling others to act. In Conner's model of resilience he described the proactive resilient leader as one who can act decisively in the midst of uncertainty and determine when to change. They are able to take risks and endure some discomfort in the belief that positive outcomes will be accomplished. They seek challenges rather than avoid them and respond to disruption by investing energy in problem solving and teamwork. They have the ability to influence others and resolve conflicts.

Senge's Fifth Discipline. When compared with Senge‘s educational model for leadership (2000), Senge cites the significance of the five key competencies. Those competencies are 
Personal Mastery, Shared Vision, Mental Models, Team Learning and Systems Thinking. The significant correlations found in this study share some concepts found in Senge's model.

In Personal Mastery he described the capacity for maintaining tension between the vision or goal and the amount of discipline required to remain focused on the goal. This practice is much like the focused dimension that is significantly related to all five of the leadership practices. In personal mastery, leaders demonstrate a commitment to accomplishing tasks and producing results. In Personal Mastery leaders have developed the competence to focus on goals and take actions based on principled leadership.

In Shared Vision an organization has developed a common purpose and a sense of commitment. These respondents evidence a strong correlation in their sense of a shared vision in influencing their positive view of the world and a positive view of themselves. They evidence a strong focus while remaining socially flexible. They are able to listen to the ideas of others and arrive at a common purpose. They are strongly proactive in taking meaningful steps toward the common goal.

In Senge's Mental Models he describes them as they relate to the educational world. It's sometimes difficult to describe the mental models that undergird education. They relate to the attitudes and the perceptions of the students and the learners. The teacher/leader takes responsibility for guiding questions that help the group determine what they know and what they don't know. This sense of the model fits principal/leaders that can confidently challenge the educational process and model the way for teachers and other leaders to question long-used educational strategies. Considering education as a moral activity, it is incumbent upon educators that they have the courage to question long held ideas about education. 
Senge described Team Learning as an integral part of the process that fosters collective thinking in educational settings. This concept fits with our leadership practice of enabling others to act. In the group learning process, successful leaders get teams to think and act together. Not to be confused with asking that the group think alike, resilient leaders welcome the diversity of ideas that emerge from group interaction in the learning environment.

In the last area, Systems Thinking, Senge described a different way of conducting actions in the workplace. Instead of leaders responding serially to the endless parade of crises and situations that require immediate heroic action, effective leaders establish systems that address most of the occurrences in the school setting. By developing protocols for most types of occurrences, successful leaders are able to develop thoughtful processes that outline a logical, and effective system for carrying out necessary actions. Effective leaders who model a methodical system of problem-solving can more efficiently enable others to act in their place.

Bolman and Deal's Four Frame Model of Leadership. In Bolman and Deal's four frame model they framed leadership in four dimensions including the structural frame, the human resource frame, the political frame, and the symbolic frame. While most leaders report that they employ a multi-framed approach to their own leadership styles, the four frames do reflect some of the resilience dimensions and leadership practices identified as significantly correlated in this study.

Modeling the way which was significantly correlated with positive views, focused action, social flexibility, and proactive and organized individuals can be associated with the structural frame. In this framework leaders establish a hierarchy for efficiency and division of labor. The human resource framework may be most closely allied with the encouraging the heart leadership 
practice. In this study this leadership practice was significantly correlated only with focused and socially flexible individuals. With this group of individuals the investment in human capital in terms of rewarding them well, sharing the wealth, and hiring the right people from the start was not as significantly aligned with school leaders as found in other leadership roles. The reduced emphasis on this dimension may be linked to the inflexibility in hiring in school settings. With teacher property rights to contracts, the advice of hiring the right person is not always easy to accomplish in WV schools. School leaders do not have the autonomy to provide financial rewards or share the wealth with employees as would be found in the private sector. In the political frame school leaders might be examined through the leadership practice of challenging the process. In this frame leadership actions are guided by a need to allocate scarce resources while balancing the needs of the stakeholders. This leadership group had significant correlations in challenging the process which is the struggle to balance the needs for learners with the demands of the educational hierarchy and the limited funds to do it with. The last framework, that of the symbolic frame is exemplified by the shared vision and encouraging the heart dimensions. The shared vision practice is strongly correlated with several resilience dimensions indicating a strength in these school leaders. School leaders who can cultivate an aura of an institution that has an enduring quality that is cherished by its members both now and long after they leave it, are able to tap into the sense of caring and investment in the educational process. School leaders who can bond students to the institution and its people are more able to develop students who are engaged in learning. 


\section{Resilience Models}

The resilience models that were used included Flach's model (1988), Henderson and Milstein's model for educational settings (2003), Conner's model (1993), and Richardson‘s model (1990). All of these models share the common concept of the need for individuals to face adversity, adjust and accommodate these changes, and return to a state of balance and equilibrium to maintain a productive and dynamic life. As applied to school leaders, they must face societal challenges, economic stresses, human capital weaknesses, hierarchical demands, and ever increasing workloads in their schools. Many of the demographic questions were asked to elicit possible stress responses for some of these specific stressors like supervising a high number of employees, having a large number of students living in poverty, serving frequently changing superintendents, and serving many years in the position. Only one of these factors, flexible: social, had a negative correlation with number of students on free and reduced lunch. That is, as the number of students receiving free and reduced lunch increased, the principals social flexibility decreased. In most occurrences, factors that would have anticipated lower resilience and less application of dynamic leadership practices didn't.

Age was one factor that showed a negative correlation with flexibility in thoughts, flexibility in social outlooks, and being proactive. The first would be an expected evolution of aging; individuals are not as flexible in the way that they think about their occupations. In the

second, principals indicated that they were not as proactive as they aged in the job. Though both of these factors had an inverse correlation, becoming less flexible and less proactive could also be considered a more seasoned and thoughtful approach which considers actions based on a wealth of past experience. The longer these principals had held their jobs and the more 
superintendents they had worked for, the more positive they felt about themselves. Just as it might seem predictable that the greater number of staff members a principal supervises would lead to greater stress, the situation had the opposite effect of leading to a more positive world view. Overall, these respondents did not seem to be adversely affected by stressors that would lead to a less resilient school leader.

\section{Relationship to Personal Practice}

There were some notable findings in this research. The first stand-out is the linkage of the leadership practice of modeling the way with six of the seven dimensions of resilience. Flexible: thoughts was not correlated with any of the leadership practices. In personal experience and observations of other professional principals, the researcher has found this to be an essential truth in practice. The most successful school leaders are those who model the expectations that they have for staff members. To achieve a high level of commitment to education, the principal must model that for their staffs whether it is their commitment to personal continuing education or the adaptation and application of new technologies. Those leaders who model change in their personal behavior are those who achieve the smoothest transitions in the educational settings.

The next most frequent occurrence of a positive correlation is that of inspiring a shared vision. High-achieving schools are those led by principals who articulate their values and vision to their co-workers. School settings are unique in the physical construct of the workplace, classroom teachers working with students are not so easily observed in an unobtrusive manner. Therefore, teachers have a lot of autonomy for their function in the classroom. The principal leader influences how teachers make decisions from a remote place, that of faculty meetings, individual conferences, and informal meetings. These are the places that principals communicate 
to staffs their expectations for the overall tone of the school. When those messages are clear and receive significant commitment from school staffs, the school is able to respond with greater resilience to the demands and constraints of public school education.

Challenging the process was positively correlated with four of the dimensions of resilience. Principals who challenge the process are those who are able to integrate facilitate change in their schools by helping to tailor the demands to the culture of their school. Principals who are able to assess the strengths and weaknesses of the new challenge, select personnel who can easily embrace the new strategies, provide resources to support the change, and support the change process through sustained staff development are more effective leaders. In challenging the process, successful principals adapt external demands to fit the personnel and culture of the school.

The dimension of resilience that had no correlation with any of the leadership practices also was interesting in its absence. Flexible, thoughts had no correlations, positive or negative, with any of the leadership practices. Since this was a survey of school leaders, the researcher expected to find some correlation with thought and thinking processes.

\section{Recommendations for Further Study}

The researcher made the following recommendations for further research in the areas of resilience and relationship to leadership.

1. This quantitative research methodology could be expanded to include a mixed methodology of both quantitative and qualitative research. Public school principals could be interviewed, surveyed, observed, or asked to participate in discussion groups to identify specific resilience practices and their application to the challenges of educational environments. 
2. A number of longitudinal studies of resilience focused on children and their responses to adverse experiences like poverty and violence in childhood. More studies need to address the longitudinal development of school leaders. These types of studies might help identify individuals who can enter the challenging field of school leadership and develop high quality skills in the multiple challenges of schools. Since dimensions of resilience have been shown to have a correlation to various dimensions of leadership skills, new research areas should investigate methods of fostering resilience in leaders. The new area of positive psychology may generate specific skill development that lead to greater resilience in leaders.

3. Leaders who exhibit greater resilience will be able to envision, develop, and carry out more sustainable responses to change. School leaders, in particular, need to be able to guide new directions in education so that new practices generated by scientifically based research in education can be adopted and implemented effectively. Many highly effective educational strategies may fail in a school setting that does not do adequate preparation and follow-up to evaluate the new strategy. This failure may lead to schools that stagnate or even decline. 4. Resilient school leaders need to be able to lead teachers and students in learning resilient practices. Additional studies could examine practices that effective leaders use to bring about change in low-performing schools.

5. School systems should encourage experimentation and innovation in schools so that principals and teachers are encouraged to develop a culture of change. Improved resilience and adaptation to change may lead to significant improvements in learning in schools.

6. Dimensions of resilience should be integrated into both administrator and teacher evaluations as mentioned in Reeves' work. Both groups' responses to change or requests to change are 
indicators of resilient educators who can adapt to and respond positively to the evolving educational arena.

7. Education leadership programs in colleges and universities could consider the inclusion of leadership training strongly grounded in resilience practices. Gonzaga University includes a full credit course in resilience in its academic program. 


\section{References}

Babbie, E.R. (1990). Survey research methods. (2 ${ }^{\text {nd }}$ edition). Belmont, CA: Wadsworth Publishing Company.

Bearman, P.S., Jones, J. \& Udry, D. (1997). The national study of adolescent health: Research design [Electronic version]. Available:

http:www.cpc.unc.edu/projects/addhealth/design.html.

Benard, B. (1991). Fostering resiliency in kids: Protective factors in the family, school, and community. San Francisco: WestEd Regional Educational Laboratory.

Bennett, E.B.; Novotny, J.A.; Green, K.E.; \& Kluever, R.C., (1998) Confirmatory factor analysis of the Resiliency Scale. Paper presented at the annual meeting of the American Educational Research Association (San Diego, CA, April, 1998).

Bennis, W.G. \& Nanus, B. (1985). Leaders: The strategies for taking charge. New York: Harper \& Row.

Bensimon, E.M., Neumann, A., and Birnbaum, R. (1989). Higher education and leadership theory. In C. Brown II (Ed.). Organization and Governance in Higher Education ( $5^{\text {th }}$ ed.) (pp. 214-222). Boston, MA: Pearson Custom Publishing.

Bernard, B. (1993). Fostering resilience in kids. Educational Leadership, 44-48.

Berry, B. a. N., John. (1996). Surviving the avalanche. Changing Schools in Louisville, 1(1), 3.

Block, J.H. \& Block, J. (1980). The role of ego-control and ego-resilience in the organization of Behavior. In W.A. Collins (Ed.) Development of cognition, affect, and social relations: Minnesota Symposia of child psychology (pp. 39-101). Hillsdale, NJ: Lawrence Eribaum Associates.

Bolman, L.G. \& Deal, T.E., (2002). Reframing the path to school leadership: A guide for teachers and principals. Thousand Oaks, CA: Corwin Press.

Bolman, L.G. \& Deal, T.E., (2003). Reframing organizations: Artistry, choice, and leadership. San Francisco: Jossey-Bass.

Burns, J.M. (1978). Leadership. New York: Harper \& Row.

Bush, J., \& Wilson, C.S. (1997). Linking schools with youth and family centers. Educational Leadership, 55, 38-41. 
Cherniss, C. (1998). Social and emotional learning for leaders. Educational Leadership, 56, 26-28.

Conner, D.R., (1992). Managing at the speed of change: How resilient managers succeed and prosper where others fail. New York: Villard Books.

Connor, K.M. \& Davidson, J.R.T. (2003). Development of a new resilience scale: The ConnorDavidson Resilience Scale (CD-RISC). Depression and Anxiety 18:76-82.

Creswell, J.W. (2003). Research design. Thousand Oaks, California: SAGE Publications.

Cunningham, W. G., \& Cordeiro, P.A. (2000). Educational administration. A problem-based approach. Boston: Allyn and Bacon.

Demos, E.V. (1989). Resiliency in infancy. In T.F. Dugan \& R. Coles (Eds.) The child in our times: Studies in the development of resiliency (pp. 3-22). New York: Brunner/Mazel.

Eisenberg, N., Guthrie, I.K., Fabes, R.A., Reiser, M., Murphy, B.C., Holgren, R., Maszk, P1, \& Losoya, S. (1997). The relations of regulation and emotionality to resiliency and competent social functioning in elementary school children. Child development, 68, 295311.

Finlayson, M. (April, 2003). Improving the well being of teachers in Scotland. Paper presented at the Symposium on Teacher Wellbeing, Northern Ireland.

Flach, F.F. (1988) Resilience: Discovering a new strength at times of stress. Fawcett Columbine, New York.

Folkman, S. \& Lazarus, R.S. (1988). Coping as a mediator of emotion. Journal of Personality and Social Psychology, 54, 466-475.

Fonagy, P., Steele, M., Steele, H., Higgit, A. \& Target M. (1993) The Emanuel Miller memorial lecture 1992. The theory and practice of resilience. Journal of Child Psychology and Psychiatry 35 (2), 231-257

Friborg, O, Barlaug, D., Martinussen, M., Rosenvinge, J.H., \& Hjemdal, O. (2005). Resilience in relation to personality and intelligence. International Journal of Methods in Psychiatric Research, 14:1, pp. 29-42.

Friborg, O., Hjemdal, O., Rosenvinge, J.H., \& Martinussen, M. (2003). A new rating scale for adult resilience: what are the central protective resources behind healthy adjustment? International Journal of Methods in Psychiatric Research, 12:2, 65-76. 
Fuller, A., Bellhouse, R. \& Johnston, G. (2003). Get It-creating resilient learners. Paper presented at the Focus on Learning Conference, Queensliff, Australia..

Gardner, W. G. (1990). On leadership. New York: The Free Press.

Garmezy, N. (1993). Children in poverty: Resilience despite risk. Psychiatry 56, 127-156.

Gates, G. \& Gmelch, W.H. (1998). The impact of personal, professional and organizational characteristics on administrator burnout. Journal of Educational Administration, 36(2), 146-59. (ERIC Document Reproduction Service EJ 566213.)

Gay, L.R. \& Airasian, P. (2000). Educational research (6 $6^{\text {th }}$ ed.). Columbus, OH: Prentice-Hall.

Gliner, J.A. \& Morgan, G.A. (2000). Research methods in applied settings. Mahwah, New Jersey: Lawrence Erlbaum Associates, Publishers.

Goldstein, J.C. (2003). Voices of Catholic school principals: A phenomenological study of Catholic school principals' perceptions of efficacy and resiliency. Unpublished doctoral dissertation, University of Houston, Houston, TX.

Goleman D., Boyatziz, R., \& McKee, A. (2002). Primal leadership: Realizing the power of emotional intelligence. Boston: Harvard Business School Press.

Goodlad, J. (1984). A place called school. New York: McGraw-Hill.

Gravetter, F.J. and Wallnau, L.B. (2004). Statistics for the Behavioral Sciences (6 ${ }^{\text {th }}$ ed.) Belmont, CA: Wadsworth/Thomson Learning.

Greenfield, W.D. (1995). Toward a theory of school administration: The centrality of leadership. Education Administration Quarterly, 31(1), 61-80.

Hackman, M.Z. \& Johnson, C.E. (2000). Leadership, a communication perspective (3 ${ }^{\text {rd }}$ ed.) Prospect Heights, Illinois: Waveland Press.

Hausman, C.S., Crow, Gary M., and Sperry, David J. (2000). Portrait of the ideal principal": Context and self. NASSP Bulletin, 84 (617).

Henderson, N., M.S.W. \& Milstein, M.M. (2003). Resiliency in schools: Making it happen for students and educators. Thousand Oaks, CA: Corwin Press.

Henderson, N., Benard, B., \& Sharp-Light, N. (Eds.). (2000). Mentoring for resiliency: Setting up programs for moving youth from "stressed to success." San Diego, CA: Resiliency in Action. 
Hoffman, J.N. (2004). Building resilient leaders. Leadership, 34(1), 35-40.

Hurley, J. (2004). Learn: Lead: Succeed, Building leadership in schools. Sydney, Australia. APAPDC.

Institute for Educational Leadership (2000). (Retrieved 10-8-05.) Reinventing the principalship. A report of the task force on the principalship, scholarship for the $21^{\text {st }}$ century initiative institute for educational leadership. Retrieved from http://www.iel.org/programs/21st.html.

Isaacs, A.J. (2003). An investigation of attributes of school principals in relation to resilience and leadership practices. Unpublished doctoral dissertation, Florida State University, Gainesville, FL.

Is There a Shortage of Qualified Candidates for Openings in the Principalship? (exploratory Study)(1998). Alexandria, VA. National Association of Elementary School Principals (NAESP) and National Association of Secondary School Principals (NASSP).

Jacelon, C.S. (1997). The trait and process of resilience. Journal of Advanced Nursing 25, $123-$ 129.

Kelehear, Z. (2003). Mentoring the organization: Helping principals bring schools to higher levels of effectiveness. NASSP Bulletin, 87(637), p. 12.

Kouzes, J.M., \& Posner, B.J. (2002). Leadership challenge ( $3^{\text {rd }}$ ed.). San Francisco: Jossey-Bass.

Kouzes, J.M. \& Posner, B.Z. (2002). The leadership practices inventory: Theory and evidence behind the five practices of exemplary leaders. Research report (May 12, 2002) retrieved from: http://www.leadershipchallenge.com/research.

Leithwood, K., Begley, P.T., \& Cousins, J.B. (1994). Developing expert leadership for future schools. London: The Falmer Press.

Legislative updates, 3-4. (2005, May). West Virginia Education Association News, Charleston, WV.

Leonard, F.R., SJ. (2002, May). Heart, knowledge and courage (the stuff for life!). Paper presented at the Strengthening the Australian School conference, Tasmania.

Locke, L.F., Silverman, S.J., and Spirduso, W.W. (1998). Reading and understanding research. Thousand Oaks, CA, Sage Publications, Inc.

Lovely, S. (2003). Staffing the principalship: Finding, coaching, and mentoring school leaders. Alexandria, VA: Association for Supervision and Curriculum Development. 
Malone, R.J. (2002). Principal mentoring: An update. (Research Roundup). Alexandria, VA: National Association of Elementary School Principals.

Montano, R.R. (1998). Resiliency characteristics of women leaders in education (educational leadership). DAI, 60, no. 02A. Flagstaff, AZ: Northern Arizona University.

Moos, R.H. \& Billings, A.G. (1994). Conceptualizing and measuring coping resources and processes. In L. Goldberger \& S. Breznitz (Eds.). Handbook of stress: Theoretical and clinical aspects (pp. 212-230). New York: Free Press.

Murphy, L.B. \& Moriarity, A.E. (1976). Vulnerability, coping and growth: From infancy to adolescence. New Haven, CT: Yale University Press.

ODR, Inc., (1996). Section (IV) Technical Information. Atlanta: Author.

Patterson, J. (1993). Leadership for tomorrow's schools. Association for Supervision and Curriculum Development, Alexandria, VA.

Payne, R.K. (1994). A study of the relationships among stress resiliency indicators and conflict management styles of school principals. Unpublished doctoral dissertation, Loyola University of Chicago, Chicago, IL.

Pfeffer, J. (2000). The ambiguity of leadership. In M. C. Brown II (Ed.) Organization and governance $5^{\text {th }}$ ed. (pp. 205-211). Boston, MA: Pearson Custom Publishing.

Pulley, M.L. \& Wakefield, M. (2001). Building resiliency: How to thrive in times of change. An ideas into action guidebook. North Carolina: Center for Creative Leadership.

Reeves, D. B. (2004). Assessing educational leaders: Evaluating performance for improved individual and organizational results (First ed.). Thousand Oaks, CA: Corwin Press, a Sage Publications Company.

Richardson, G. E. (2002). The metatheory of resilience and resiliency. Journal of Clinical Psychology, 58(3), 307-321.

Richardson, G.E., Neiger, B.L., Jensen, S., \& Kumpfer, K.L. (1990). The resiliency model. Health Education 21, 33-39.

Roza, M. (2003a). A shortage of school principals: fact or fiction? (policy brief). Seattle, Washington: University of Washington.

Roza, M. (2003b). A matter of definition: Is there truly a shortage of school principals? (executive summary). Seattle, Washington: University of Washington. 
Rutter, M. (1989). Pathways from childhood to adult life. Journal of Child Psychology and Psychiatry, 30(1), 23-51.

Schmidt, L. (2004). Living well is the best revenge. . Principal, 83, 4, 58-59.

Scott, R. M., Jr., (2001). A symbolic interactionist, collective case study of veteran, secondary principals' experiences with regard to stress. DAI, 62, no. 02A: p. 418. University of Northern Colorado.

Senge, P. (2000). Schools that learn. New York: Doubleday.

Shaw, P. (March, 2002). Challenges and complexities in school leadership: Finding the courage to lead. Paper presented at the Australian Conference on School Leadership, University of Wollongong, NSW.

Shepard, J. (2004). Leadership and resilience, a course syllabus. Spokane, WA: Gonzaga University, Doctoral Program in Leadership Studies 773 sp 04. Retrieved 7-1-05 from http://www.gonzaga.edu/Academics/LeadershipStudies/CourseSyllabi.

Shields, D.G., (1998). An analysis of the relationship between creativity and resiliency. Unpublished master's thesis, East Carolina University, Greenville, NC.

Smith, W.F. \& Andrews, R.L. (1989). Instructional leadership: How principals make a difference. Alexandria, VA: Association for Supervision and Curriculum Development.

Spillane, J.P., Halverson, R., Diamond, J.B., (1999). Toward a theory of leadership practice: A distributed perspective. Institute for Policy Research Working Paper. Chicago: Northwestern University. Retrieved at http://www.letus.org/PDF/DLS ipr paper.doc.

Spoehr, L. (2004). Where do principals come from? Journal of Education, 184(1), 57-68.

Suskie, L.A. (1996). Questionnaire survey research, what works $\left(2^{\text {nd }}\right.$ ed.). Tallahassee, Florida: The Association for Institutional Research.

Tichy, N.M. (1997). The leadership engine: How winning companies build leaders at every level. New York: HarperCollins.

Tirozzi, G. N. (2001). The artistry of leadership. The evolving role of the secondary school principal. Phi Delta Kappan, 86(6), 438-439.

Toffler, Alvin, (1970). Future shock. New York: Bantam Books. 
Tugade, M.M., \& Fredrickson, B.L. (2004). Resilient individuals use positive emotions to bounce back from negative emotional experiences. Journal of Personality and Social Psychology 86, 2, 320-333.

U.S. Department of Education, National Institute on Educational Governance, Finance, Policymaking, and Management, \& Office of Educational Research and Improvement (1999). Effective leaders for today's schools: Synthesis of a policy forum on educational leadership. Retrieved from http://www.ed.gov/pubs/EffectiveLeaders/.

U.S. Department of Education (2005). Innovations in education: Innovative pathways to school leadership. Retrieved from Http://www.ed.gov/admins/recruit/prep/alternative/report_pg5.html.

Wagnild, G. \& Young, H.M. (1993). Development and psychometric evaluation of the resilience scale. Journal of Nursing Measurement 1 (2), 165-178.

Werner, E.E. \& Smith, R.S. (2001). Journeys from childhood to midlife: Risk resilience, and recovery. New York: Cornell University Press.

WestEd. (2000). The healthy kids' resilience module. San Francisco: WestEd Regional Educational Laboratory.

West Virginia County Profiles (2004). Retrieved from: http://www.epodunk.com/cgi-bin/genInfo.php?locIndex=23071 and 23066.

West Virginia Department of Education (2007). Our Schools. Retrieved from: http://www.wvde.edu.

Wheatley, M.J. (1999). Leadership and the new science: Discovering order in a chaotic world revised. San Francisco: Berrett-Koehler Publishers.

Williams, H.W., (2004). A study of the characteristics that distinguish outstanding urban principals: Emotional intelligence, problem-solving competencies, role perception and environmental adaptation. The consortium for research on emotional intelligence in organizations. Cleveland, Ohio: Case Western Reserve University.

Winter, J., (2004). She who laughs last. Principal, 83(4), 28-29.

Wolin, S.J., \& Wolin, S. (1994). Survivor's pride: Building resilience in youth at risk. Vernona, WI: Attainment Company. 
Appendix A: Letter to Dr. Paine

\title{
West Virginia University
}

\author{
155 Glen Road \\ Shepherdstown, WV 25443 \\ May 15, 2007
}

Dr. Steven Paine

WV State Superintendent of Schools

Charleston, WV 25301

Dear Dr. Paine,

I am a doctoral student in the Higher Education Leadership program in the College of Human Resources and Education at West Virginia University. I am conducting research into the nature of resilience and leadership in elementary school principals as a partial fulfillment of the requirements for a dissertation. I am requesting your permission to survey all 464 elementary public school principals in the state. If you grant this permission, I would need to have the names, school affiliations, addresses, and email addresses of all of these principals from your office.

The purpose of the study is to determine whether there is a relationship between resilience characteristics and leadership in elementary school principals as a partial fulfillment of the requirements for a dissertation. I am pursuing Institutional Review Board approval through West Virginia University in order to conduct this research. Those guidelines require that I permit voluntary participation in the study and any failure to do so would not affect job performance. I am using two online surveys with a set of demographic questions to gather data about these principals. Complete anonymity will be maintained; no individuals or schools will be identified in the results of the study. This study is significant because it will broaden our understanding of how we train and support elementary principals to be effective school leaders.

I look forward to hearing from you or someone in your office. You may contact me at one of the following: Home, 304-876-3165; Work, 304-876-6270; Cell, 304-676-8316 and by email at: msoffutt@access.k12.wv.us or by writing me at the above address.

Sincerely,

Suzanne Offutt 
Appendix B: Letter to Participants

\author{
West Virginia University \\ No. \\ 155 Glen Road \\ Shepherdstown, WV 25443 \\ June 15, 2007
}

(Principal's Name \& Address)

Dear Mr./Ms.

I am a doctoral student in the in the Higher Education Leadership program in the College of Human Resources and Education at West Virginia University. I am conducting research into the nature of resilience and leadership in elementary school principals as a partial fulfillment of the requirements for a dissertation. I would like to include your responses to two surveys and some demographic information in my study.

The purpose of the study is to determine whether there is a relationship between resilience characteristics and leadership qualities. ADD A COUPLE OF SENTENCES ABOUT SIGNIFICAN OF STUDY. I am using two Web-based standardized survey tools and a set of questions about your demographics to gather data. In order to participate please go to the Internet and type this URL: http://www... . This address will open an Informed Consent" window that requires your acceptance before going on to the questionnaires. After reading the consent, please enter the access code printed in the upper right corner of this letter and then click on -Eontinue to Questionnaire.” Each page will provide clear directions for completing and moving to the next section.

Complete anonymity will be maintained; neither you nor your school will be identified in the results of my research. The access code listed above only provides a means for me to determine who has responded to the survey request and who will need a reminder letter. Your participation is voluntary and your participation or non-participation will not affect your job status. It will take approximately 45-50 minutes for you to complete these two surveys and the demographic questions. You have the option to not respond to some questions. I look forward to your participation and assistance in conducting this research. I will be happy to share my results in an executive summary with anyone who requests that from me within one year of the completion of the study.

Questions about this research may be addressed to me; questions about your rights as a research participant may be addressed to Dr. Lynn Cartwright, IRB Chairperson, 304-293-2377. Thank you so much for your consideration and for giving up your valuable time.

Sincerely,

Suzanne Offutt

WVU Graduate Student 
Appendix C: Follow-up Letter to Participants

\section{West Virginia University}

No.

155 Glen Road

Shepherdstown, WV 25443

June 15, 2007

(Principal's Name \& Address)

Dear Mr./Ms.

You recently received a letter requesting your participation in a research project that I am doing for my doctoral dissertation which focuses on the nature of resilience and leadership in elementary school principals. If you have already responded, please disregard this letter.

If not, could you please take about 45 minutes to complete the two questionnaires and the demographic characteristics by going to this website and entering the number in the upper right corner of this page. This number assures the anonymity of your responses. While participation in this research project is not mandatory and failure to do so will not have an adverse effect upon your job, I would be personally appreciative of your sharing your limited professional time with me. I will be happy to share an executive summary of these results with anyone who requests this within one year of the completion of this research project.

Questions about this research may be directed to me or my major professor, Dr. Elizabeth Jones. Thank you for your time in sharing about your own leadership practices.

Sincerely,

Suzanne Offutt

WVU Graduate Student 


\section{Appendix D: IRB Proposal}

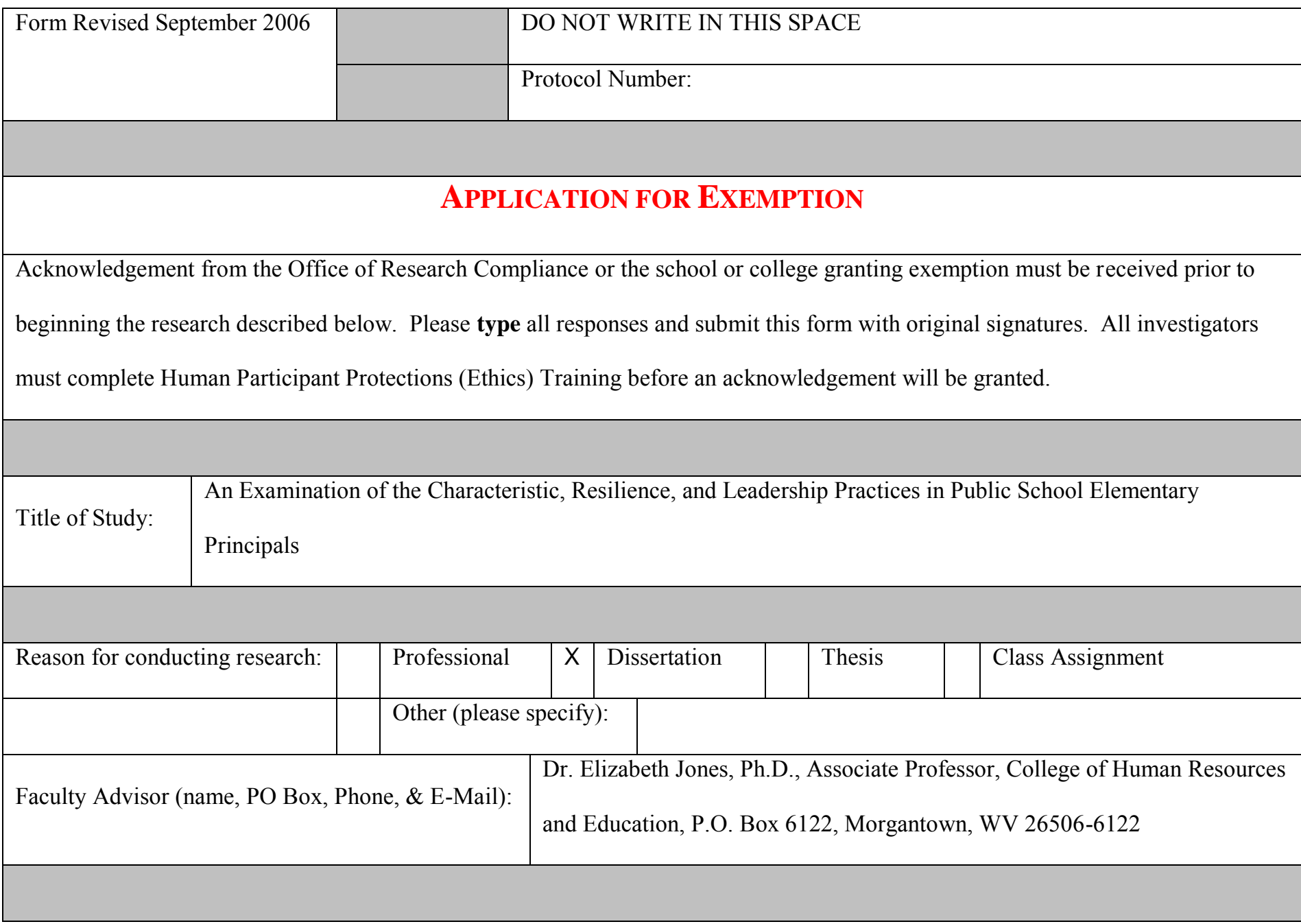

\begin{tabular}{|l|l|l|l|l|l}
\hline \multicolumn{2}{l}{} \\
\hline \multicolumn{2}{|l|}{ Investigators (list all investigators, principal investigator first; attach additional sheets if necessary): } \\
\hline Name (type or print FULL name) & Signature & College/School \& & PO Box \\
\hline PI & M. Suzanne Offutt & & Human Resources and & 155 Glen & Road, \\
& & & Education/Education & Leadership & Shepherdstown \\
\end{tabular}




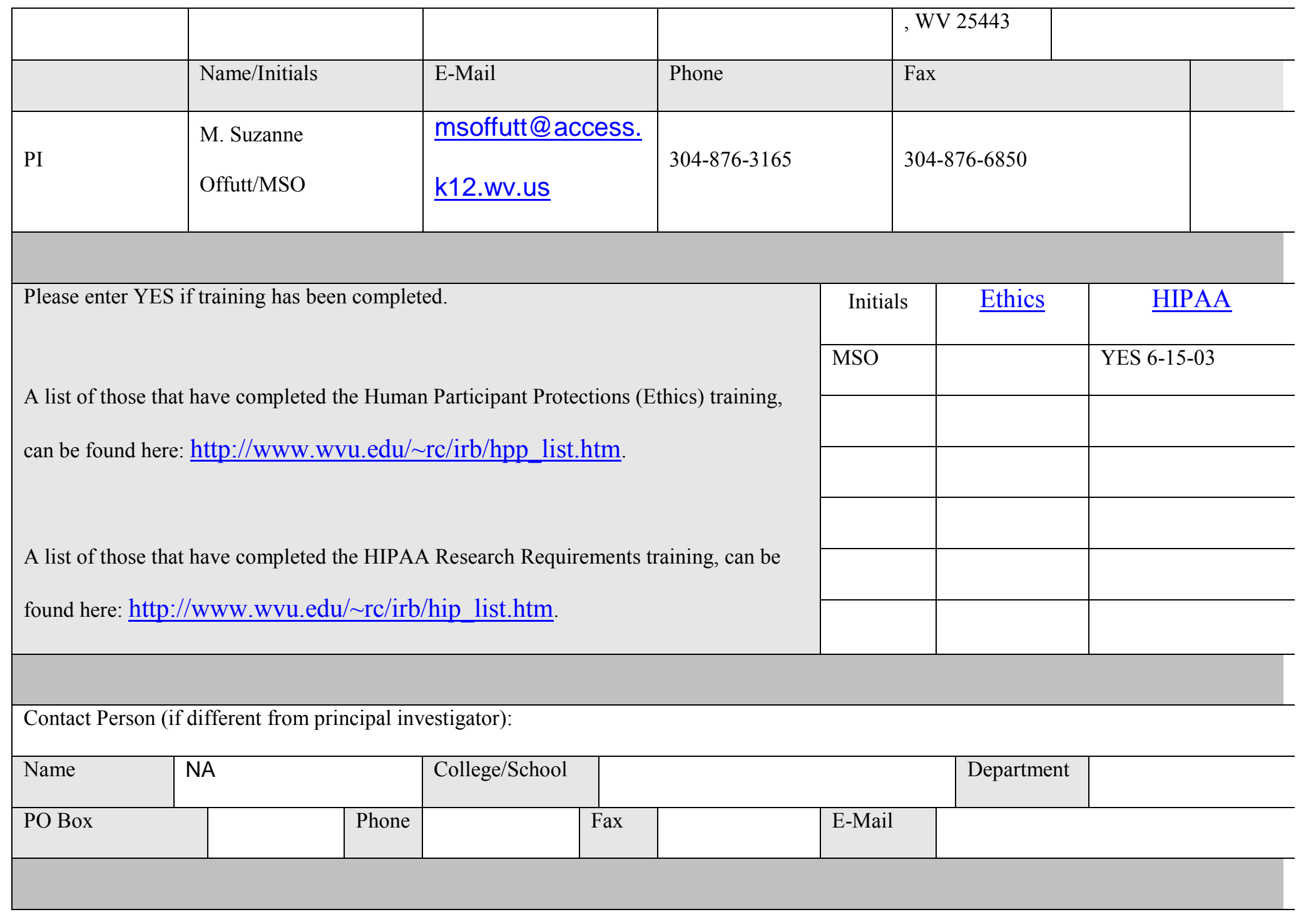

\begin{tabular}{|l|l|l|l|l|l|}
\hline $\begin{array}{l}\text { Proposed start/end date of project or human subject } \\
\text { involvement: }\end{array}$ & $\begin{array}{l}\text { Start } \\
\text { Date: }\end{array}$ & May, 2007 & $\begin{array}{l}\text { End } \\
\text { Date: }\end{array}$ & August, 2007 \\
\hline $\begin{array}{l}\text { Source of funding (if } \\
\text { applicable): }\end{array}$ & NA & Number of projected records or & 1200 \\
\hline Number of projected & 400 &
\end{tabular}


subjects:

data files:

Review the "Determination that a Proposed Activity is not Human Research According to

\section{DHHS or FDA Regulatory Definition". If it is human subject research and if it corresponds to one of}

the categories for exempt research, according to Chapter II of the guidelines, indicate the category or categories that make this research eligible for an exemption determination:

\begin{tabular}{|l|l|}
\hline Category (mandatory): & $\# 2$ \\
\hline
\end{tabular}

In addition to fulfilling the requirements of being research and appropriate to one or more of the specified categories, the research must also: (please check, if appropriate and add adequate information for the reviewer)

\begin{tabular}{|c|c|}
\hline \multirow[t]{3}{*}{$X$} & Adequately describe procedures and the purpose of the study. \\
\hline & $\begin{array}{l}\text { The purpose of the study is to determine whether there are any correlations between leadership practices and } \\
\text { resilience characteristics in public school administrators. The examiner will study elementary school principals } \\
\text { in WV to determine any correlations among their responses on the Leadership Practices Inventory }(L P I) \text { and } \\
\text { their responses on the Personal Resilience Questionnaire (PRQ). The researcher will request supplemental } \\
\text { demographic data from the subjects. }\end{array}$ \\
\hline & The research must present no more than minimal risk to participants. \\
\hline \multirow[t]{2}{*}{$\mathrm{X}$} & Describe why you feel this study represents no more than minimal risk: \\
\hline & $\begin{array}{l}\text { There are no known or expected risks from participating in this study, except for the mild frustration } \\
\text { associated with answering the questions. }\end{array}$ \\
\hline \multirow[t]{2}{*}{$\mathrm{X}$} & $\begin{array}{l}\text { Describe in detail how participants will be chosen. Provide evidence that the selection of participants is } \\
\text { equitable. Describe how participants are chosen to assure that the process is equitable: }\end{array}$ \\
\hline & All elementary principals in WV, the targeted audience, will be invited to participate. Each elementary \\
\hline
\end{tabular}




\begin{tabular}{|c|c|c|}
\hline & \multicolumn{2}{|c|}{$\begin{array}{l}\text { principal in the state will receive a letter requesting their participation and directing them to websites to } \\
\text { complete the questionnaires. }\end{array}$} \\
\hline $\mathrm{X}$ & \multicolumn{2}{|c|}{$\begin{array}{l}\text { Provide information in sufficient detail to establish that participants will not be subject to coercion or undue } \\
\text { influence (if the possibility for coercion or undue influence exists.) }\end{array}$} \\
\hline & \multicolumn{2}{|c|}{$\begin{array}{l}\text { Participation in this study is voluntary and participants may withdraw at any time. Participation or refusal to } \\
\text { participate will not have any impact on the participants' employment, benefits, or employee evaluation. }\end{array}$} \\
\hline $\mathrm{X}$ & \multicolumn{2}{|c|}{ Provide sufficient detail about how anonymity will be assured, if this is relevant. } \\
\hline & \multicolumn{2}{|c|}{$\begin{array}{l}\text { In the letter to potential subjects, principals will be given a randomly assigned number. The respondents will } \\
\text { use this number as their identifier when they go to the websites to enter their responses. }\end{array}$} \\
\hline & \multicolumn{2}{|c|}{$\begin{array}{l}\text { For medical records or chart reviews, describe the nature of the data to be recorded and assure that either no } \\
\text { private identifying data are recorded, or provisions for maintaining the confidentiality of data are adequate and } \\
\text { explained in sufficient detail. If a HIPAA waiver of authorization is required to obtain Protected Health } \\
\text { Information (PHI), its use must be justified (Why cannot the research be practicably carried out without } \\
\text { obtaining the PHI, and why cannot the PHI be practicably obtained without a waiver of authorization?). The } \\
\text { request for a waiver of HIPAA authorization must be approved by the IRB prior to initiating the research. }\end{array}$} \\
\hline $\mathrm{X}$ & \multicolumn{2}{|c|}{ Provide a complete list of variables to be collected from records or data set (variables list) } \\
\hline & \multicolumn{2}{|c|}{ Seven Dimensions of Personal Resilience Questionnaire $\quad$ Five Leadership Practices of Leadership } \\
\hline & POSITIVE (The World) & Challenging the process \\
\hline & POSITIVE (Yourself) & Inspiring a Shared Vision \\
\hline & FOCUSED & Enabling others to act \\
\hline
\end{tabular}




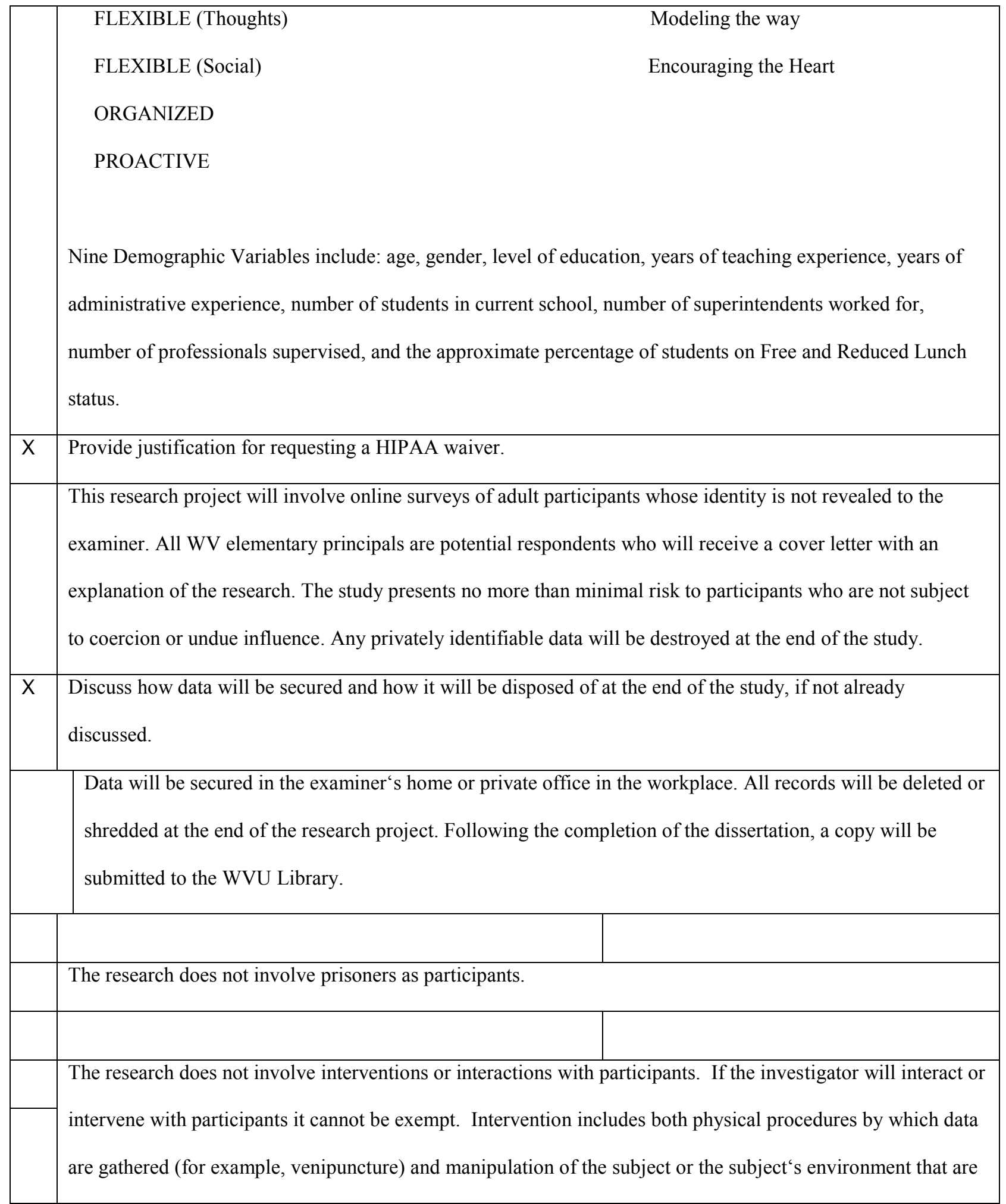




\begin{tabular}{|l|l|l|}
\hline & performed for research purposes. Interaction includes communication or interpersonal contact between \\
& investigator and subject. \\
\hline $\mathrm{X}$ & Be sure to include copies of all advertisements, surveys, scripts, cover letters, and letters of permission. \\
\hline & \multicolumn{2}{|l}{} \\
\hline & If incentives are provided (extra credit, coupons, payment vouchers, etc.), please describe adequately. \\
\hline &
\end{tabular}

A cover letter addressed to respondents must accompany any survey or questionnaire. The Cover letter must be on

the investigator's WVU departmental letterhead and must include the following:

1. a statement that the project is research and that it is being conducted in partial fulfillment of the requirements for a course, master's thesis, dissertation, etc.

2. purpose of study (what do you want to show)

3. a statement that subjects responses will be kept anonymous or confidential (explain extent of confidentiality if subjects' names are requested)

4. if audio taping, a statement that the subject is being audio taped (explain how tapes will be stored or disposed of during and after the study

5. a statement that subjects do not have to answer every question

6. a statement that the subject's class standing, grades, or job status (or status on an athletic team, if applicable) will not be affected by refusal to participate or by withdrawal from the study

7. a statement that participation is voluntary

8. if survey contains items that may be considered sensitive, provide phone numbers and a location where participant can obtain counseling.

I request that this project be acknowledged as exempt from DHHS regulations, 45 CFR 46. 
Signatures: The protocol will not be reviewed without the signature of the departmental chair. For other protocols, the signature for hospital administration, faculty advisor, or others is required. By signing, department chairs acknowledge approval of this study on the basis of scientific merit and compliance with applicable professional standards. Other administrators signify their approval of the use of resources and faculty and student effort on the study. Multi-Unit protocols require the signatures of each chair and dean. 


\section{Appendix E: Personal Resilience Questionnaire}

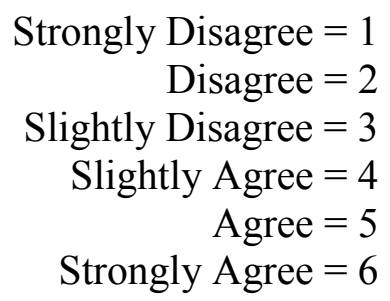

\begin{tabular}{|c|c|c|c|c|c|c|}
\hline \multirow{2}{*}{$\begin{array}{l}\text { Statements } \\
\text { 1. Tasks that don't have a simple or clear-cut solution are fun. }\end{array}$} & 1 & 2 & 3 & 4 & 5 & 6 \\
\hline & & & & & & \\
\hline \multicolumn{7}{|l|}{ 2. I like myself. } \\
\hline \multicolumn{7}{|l|}{ 3. Stressful situations are no time for joking. } \\
\hline \multicolumn{7}{|l|}{ 4. I am committed to getting what I want out of life. } \\
\hline \multicolumn{7}{|l|}{ 5. If a day starts out badly, things will probably be bad all day. } \\
\hline \multicolumn{7}{|l|}{ 6. I am comfortable in a variety of social situations. } \\
\hline \multicolumn{7}{|l|}{ 7. Questions that don't have a right answer are really frustrating. } \\
\hline \multicolumn{7}{|l|}{ 8. It's easy for me to become depressed and unexcited about things. } \\
\hline \multicolumn{7}{|l|}{ 9. I feel at ease fairly quickly with most people. } \\
\hline \multicolumn{7}{|l|}{ 10. If I read, I tend to stick to favorite magazines or familiar authors. } \\
\hline \multicolumn{7}{|l|}{ 11. If you want to be happy, you will be happy. } \\
\hline \multicolumn{7}{|l|}{$\begin{array}{l}\text { 12. There are people in my life who sometimes turn to me for support } \\
\text { and advice. }\end{array}$} \\
\hline \multicolumn{7}{|l|}{ 13. People find me cheerful and happy. } \\
\hline \multicolumn{7}{|l|}{ 14. I prefer to stick to tried and true clothing styles. } \\
\hline \multicolumn{7}{|l|}{ 15. I am willing to take a few risks to get what I want. } \\
\hline \multicolumn{7}{|l|}{ 16. I have a lot of confidence in myself. } \\
\hline \multicolumn{7}{|l|}{$\begin{array}{l}\text { 17. I usually wake up in the morning excited about what the day will } \\
\text { bring. }\end{array}$} \\
\hline \multicolumn{7}{|l|}{ 18. I can solve any problems I am faced with. } \\
\hline \multicolumn{7}{|l|}{$\begin{array}{l}\text { 19. I have one or more very close friends who I can tell my private } \\
\text { thoughts to. }\end{array}$} \\
\hline \multicolumn{7}{|l|}{$\begin{array}{l}\text { 20. I use lists a lot to remind me of all the little things that need to be } \\
\text { done. }\end{array}$} \\
\hline \multicolumn{7}{|l|}{ 21. When times are rough, I focus my attention on a brighter tomorrow. } \\
\hline \multicolumn{7}{|l|}{ 22. I am a creative person. } \\
\hline \multicolumn{7}{|l|}{$\begin{array}{l}\text { 23. One thing I am really good at is making sense out of confusing } \\
\text { situations. }\end{array}$} \\
\hline \multicolumn{7}{|l|}{ 24. I am happiest when I've established a predictable routing in my life. } \\
\hline \multicolumn{7}{|l|}{ 25. Other people see me as an optimist. } \\
\hline \multicolumn{7}{|l|}{$\begin{array}{l}\text { 26. I don't feel comfortable sharing my most private thoughts with } \\
\text { anyone. }\end{array}$} \\
\hline $\begin{array}{l}\text { 27. I can think down the road five years and picture what I will be } \\
\text { doing. }\end{array}$ & & & & & & \\
\hline
\end{tabular}




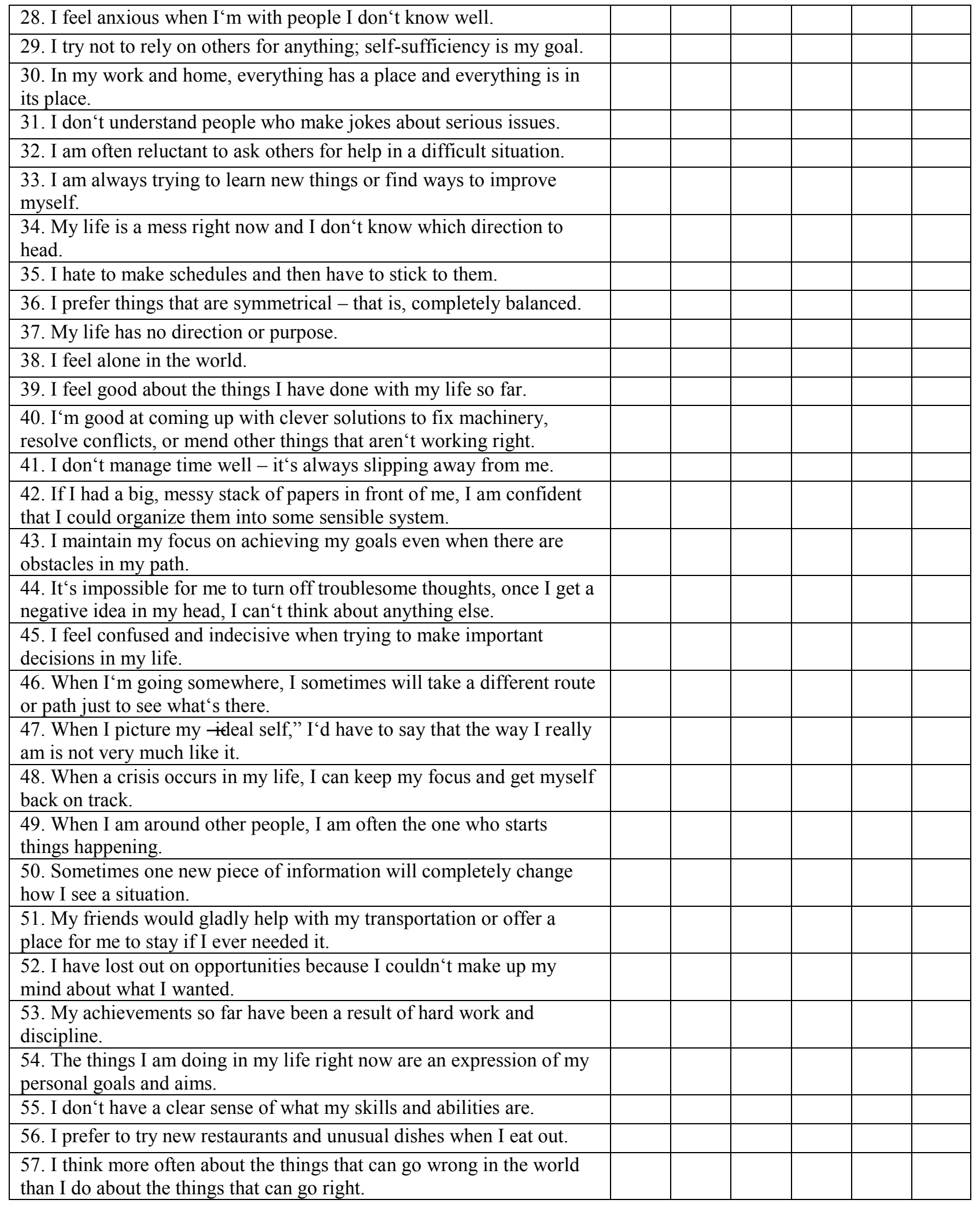




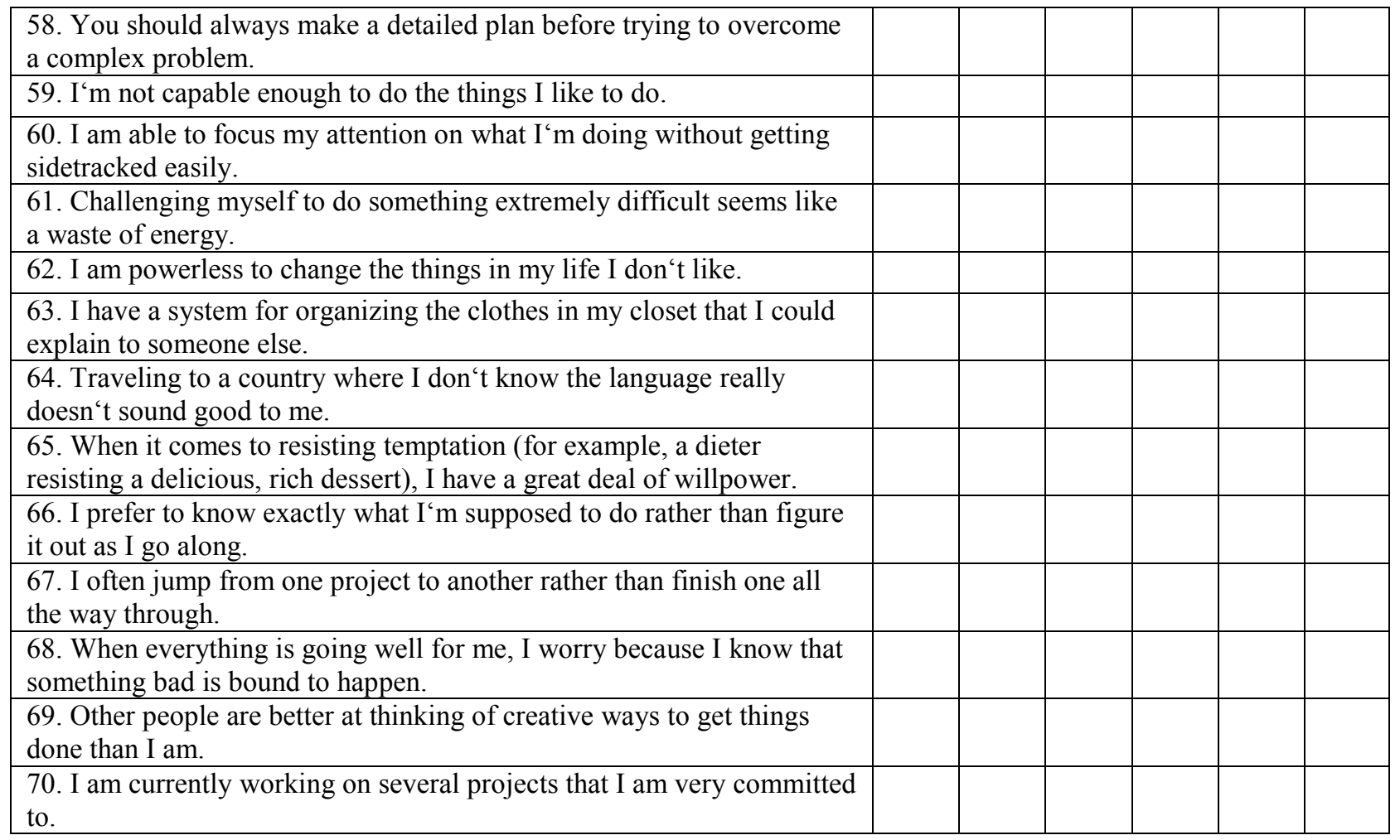




\section{Appendix F}

\section{Leadership Practices Inventory}

Following are thirty descriptive statements about various leadership behavior and activities. Please read the statements carefully. Record the frequency with which you engage in that behavior by choosing the number that corresponds to that description from 1-10 with 1 indicating the least frequency.

$\begin{aligned} \text { Almost Never } & =1 \\ \text { Rarely } & =2 \\ \text { Seldom } & =3 \\ \text { Once in a While } & =4 \\ \text { Occasionally } & =5 \\ \text { Sometimes } & =6 \\ \text { Fairly Often } & =7 \\ \text { Usually } & =8 \\ \text { Very Frequently } & =9 \\ \text { Almost Always } & =10\end{aligned}$

\begin{tabular}{|c|c|c|c|c|c|c|c|c|c|c|}
\hline \multirow{2}{*}{$\begin{array}{ll}\text { Statement } & \text { Response: } \\
\text { 1. I set a personal example of what I expect from others. } & \end{array}$} & 1 & 2 & 3 & 4 & 5 & 6 & 7 & 8 & 9 & 10 \\
\hline & & & & & & & & & & \\
\hline \multicolumn{11}{|l|}{$\begin{array}{l}\text { 2. I talk about future trends that will influence how our work gets } \\
\text { done. }\end{array}$} \\
\hline \multicolumn{11}{|l|}{$\begin{array}{l}\text { 3. I seek out challenging opportunities that test my own skills and } \\
\text { abilities. }\end{array}$} \\
\hline \multicolumn{11}{|l|}{ 4. I develop cooperative relationships among the people I work with. } \\
\hline \multicolumn{11}{|l|}{ 5. I praise people for a job well done. } \\
\hline \multicolumn{11}{|l|}{$\begin{array}{l}\text { 6. I spend time and energy making certain that the people I work with } \\
\text { adhere to the principles and standards we have agreed on. }\end{array}$} \\
\hline \multicolumn{11}{|l|}{ 7. I describe a compelling image of what our future could be like. } \\
\hline \multicolumn{11}{|l|}{$\begin{array}{l}\text { 8. I challenge people to try out new and innovative ways to do their } \\
\text { work. }\end{array}$} \\
\hline \multicolumn{11}{|l|}{ 9. I actively listen to diverse points of view. } \\
\hline \multicolumn{11}{|l|}{$\begin{array}{l}\text { 10. I make it a point to let people know about my confidence in their } \\
\text { abilities. }\end{array}$} \\
\hline \multicolumn{11}{|l|}{ 11. I follow through on the promises and commitments that I make. } \\
\hline \multicolumn{11}{|l|}{ 12. I appeal to others to share an exciting dream of the future. } \\
\hline \multicolumn{11}{|l|}{$\begin{array}{l}\text { 13. I search outside the formal boundaries of my organization for } \\
\text { innovative ways to improve what we do. }\end{array}$} \\
\hline 14. I treat others with dignity and respect. & & & & & & & & & & \\
\hline
\end{tabular}




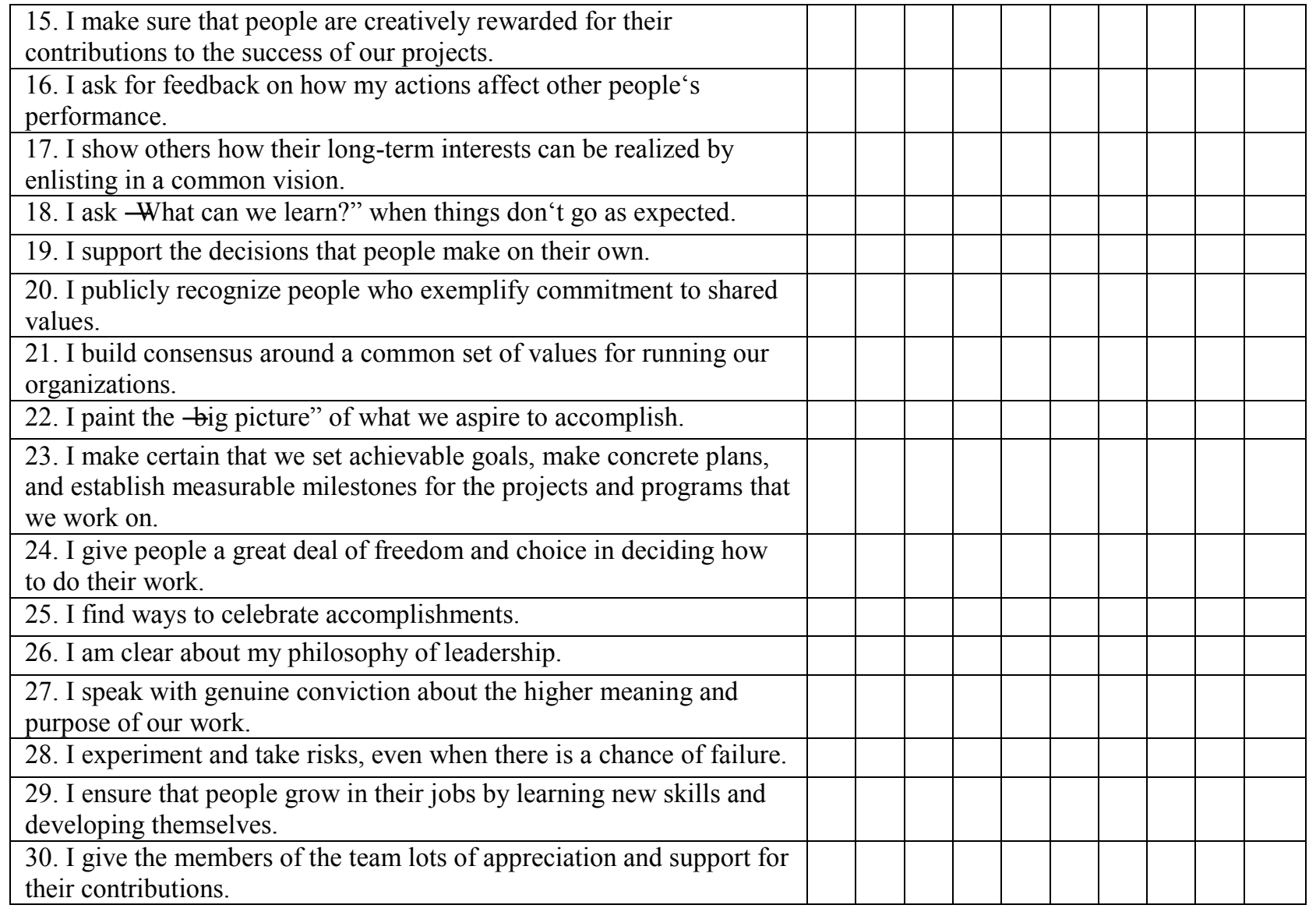

Copyright 2003 James M. Kouzes and Barry Z. Posner. All rights reserved. Used with permission. 
Appendix G

No.

Demographic Information for -An Examination of the Characteristic, Resilience, and Leadership Practices in Public School Elementary Principals"

(For each item below, please select the most appropriate response)

1) What is your age?
a. $20-30$
b. $31-40$,
c. $41-50$
d. $51-60$
e. $61+$

2) What is your gender?
a. Female
b. Male

3) What is your highest level of education?

a.Bachelor's
b. Master's
c. Specialist
d. Doctorate

4) How many years have you taught?
a. $0-5$
b. $6-10$
c. $11-15$
d. $16-20$
e. $21+$ 
5) How many years have you worked as a principal?

a. $0-5$
b. $6-10$
c. $11-15$
d. $16-20$
e. $21+$

6) What is the number of students in current school:
a. $<100$
b. $101-200$
c. $201-300$
d. $301-400$
e. $400+$

7) As a principal how many superintendents have you worked for?
a. $1-2$
b. $3-5$
c. $6-8$
d. $>8$

8) How many professionals do you supervise?
a. $1-15$
b. $16-30$
c. $31-45$
d. $45+$ 
9) Approximately what percentage of your students receive Free and Reduced Lunch:

a. $0-25 \%$

b. $26-50 \%$

c. $51-75 \%$

d. $>76 \%$ 


\section{Appendix $\mathrm{H}$}

Page 1 of 2

\section{Suzanne Offutt}

$\begin{array}{ll}\text { From: } & \text { "Lynn Talerico" < Lynn.Talerico@connerpartners.com> } \\ \text { To: } & \text { <msoffutt@access.k12.wv.us> } \\ \text { Cc: } & \text { "Linda Hoopes" <Linda.Hoopes@connerpartners.com> } \\ \text { Sent: } & \text { Monday, July 03, 20061:04 PM } \\ \text { Subject: } & \text { FW: Use of Personal Resilience Questionnaire }\end{array}$

Hi Suzanne,

My name is Lynn Talerico and I work with Linda Hoopes at Conner Partners. Linda forwarded your email below to me. We will be happy to allow you to use the Personal Resilience Questionnaire for your dissertation research and would love to receive a copy of your findings. Here is the assistance we can provide:

There will be no cost involved since you are using the PRQ for research purposes. We can provide you with a spreadsheet of the resilience scores. Regarding protecting your subjects' confidentiality, I would work with your committee to determine how best to do so; my guess is that you will need their names associated with their Resilience results so that you can use this information to conduct other parts of your analysis; if not, please let me know and I can send you the results without the associated names.

When you are ready to administer the Personal Resilience Questionnaire, I will set you up with an Organization Code and Group Code that people can enter at the beginning of the survey so that your results can be easily compiled - just let me know when you are ready.

I look forward to working with you. Please don't hesitate to contact me with any questions you may have along the way.

Lynn

From: Linda Hoopes

Sent: Friday, June 30, 2006 5:52 PM

To: Lynn Talerico

Subject: FW: Use of Personal Resilience Questionnaire

Please reach out to her and let her know that you'll be in contact with her soon. Then let's you and I spend some time at our meeting on Thursday where we process the dissertation data from the other guy to discuss our standard response to inquiries like this.

Thanks,

Linda

From: Suzanne Offutt [mailto:msoffutt@access.k12.wv.us]

Sent: Friday, June 30, 2006 11:33 AM

To: Linda Hoopes

Subject: Use of Personal Resilience Questionnaire

Dear Dr. Hoopes,

I am working on a dissertation on personal resilience and leadership in elementary school principals and am interested in using the Personal Resilience Questionnaire in my research. I have found that Colgate used it in her research with resilience and exercise, and Jing Wang used it to study the adjustment of international graduate students.

Specifically, I would like to know how to get permission to use the instrument; what costs would be involved; and whether I can get scoring support from ODR. I also need to have an understanding of how I protect my subjects confidentiality.

Thank you so much for all the help that you can provide me. I'm really excited about this research. 


\section{Appendix I}

\section{KOUZES POSNER INTERNATIONAL \\ 15419 Banyan Lane \\ Monte Sereno, California 95030 \\ FAX: (408) 354-9170}

July 16, 2005

Ms. Suzanne Offutt

155 Glen Road

Shepherdstown, West Virginia 25443

Dear Suzanne:

Thank you for your request to use the Leadership Practices Inventory (LPI) in your dissertation. We are willing to allow you to reproduce the instrument as outlined in your request, at no charge, with the following understandings:

(1) That the LPI is used only for research purposes and is not sold or used in conjunction with any compensated management development activities; (2) That copyright of the LPI, or any derivation of the instrument, is retained by Kouzes Posner International, and that the following copyright statement is included on all copies of the instrument: "Copyright (C) 2003 James M. Kouzes and Barry Z. Posner. All rights reserved. Used with permission.";

(3) That one (1) bound copy of your dissertation and one (1) copy of all papers, reports, articles, and the like which make use of the LPI data be sent promptly to our attention; and,

(4) That you agree to allow us to include an abstract of your study and any other published papers utilizing the LPI on our various websites.

If the terms outlined above are acceptable, would you indicate so by signing one (1) copy of this letter and returning it to us. Best wishes for every success with your research project.

Cordially, ?

Barry Z.Pdsner, Ph.D.

Managing Partner

I understand and agree to abide by these conditions:

(Signed)

Date: 